University of Louisville

ThinkIR: The University of Louisville's Institutional Repository

Electronic Theses and Dissertations

$5-2017$

\title{
Identifying the signaling mechanisms of EGFR-mediated apoptosis.
}

Nicole Marion Jackson

University of Louisville

Follow this and additional works at: https://ir.library.louisville.edu/etd

Part of the Cancer Biology Commons, and the Cell Biology Commons

\section{Recommended Citation}

Jackson, Nicole Marion, "Identifying the signaling mechanisms of EGFR-mediated apoptosis." (2017). Electronic Theses and Dissertations. Paper 2715.

https://doi.org/10.18297/etd/2715

This Doctoral Dissertation is brought to you for free and open access by ThinkIR: The University of Louisville's Institutional Repository. It has been accepted for inclusion in Electronic Theses and Dissertations by an authorized administrator of ThinkIR: The University of Louisville's Institutional Repository. This title appears here courtesy of the author, who has retained all other copyrights. For more information, please contact thinkir@louisville.edu. 


\title{
IDENTYFING THE SIGNALING MECHANISMS OF EGFR-MEDIATED APOPTOSIS
}

By

Nicole Marion Jackson

B.A., Cheyney University of Pennsylvania, 2012 M.S., University of Louisville, 2015

\author{
A Dissertation \\ Submitted to the Faculty of the \\ School of Medicine of the University of Louisville \\ In Partial Fulfillment of the Requirements \\ for the Degree of \\ Doctor of Philosophy \\ In Pharmacology and Toxicology \\ Department of Pharmacology and Toxicology \\ University of Louisville \\ Louisville, Kentucky
}

May 2017 



\section{IDENTIFYING THE SIGNALING MECHANISMS OF EGFR-MEDIATED}

APOPTOSIS

\section{By}

Nicole Marion Jackson

B.A., Cheyney University of Pennsylvania, 2012

M.S., University of Louisville, 2015

A Dissertation Approved on

March 7, 2017

By the following Dissertation Committee:

Brian P. Ceresa, Ph.D.

Paula J. Bates, Ph.D.

Levi J. Beverly, Ph.D.

Geoffrey J. Clark, Ph.D.

Leah J. Siskind, Ph.D. 


\section{ACKNOWLEDGMENTS}

There are so many people that I would like to express gratitude to for helping me succeed in obtaining my Ph.D. The first person I would like to thank is my parents, Reuben and Marion Jackson. There were countless times when I wanted to quit, but you pushed me to persevere and to remain tenacious. Without you guys, I would have never prospered. I would also like to thank my mentor, Dr. Brian Ceresa, for his steadfast guidance and patience with both my project and with me. We did not always see eye-to-eye on things, but nonetheless, we made it work. Thank you for allowing me to complete my dissertation studies within your laboratory, for granting me the opportunity to present my research in Germany, and for being open to me driving this project in the direction I saw fit.

I would like to thank my husband, Bobby. Thank you for being my rock, and for enduring my late nights, early mornings, tantrums, crying spells, practice talks, my ups and my downs. It means the world to me that you would guide me to the end of this journey. I'm eternally grateful for that. I want to thank my son, Shane. I'm sorry for the long days in daycare, and for spending weekends writing instead of playing with you. I promise this will all be worth it. Thank you for being so patient while mommy earned her degree. 
I'd like to thank my siblings, Lisa, Trina, and Brian. Thanks for always encouraging me to strive for more, and for embracing my excellence. I love you guys. 


\section{ABSTRACT \\ IDENTIFYING THE SIGNALING MECHANISMS OF EGFR-MEDIATED APOPTOSIS}

Nicole Marion Jackson

March 7, 2017

The Epidermal Growth Factor Receptor (EGFR) is a 170-kilodalton transmembrane protein that belongs to the ErbB family of receptor tyrosine kinases. Upon ligand-mediated activation, the EGFR is responsible for cell growth, proliferation, and tissue homeostasis; however, the EGFR is overexpressed in many human malignancies, including MDA-MB-468 cells, a metastatic breast epithelial cell line. Studies within this cell line, and other cell lines characterized with high EGFR levels, have shown that EGF stimulation results in the induction of apoptosis. However, the mechanisms and signaling effectors implicated in this process have yet to be elucidated. The overarching research goal of this dissertation was to better understand the molecular mechanisms employed by the receptor that result in the induction of apoptosis in MDA-MB-468 cells. Identifying key regulators/mediators of EGF-induced apoptosis will help elucidate new pharmacological targets that better attenuate cell growth in cancers characterized by EGFR hyperexpression.

Through an extensive review of the literature, we have identified Cyclic 
GMP dependent protein kinase (PKG) and Signal Transducer and Activator of Transcription 3 (STAT3) as potential signaling intermediates of EGF-induced apoptosis. EGF stimulation resulted in a dose-dependent increase in PKG activity. Agonists of PKG did not induce EGFR activation, confirming that PKG activity occurred downstream of receptor activation. RNA Interference (RNAi) targeting PKG resulted in a significant reduction in EGF-induced cell death, as well as a reduction in apoptosis. Similarly, we used siRNA to ablate STAT3 activity, which resulted in a significant attenuation of apoptosis, as measured by PARP cleavage. Additionally, cytokine-mediated (EGFR-independent) activation of STAT3 induced PKG activation, and resulted in a significant induction of apoptosis that was sustained over time.

Together, our results indicate that PKG and STAT3 are molecular targets for cancers with high levels of EGFR, and that activation of proteins that induce cell death may be more beneficial, therapeutically, than antagonizing proteins that promote cell growth. 


\section{TABLE OF CONTENTS}

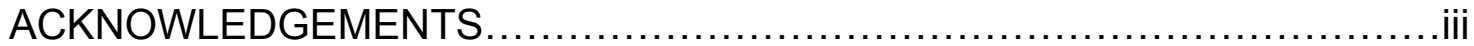

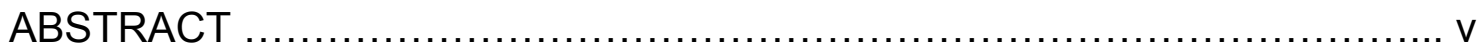

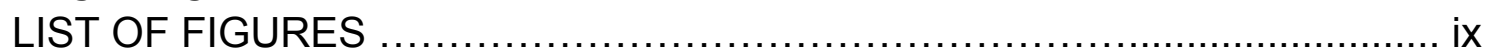

CHAPTERS PAGE

I. BACKGROUND AND INTRODUCTION ..................... 1

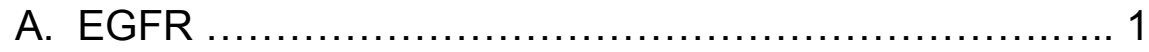

B. Summary of Ceresa Laboratory Preliminary Findings.....12

C. Cell Death and Apoptosis .......................... 14

D. Protein Kinase G (PKG) .......................... 20

E. Signal Transducer and Activator of

Transcription 3 (STAT3) ............................ 24

F. Significance and Statement of Specific Aims........... 27

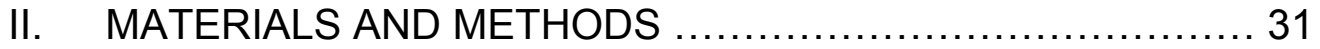

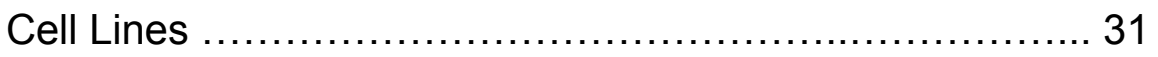

Cell Viability Analyses ............................... 32

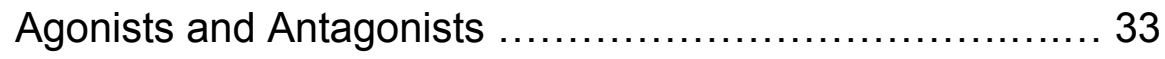

Cell Lysate Preparation and Immunoblot Analyses .......... 34

siRNA knockdown in MDA-MB-468 cells................. 35

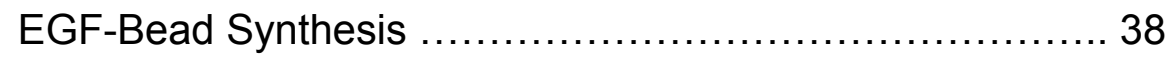

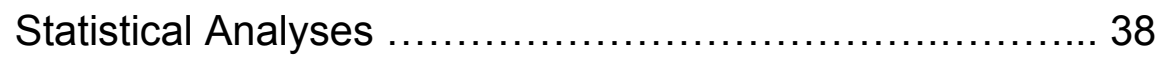


III. PROTEIN KINASE G FACILITATES EGFR-MEDIATED CELL DEATH IN MDA-MB-468 CELLS ......................... 40

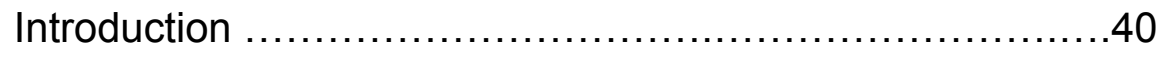

Results ................................................... 43

Discussion ................................................. 59

IV. EGFR-MEDIATED APOPTOSIS VIA STAT3 ................... 63

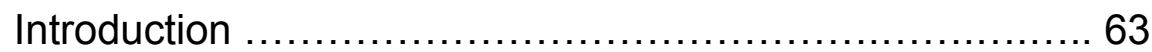

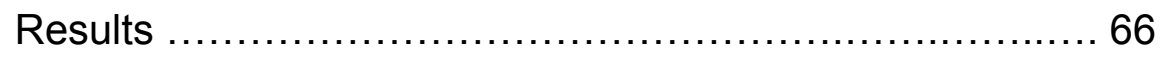

Discussion ................................................. 88

V. SUMMARY AND FUTURE DIRECTIONS ...................... 95

A. Restatement of Research Goals ......................... 95

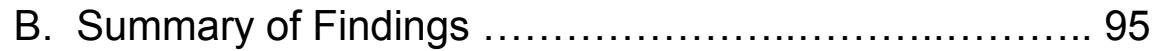

C. Significance of Findings .................................. 96

D. Strengths and Weaknesses .............................. 102

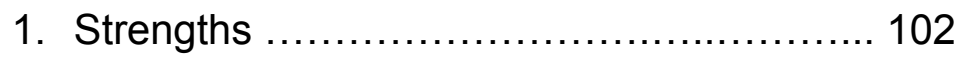

2. Weaknesses ................................. 103

E. Future Directions ......................................104

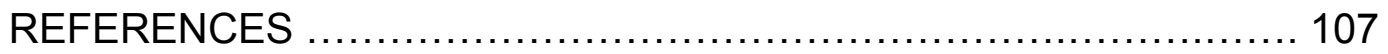

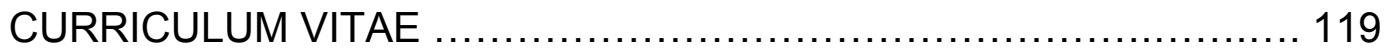




\section{LIST OF FIGURES}

FIGURE

PAGE

1.1 EGFR Domains and Activation..................................... 4

1.2 Differential EGFR endocytic sorting depends on the ligand to which the

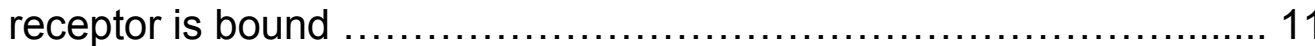

1.3 Schematic representation of the intrinsic and extrinsic signaling pathways resulting in the induction of apoptosis 18

1.4 Schematic representation of intracellular signaling events that result in PKG activation

1.5 Schematic representation of STAT dimer formation and subsequent activation

2.1 Compilation of all western blot antibodies employed 36

3.1 Increases in EGF ligand concentration elicit a dose dependent increase in pVASPSer239 phosphorylation in MDA-MB-468 cells 44

3.2 Increases in EGF ligand concentration elicit a dose dependent increase in pVASPSer239 phosphorylation in A431 and HeLa cell lines 47

3.3 PKG agonists do not elicit EGFR phosphorylation, but do induce dose dependent decreases in MDA-MB-468 cell viability 50

3.4 PKG agonists induce apoptosis in the MDA-MB-468 cell line 53

3.5 Reduction in PKG activity yields a significant increase in MDA- MB-468 cell 
viability upon exposure to EGF ligand

3.6 Reduction in PKG activity yields less apoptosis

in MDA-MB-468 cells

57

4.1 Phosphorylation of MAPK, SRC, AKT, and BAD in response to high and low EGF concentrations 67

4.2 STAT3 is tyrosine phosphorylated in response to high, but not low, EGF concentrations 70

4.3 EGF phosphorylates STAT3 in a dose-dependent manner in MDA-MB-468 and $\mathrm{A} 431$ cell lines 71

4.4 STAT3 is preferentially upregulated with soluble EGF, and not with EGFBeads 73

4.5 EGFR-independent activation of STAT3 promotes apoptosis in MDA-MB-468 cells 75

4.6 Models of STAT3 Activity and its potential role(s) in EGFR- mediated

Apoptosis 77

4.7 STAT3 inhibitors attenuate cell viability and EGFR activity in MDA-MB-468 cells 79

4.8 STAT3 inhibitors attenuate EGFR activity in A431 cells ................ 81

4.9 STAT3 inhibitors reduce cell viability in STAT3-null, PC3 cells .......... 84

4.10 Knockdown of STAT3 attenuates EGFR-mediated apoptosis in MDA-MB-468 cells 86 


\section{CHAPTER I \\ BACKGROUND AND INTRODUCTION}

\section{A. EGFR}

The epidermal growth factor receptor (EGFR) is a cell surface receptor that is expressed ubiquitously throughout the body and plays critical roles in development and tissue homeostasis. Further, many cancers are characterized by hyperactivated EGFR signaling, either due to overexpression of the receptor or somatic activating mutations of the receptor. These perturbations in EGFR expression and/or activation are associated with poor patient prognosis. Over the last 15-20 years, there has been a concerted effort to develop cancer therapeutics that specifically target the aberrant EGFRs, with the goal of inhibiting the progression of those cancers. Understanding the basic cell biology of the EGFR helps to understand its implications, and define its typical role in normal cell biology.

In order to better understand the function of the EGFR, it is best to start with the discovery of one of the principal ligands that initiates its activity. Dr. Stanely Cohen isolated and discovered its endogenous ligand, Epidermal Growth Factor (EGF) from murine submaxillary glands in the early 1960's. Frozen 
submaxillary glands were obtained from mice and homogenized in acetic acid, prior to being frozen in a dry ice-alcohol bath. The material was then thawed and subjected to a series of ultra-centrifugations at $100,000 \times \mathrm{g}$, and acetic acid washes. The newly formed pellet was then subjected to size exclusion, and ion exchange chromatography for purification [1]. Amino acid analysis of the purified product revealed that EGF is a 53 amino acid residue polypeptide, containing three internal disulfide bonds, as depicted in Figure 1.1.

Dr. Cohen observed that injecting the purified, crude, submaxillary gland preparations into newborn mice stimulated growth of embryonic neurons and induced precocious eyelid opening. Having identified a growth factor that was able to initiate some very specific physiological responses, the next goal was to identify the receptor. In 1978, he and Dr. Graham Carpenter were able to identify the presence of the 170-kilodalton EGFR specific for EGF ligand through the use of radiolabeled ( ${ }^{125}$ I-labeled) EGF ligand in A-431 cells, a human epidermoid carcinoma cell line. They reported increased ${ }^{32} \mathrm{P}$ incorporation in the A-431 cells in response to EGF ligand stimulation, suggesting that phosphorylation of EGFR components might be critical for its function [2]. In 1982, Dr. Cohen proceeded to then successfully isolate and purify the EGFR from A-431 cells, and from normal mouse liver cells by means of affinity chromatography. Purification of the receptor aided in the confirmation that the EGFR was able to bind ${ }^{125} \mathrm{I}$-labeled EGF, and that the receptor possessed ligand stimulated, intrinsic kinase activity, which was responsible for auto-phosphorylation of tyrosine residues, upon binding of EGF. This particular study also confirmed that the receptor in normal 
liver cells had biochemical similarities to receptors found in the carcinoma cell line [3]. The contributions of Dr. Cohen and Dr. Carpenter have allowed for subsequent studies to unveil further information about the receptor, including its physiology, function, and regulation.

Another huge leap in our understanding of the molecular mechanism of EGFR-mediate signaling came in 1984 when Ullrich and colleagues used the newly identified tools of molecular biology to clone the human EGFR. From this report, a model (which has been modified numerous times over the years) was generated that described the functional domains of the EGFR.

The EGFR is comprised of three major domains: 1) an extracellular, ligand binding domain with cysteine rich regions, 2) a cytosolic, intrinsic kinase domain, and 3) a cytosolic domain containing tyrosine residues (Fig 1.1) [4]. Studies by Lax et al. devised a method utilizing ${ }^{125}$ I-labeled EGF to label the EGFR for subsequent isolation, and cleavage through use of Cyanogen Bromide ( $\mathrm{CNBr})$. Site-specific antibodies were then used to identify certain residues (294 and 543) that are critical for the function of the receptor. On the basis of amino acid sequence conservation, it was then determined that the extracellular domain is comprised of 621 amino acid residues, and could be divided into 4 sub-domains [5]. Domains I and III are ligand binding regions, with 37\% homology that physically bind the ligand. Domains II and IV are rich in cysteine, and have $17 \%$ amino acid homology that interfaces with other receptors for dimerization $[6,7]$.

The model of how these domains come together is based on crystallographic analysis that was done by the Lemmon laboratory. In the 
Unliganded, monomer

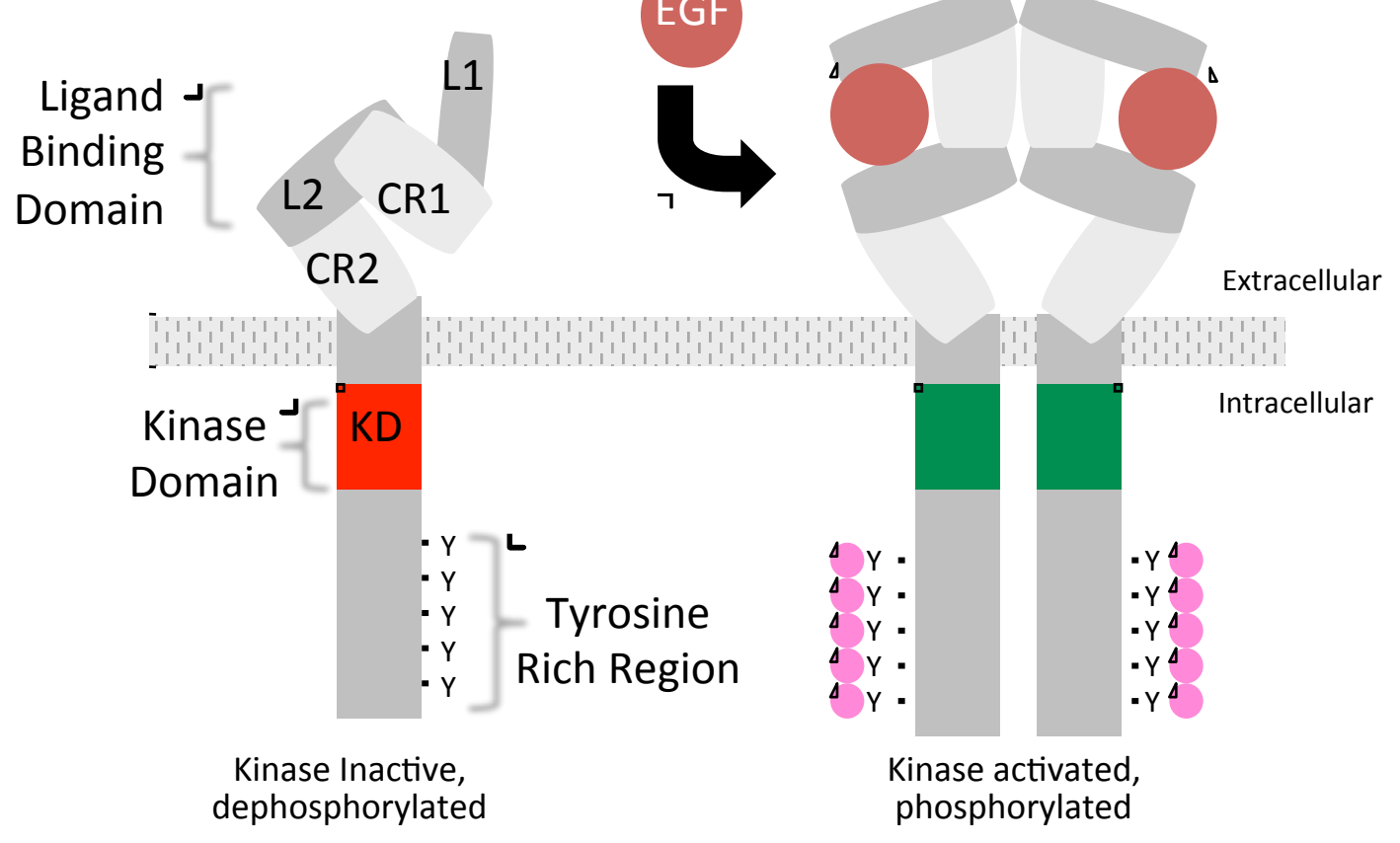

Figure 1.1 EGFR Domains and Activation (Adapated from Brian P. Ceresa).

The EGFR is comprised of a ligand binding domain, and intracellular kinase domain, and a domain containing tyrosine rich region at the cytosol. Ligand binding induces a conformational change at the ligand biding domain, which allows for two receptor monomers to dimerize and form an active receptor:ligand complex. 
unliganded state, the cysteine-rich domains of a monomeric receptor bind to one another through an intramolecular interaction. Upon the introduction of ligand, the receptor undergoes a conformational change such that both ligand binding domains bind the ligand and disrupt the interaction between the two cysteine rich domains. The exposure of cysteine rich domain I then can interact with the corresponding domain with another EGFR to form a dimer. Ligand binding also brings about a conformational change that activates the intrinsic kinase domain, which then leads to autotransphosphorylation of the cytosolic tyrosine residues (Fig. 1.1) [8]. The kinase domain of each receptor moiety will phosphorylate tyrosine residues on its adjacent dimer partner by a conformational change in the receptor that places the tyrosine substrate in access to the kinase domain. These phosphotyrosines then serve as docking sites for various cytoplasmic enzymes, known as effector molecules. By docking to the phosphotyrosines, these effectors become activated and modulate various cellular processes that contribute to the overall cell biology [9]. Activation of alternative downstream signaling cascades by the EGFR induces known responses for cellular differentiation, proliferation, migration, and protection from apoptosis [10].

Although the EGFR is expressed at the cell surface of many normal cells and is critical for animal development and cellular homeostasis, it is often mutated and/or hyper-expressed in a number of human malignancies [11]. In a study conducted by Real et al., mouse monoclonal antibodies specific for the EGFR were used to assess the distribution of the receptor in various human cell and tissue types. These studies have confirmed EGFR expression in normal 
stomach, bladder, colon, esophageal, and lung tissue; however, no expression was determined in normal brain tissue or skeletal muscle [12]. In regard to malignant cells and tissue, the EGFR has shown to be hyper-expressed in colon, kidney, lung and sarcoma cancers; however, it is non-prevalent in primary melanoma [12] and gliosarcoma malignancies [13].

In the analysis of large populations of cancers with EGFR mutations, one of the most common mutations entails a deletion of exons 2-7 of the EGFR gene that removes virtually the entire extracellular domain of the receptor. In the absence of a ligand binding domain or cysteine rich domains that have intramolecular binding to prevent dimerization, this receptor is free to associate with other mutant receptor and is constitutively active. This mutant receptor is referred to as EGFRvIII, and is substantially expressed in patients with glioblastoma malignancies [14, 15]. Mutated tyrosine residues of the EGFR at the cytosol have also been shown to induce aberrant signaling as well as drug resistance in cancers characterized by hyper-expression of the EGFR $[16,17]$. In addition to the EGFR itself, studies have shown that alterations in EGFR ligand expression can hinder certain tissue physiology. Luetteke et al. bred knockout mice that lacked endogenous expression of various, endogenous EGFR ligands. Pups born to these knockout mice were runted, and showed stunted growth and survival. These data provide confirmation of a requirement for EGFR ligands to initiate receptor signaling in order for proper development of the mouse mammary gland [18]. Overall, it can be inferred that regulation of tyrosine 
phosphorylation as well as endogenous EGFR ligands are both critical for proper signaling and modulation of cellular effects of the activated receptor.

Numerous cellular processes play a role in controlling EGFR activity. Chief among these is ligand-mediated endocytosis. Co-incident with ligand binding to the EGFR and activation of the intrinsic kinase domain, the ligand:receptor complex is internalized into the cell in either a clathrin-mediated, or clathrinindependent manner. Clathrin-coated vesicles were first identified in osteocytes [19], and then later in neurons [20]. In 1975, Barbara Pearse biochemically characterized these clathrin-coated vesicles as transport vesicles upon isolating and purifying them from pig brains prior and analyzing their physical properties via electron microscopy. She described these vesicles as intracellular vesicles with unique "coats" on their cytoplasmic surfaces [21]. Her discovery serves as the foundation of biochemical studies entailing clathrin-mediated endocytosis and membrane trafficking in general.

Sigusmund et al. stimulated receptor activation with EGF for 2 minutes in HeLa cells prior to immunostaining and subjecting the fixed cells to immunoelectron microscopy. Immunoelectron microscopy allowed for viewing and imaging of the immunostained cells in their various compartments during EGFR mediated endocytosis [22]. These studies, as well as subsequent studies, revealed that Clathrin-mediated EGFR endocytosis is observed at all ligand concentrations, where as with higher concentrations of ligand, $(10-100 \mathrm{ng} / \mathrm{mL})$ the receptor undergoes Clathrin-independent endocytosis via caveole [23, 24]. 
Once internalized within the cell, the EGFR is subjected to the endocytic pathway, a pathway responsible for sorting and determining the ultimate fate of the internalized ligand:receptor complex. An intermediate vesicle containing the ligand:receptor complex fuses with an early endosome. The mildly acidic environment of the early endosome $(\mathrm{pH}$ 6) allows certain EGFR ligands (EGF and transforming growth factor-alpha (TGFA)) to dissociate from the EGFR, should the ultimate fate of the receptor be recycling back to the plasma membrane [25]. From here, the unbound-receptor will recycle back to the cell membrane via recycling endosomes for additional ligand binding and signaling. These recycling endosomes, slightly acidic at $\mathrm{pH} 6.4$, are centered around the microtubule-organizing center [26]. These recycling endosomes exhibit tubularvesicular morphology, which suggests dynamic trafficking activity and supports their involvement with the underlying connection of endocytosis with exocytosis $[27,28]$. Should the ligand:receptor complex remain inside of the early endosome, however, the early endosome will mature into a late endosome with the complex intact. The late endosome then fuses with the lysosome just prior to the ultimate degradation of the ligand:receptor complex [29]. This endocytic pathway is essential for regulating the activity of the EGFR, both temporally and spatially. Temporally, meaning that the time it takes the receptor to transverse the entire endocytic pathway will ultimately dictate the duration of its signaling. Spatially, in regard to the fact that at different subcellular locations, the receptor will interact with different effector proteins, activating different signaling cascades [30]. 
Due to hyper-expression of the EGFR in a number of human malignancies, including kidney, breast, pancreatic, and cervical cancers [31], the correlation between signaling by the EGFR and the endocytic pathway has important implications in both receptor tyrosine kinase and cancer biology [30]. One approach utilized to assess this correlation involves studying EGFR signaling and endocytosis upon activation with different ligands. Currently, there are seven identified growth factors that are able to bind to and activate the EGFR: these include EGF, amphiregulin (AREG), betacellulin (BTC), epigen (EPGN), epiregulin (EREG), heparin-binding EGF-like growth factor (HBEGF), and transforming growth factor- $\alpha$ (TGFA) [32]. Although each of these ligands stimulate EGFR activation and internalization, they yield diverse effects on endocytic sorting [33]. This information can be used advantageously to assess the differential effects and regulatory mechanisms different ligands have on EGFR signaling. One of the critical components of this dissertation entails determining if EGFR ligands have differential effects on EGFR-mediated apoptosis.

EGF is a 53 amino acid, 6.4 kilodalton $(\mathrm{kDa})$ protein that has been shown to be involved in regulation of cellular proliferation in mammals [34, 35]. Similarly to EGF, TGFA ligand contains 50 amino acids and has a molecular weight of approximately $6 \mathrm{kDa}$. Both EGF and TGFA bind the EGFR however; however, TGFA binds with 10-30 fold less affinity to the receptor in rat hepatocytes in comparison to EGF. Thoresen et al. isolated hepatocytes from Wistar rats prior to stimulating the cells with increasing concentrations of ${ }^{125}$ I-EGF and ${ }^{125}$ I-TGFA. 
Surface binding curves after 24-hour ligand exposure exhibit a binding affinity of $11.9 \mathrm{nM}$ for TGFA, and $0.42 \mathrm{nM}$ for EGF. The data within this study suggest that the two ligands compete for a single population of binding sites in rat hepatocytes, although EGF has a significantly higher binding affinity for the EGFR than TGFA [36]. It is important to note that TGFA is synthesized and most prevalent in cancer cells, and cells transformed by oncogenes and retroviruses [37]. BTC, a slightly larger ligand ( $9 \mathrm{kDa})$ comprised of 80 amino acids, was originally isolated from mouse insulinoma cells, and is able to activate EGFR and ErbB4 [38]. Studies utilizing ${ }^{125} \mathrm{I}$-BTC in Balb/c 3 T3 fibroblasts confirm a binding affinity of $0.5 \mathrm{nM}$ for the EGFR, and suggest that the preferred receptor for BTC is the EGFR [39].

All three of these ligands are able to bind to the EGFR, and stimulate kinase activity; however, they differ in regard to their binding affinities to the EGFR, and their ultimate fates upon endocytosis and endocytic trafficking (Fig. 1.2). In order to compare ligand internalization upon EGFR stimulation, Roepstorff et al. used an approach of pre-binding various EGFR ligands on ice to view the synchronized wave of receptor internalization. After determining optimal incubation time using ${ }^{125} \mathrm{I}-\mathrm{EGF}, \mathrm{HEp} 2$ cells were incubated with increasing ligand concentrations for 100 minutes. The amount of total cell surface receptors was 


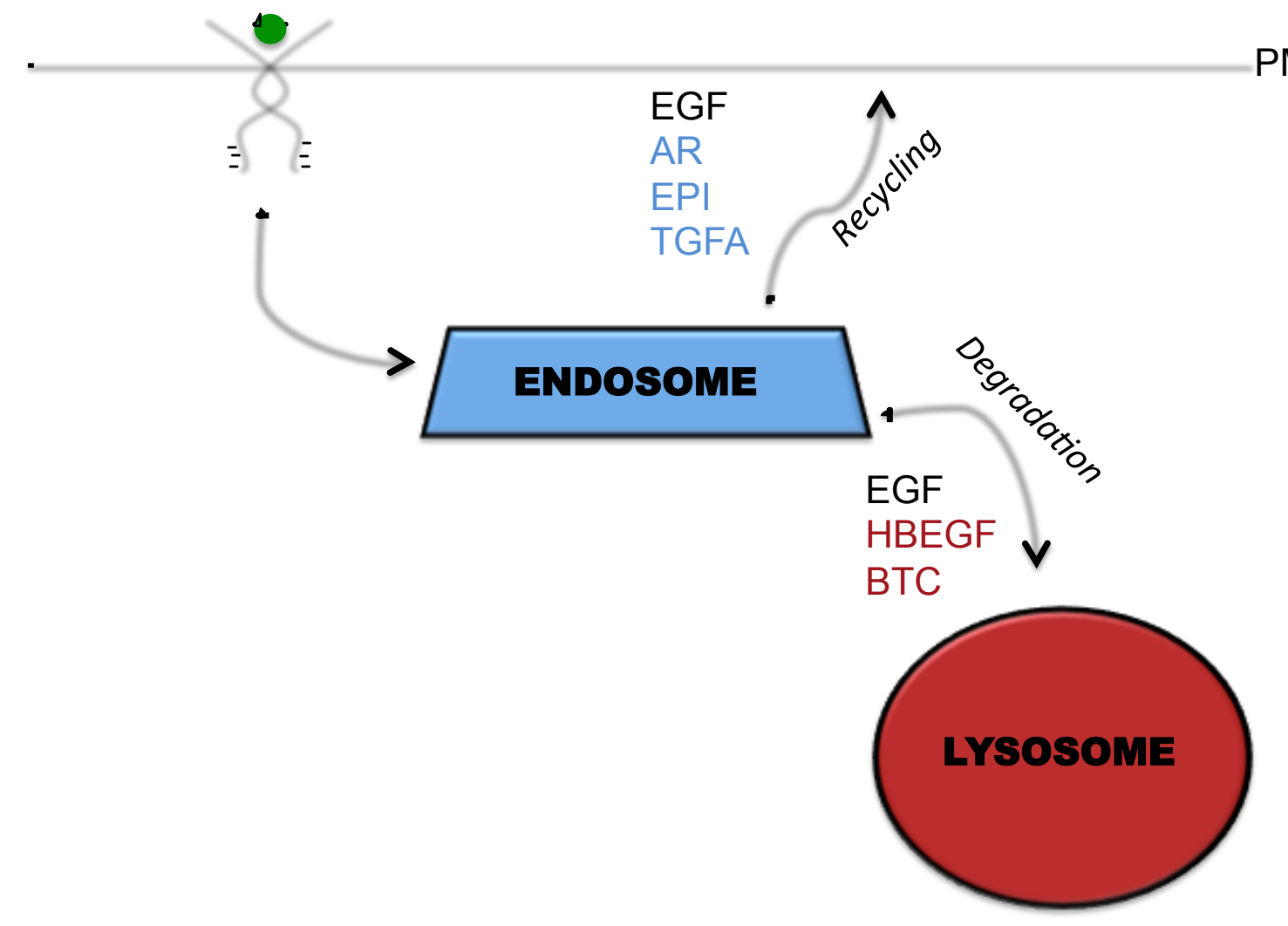

Figure 1.2. Model depicting how differential EGFR endocytic sorting depends on the ligand to which the receptor is bound (Adapted from Roepstorff et al., Traffic, 2009). When bound to HBEGF and BTC ligands, the receptor is preferentially targeted for lysosomal degradation. In contrast, AR, EPI, and TGFA ligands almost always promote recycling of the EGFR to the plasma membrane (PM). EGF stimulation leads to receptor degradation for the majority of EGFRs, but is noted to promote recycling in some instances. 
then determined via FACS analysis. These data report that EGF and BTC ligands both target the EGFR for lysosomal degradation. In contrast, TGFA almost always promotes recycling of the EGFR to the cell membrane within 90 minutes of ligand exposure [33]. EGF and BTC can both withstand the acidic conditions of the endosomes, dissociating at around pH 5. In contrast, TGFA rapidly dissociates from the receptor at $\mathrm{pH} 7$, and is unable to withstand the acidic environment of the early endosome. This therefore causes the ligand-free receptor to recycle back to the cell membrane $[33,40]$. The fate of the EGFR, whether it is for degradation or recycling, is critical for its duration of signaling, which will can vary based on different ligands bound to the receptor. This has ultimate implications in the initiation different signaling cascades.

\section{B. Summary of Ceresa Laboratory Preliminary Findings.}

Although the EGFR is typically associated with cell growth and proliferation, forms of cancer that hyper-express the receptor often undergo EGFR-mediated apoptosis. MDA-MB-468 cells are a metastatic breast epithelial cell line, derived from the M.D. Anderson Cancer Center in Houston, Texas [41]. In this cell line, the EGFR is hyper-expressed, with approximately $1.3 \times 10^{6}$ receptors per cell [42]. Additionally, this cell line has been documented to undergo EGFR-mediated apoptosis [43]. Given these earlier reports of the EGFR inducing apoptosis in MDA-MB-468 cells, our lab became interested in further elucidating the mechanisms entailed within receptor-mediated apoptosis.

Because the endocytic pathway is the primary mode of regulating the receptor and its duration of signaling, this was logically the best place to begin our studies. 
Identifying where within the endocytic pathway EGF-induced apoptosis initiated might provide some insight in terms of the effectors that were involved in this apoptotic mechanism.

To begin assessing this, polystyrene beads of 0.9 -micrometer size, covalently conjugated to EGF ligand, were employed. The polystyrene bead itself is too large for clathrin-mediated endocytosis; however, the conjugated EGF is able to activate the receptor while the bead retains the activated receptor at the cell membrane. Hyatt et al. showed that when activated and retained at the cell membrane, the EGFR elicits signals for cell growth; however, once internalized within the endosomes, the receptor elicits signals for apoptosis, as measured by Caspase activity [44]. Subsequent studies within our lab went on to further disclose that there is a defect in endocytic trafficking within the MDA-MB-468 cell line [44]. Through use of Percoll gradient and indirect immunofluorescence assays, Rush et al. showed that instead of traversing the entire endocytic pathway to the lysosome for degradation, the EGFR accumulates on the limiting membrane of the early endosome in this cell line [45]. These preliminary studies set the premise for the work described within this dissertation, which entailed furthering our findings by identifying protein effectors with direct implications in mediating EGF-induced apoptosis.

It has been established that the EGFR is a transmembrane tyrosine kinase with critical implications in normal cell growth, proliferation, wound healing, and tissue homeostasis. It is regulated in both a spatial and a temporal manner. Trafficking of the receptor can vary depending on the ligand it is bound 
to. The EGFR is however hyperexpressed in mammalian cancer [31]. There is more known about EGFR cell biology in non-malignant tissue, more than in cancer cells. Research has shown that pharmaceutically available EGFR inhibitors provided to cancer patients triggers autophagy, a degradative process that actually helps cancer cells withstand nutrient-poor conditions [46]. Therefore, it is of interest to employ other strategies and therapies, to better attenuate malignant cell growth and induce cell death and/or apoptosis.

\section{Cell Death and Apoptosis}

The EGFR is typically associated with cell growth, development and tissue homeostasis; however, it has been also known to mediate cell death in cancers that hyperexpress EGFRs [43, 47, 48]. Using a cell line that undergoes EGFRmediated apoptosis uniquely allows for the enlightenment of the biochemical regulation of signaling by using a sensitive, tractable and irreversible readout. These findings can be used to better understand other signaling pathways and biological responses to cell growth, and its counterpart, programmed cell death.

The term apoptosis entails the process of programmed cellular death in both single-cellular and multicellular organisms. Programmed cell death refers to the time and position of cell death during development of a given organism. It has many functions during the development process, including adjusting and deleting cell numbers [49]. Both apoptosis and programmed cell death are normal processes in growth, development and aging as a homeostatic mechanism for 
proper maintenance of cell populations in tissues [50]. John Kerr first used the term apoptosis in 1972, in order to describe a morphologically distinct form of cell death. Through the use of light and electron microscopy, morphological events that occur during apoptosis have been identified [51]. The process of apoptosis entails structural changes that take place in two distinct stages: During stage one, the cell rounds in shape, shrinks, and breaks into well-preserved fragment. Its nuclear and cytoplasmic compartments condense, causing the cellular organelles to become more tightly packed as well as fragmented [50, 52]. Pyknosis, or chromatin condensation, is a key characteristic component of apoptosis [50]. During the second stage, the apoptotic body, a small sealed membrane that is released by cells undergoing programmed cell death [53], is taken up by other cells just prior to being degraded and broken down within the lysosome [52]. This helps to remove any superfluous material, and provide nutrients that were once in the apoptotic cell to the cell that is viable [54]. The apoptotic process is a critical component in normal human embryonic development, and tissue homeostasis in all living organisms [50, 55]. However, cancer cells often have the ability to avoid apoptosis, and continue to proliferate [56]. This dysregulation of apoptosis is associated with many malignancies, including breast, ovarian and colon cancers $[57,58]$. Consequently, this can lead to cellular accumulation within a given organism, creating a permissive environment for genetic instability and oncogene activation. These events are known to disrupt cell turnover and function, as well as damage and kill healthy, viable cells [59]. 
Alternatively to apoptosis, cell death can also occur in a necrotic manner. Necrosis is considered to be a degradative, toxic process that consequently induces cell swelling [60,61], opposite of apoptosis [60]. Necrosis is an uncontrolled process and requires no energy input. It typically affects a large population of cells, and causes inflammation, in vivo. Conversely, apoptosis is a controlled and energy-dependent process that does not induce inflammation, and can occur in individual cells as well as large clusters of cells [50]. The manner of cell death by either necrosis or apoptosis depends on the nature of the tissue type, its developmental stage, and the cell death signal itself [62].

There are several biochemical modifications of apoptotic cells, which can be used to help differentiate and identify them. Such modifications include DNA breakdown, phagocytic recognition, and protein cleavage and cross-linking [63]. The caspase proteins are a family of aspartic acid-specific proteases that have proteolytic activity and are major effectors of apoptosis [50,64]. They are normally synthesized as inactive precursors, or pro-enzymes, and only become activated upon the induction of apoptosis. The pro-enzymatic form gets cleaved and activated by other caspases, initiating a signaling cascade as well as apoptosis induction [64]. Currently, there are 14 caspases that have been identified [65]. These are categorized into three subgroups based on their function within the signaling cascade. Initiator capsases (caspases 2, 8, 9, and 10) begin the cascade by activating and cleaving the executioner caspases (caspases 3, 6, and 7) at aspartic acid residues. Once executioner caspases are activated, they cleave and activate other cellular substrates, such as poly (ADP- 
ribose) polymerase (PARP), which begin the apoptotic process $[50,66]$. The third subgroup of caspase proteins includes caspases 1, 4 and 5, which have more active roles in inflammation [67]. It should be noted however that Caspase-1 has been documented to induce PARP cleavage [68], suggesting that PARP activation can occur in manners mediated by intrinsic and extrinsic pathways of apoptosis.

Mechanistically, apoptosis is quite complex, involving two main pathways: the extrinsic and intrinsic pathways (Fig. 1.3). The extrinsic signaling pathway entails initiating apoptosis via transmembrane receptor-mediated interactions. These receptors are known as "death receptors", and are members of the tumor necrosis factor (TNF) receptor family [69]. Members of this family have a "death domain", which is a cytoplasmic domain comprised of 80 amino acids.

The death domain of TNF receptors is primarily responsible for relaying signals for cell death from the cell membrane to the intracellular signaling pathways $[50,70]$. Upon ligand binding, adapter proteins are recruited to the death receptors at corresponding death domains. For instance, Fas ligand, a ligand with a known biological function of inducing apoptosis [71], binds to the Fas receptor, a member of the TNF receptor family. This ligand-receptor interaction promotes the intracellular recruitment of the FADD adapter protein [72]. FADD then associates with procaspase-8, forming a death-inducing signaling complex (DISC). This then results in the auto-catalytic activation of caspase-8 from procaspase-8 [73]. The activated caspase-8 then activates executioner caspases, which leads to the induction of apoptosis. Defects in Fas 


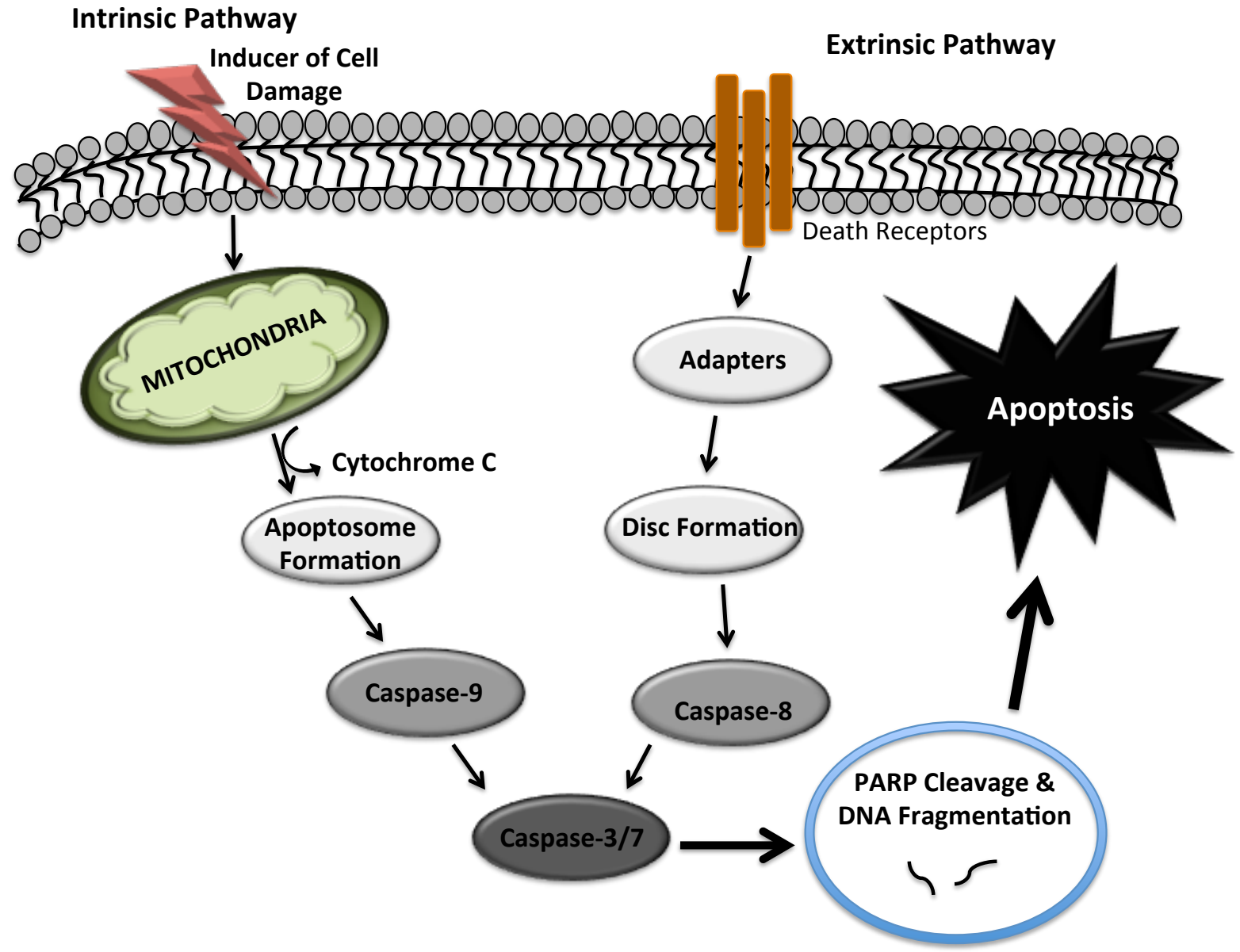

Figure 1.3. Schematic representation of the intrinsic and extrinsic signaling pathways resulting in the induction of apoptosis (Adapted from Elmore et al., Toxicol Pathol., 2007). The intrinsic signaling pathway of apoptosis initiates apoptosis in a non-receptor mediated manner, via mitochondrial-initiated signaling events. The extrinsic signaling pathway entails initiating apoptosis via transmembrane receptor-mediated interactions. Both pathways mediate apoptosis via Caspase cleavage and subsequent activation. 
ligand and Fas receptor are causes of various autoimmune diseases. It has been shown that upon knocking out the fas gene by homologous recombination, generalized lymphoproliferative disease (gld) can be completely recapitulated in mouse models [74]. Similarly, gld can be completely cured by simply expressing the normal fas gene in the same knockout mice [75]. These studies exhibit how critical Fas-induced apoptosis is to the regulation and cellular homeostasis of immunocompromised organisms.

The intrinsic signaling pathway of apoptosis initiates apoptosis in a nonreceptor mediated manner. This pathway entails mitochondrial- initiated events, involving certain stimuli that send intracellular signals to act on specific targets within the cell. These intercellular signals can be positive or negative signals. Negative signals often lead to withdrawal of certain growth factors, which fails to suppress death processes and essentially triggers apoptosis. On the other hand, positive signals include those for free radicals, toxins, and viral infections [50]. Apoptotic signals originating from the cell surface lead to the release of cytochrome $\mathrm{c}$ from the mitochondria into the cytosol, where it ultimately binds to the Apoptotic Protease Activation Factor-1 (Apaf-1). The binding of cytochrome c to Apaf-1 initiates apoptosome formation, which catalyzes the activation of caspase $9[50,76]$. Identical to the extrinsic pathway of apoptosis, activation of caspase 3 then leads to the downstream induction of apoptosis.

Apoptosis and programmed cellular death are normal processes within the lifespan of the cell. There are key physiological and morphological features that distinguish apoptotic cells from necrotic and viable cells. The EGFR is implicated 
in apoptosis in cell lines that hyperexpress it. Data from the Ceresa laboratory indicate that in addition to undergoing EGFR-mediated apoptosis, this apoptotic process is spatially regulated within MDA-MB-468 cells. Progression within this project involves determining necessary protein components implicated in EGFRmediated apoptosis. Through an extensive review of the literature, two candidate proteins have emerged as potential signaling intermediates in EGFR-mediated apoptosis: Cyclic GMP Dependent Protein Kinase (PKG) and Signal Transducer and Activator of Transcription 3 (STAT3). This dissertation describes our findings in terms of defining each of their individual roles in EGF-induced apoptosis.

\section{Protein Kinase G (PKG)}

Cyclic guanosine monophosphate (cGMP), a second messenger protein derived from GTP, elicits downstream signaling events through interactions with intracellular receptor proteins. It has implications in the regulation of smooth muscle tone, cardiac protection, bone growth, platelet aggregation, and regulating apoptosis [77-79] (Fig. 1.4). Nitric Oxide (NO), produced from nitric oxide synthase, is the first component involved in the activation of cGMP. NO diffuses through the plasma membrane of the cell to activate NO-soluble guanylate cyclases, which subsequently increase cGMP levels. Cyclic-GMP then proceeds to bind to and activate a number of downstream substrates [78]. One of the more prominent receptor substrates of cGMP is the cGMP-dependent protein kinase, or Protein Kinase G (PKG). PKG was first discovered in 1970 in the 
muscle of lobster tails [80]. It is a serine/threonine protein kinase whose substrates include receptors, enzymes and ion channels [81] (Fig. 1.4).

The binding of 2 cGMP molecules is required for the complete activation of one PKG molecule [81]. (Fig. 1.4). PKG is a homodimer consisting of two of the same monomers, each of which contains a regulatory domain and a catalytic domain on one polypeptide chain [77-79, 81]. Dimerization, auto-inhibition, and autophosphorylation all occur at the regulatory domain [78]. The catalytic domain contains a conserved threonine residue, whose phosphorylation is critical for relieving auto-inhibition, and essentially for kinase activity [78, 82]. PKG exists in two homologous forms: PKG I and PKG II. PKG I is localized within the cytoplasm whereas PKG II is generally associated with the cell membrane [81]. Additionally, there are two isoforms of the type I PKG homologue: PKGI $\beta$ and PKGla. These two isoforms are closely related, except in the $\mathrm{N}$-terminal domain of the PKGla isoform, which has 16 fewer residues than the PKGI $\beta$ isoform [81]. More recently, the NO/cGMP/PKG pathway has been discovered to play critical roles in cell proliferation and chemoresistance in cancer cells [83, 84]. Studies have shown that cells that express PKGla and PKGI $\beta$ undergo a biphasic response when exposed to NO. A low level of NO result in the specific activation of PKGla, which induces cell proliferation and suppresses the induction 


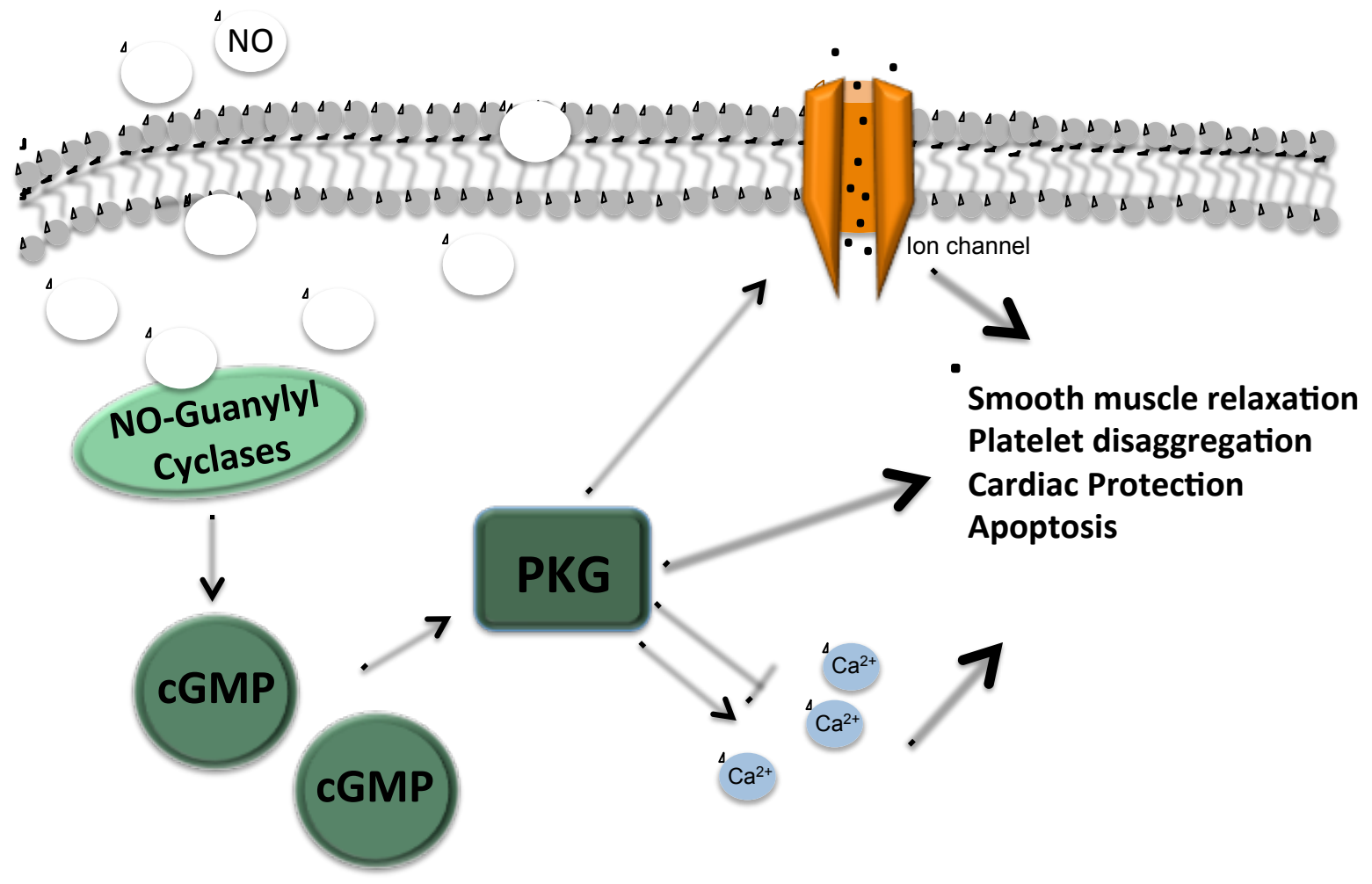

Figure 1.4. Schematic representation of intracellular signaling events that result in PKG activation. Two cGMP molecules must bind to the regulatory domain of PKG in order to promote PKG homodimer formation. PKG has a few downstream substrates, which include ion channels and pumps, and enzymes that regulate intracellular calcium ion concentrations (Wall et.al., PNAS, 2003). Ultimately, PKG has been well documented to promote smooth muscle relaxation, cardiac protection, platelet disaggregation, as well as regulate apoptosis. 
of apoptosis. This is because the PKGla isoform has a higher sensitivity to NO than the PKGI $\beta$ isoform. Conversely, a high level of NO leads to activation of both PKG isoforms, and tends to promote cell apoptosis and suppress cell proliferation. It is believed that the activation of PKGI $\beta$ by high-level NO contributes to the induction of apoptosis in cancer cells [85].

There have also been studies correlating EGFR activity and PKG activation. When OV2008 cells, an ovarian cancer cell line, were treated with increasing EGF ligand concentrations, immunoblot analyses displayed increased phosphorylation of serine-239 residue of VASP, a PKG-specific protein substrate. Western blot data from this study also exhibit increased phosphorylation of Src, a non-receptor tyrosine kinase protein that encodes for the SRC gene. These data suggest that activation of the EGFR and subsequent PKG activation occurs in a Src-dependent manner [84].

Recently, activation of PKG by cGMP has become of significant interest as a novel molecular tool in the induction of apoptosis in cancer [86]. PKG activation has been shown to induce dose dependent decreases in cell viability, as well as time dependent increases in caspases 3 and 9 activity within the MDAMB-468 cell line. The reduction in cell viability due to PKG activation was remarkably rescued with the addition of a PKG-specific antagonist to the MDAMB-468 cells [86]. Therefore, it is of interest to explore the activation of PKG and subsequent induction of PKG-mediated apoptosis in regard to EGFR-mediated 
apoptosis. Correlation of these two apoptotic pathways within the MDA-MB-468 cell line shows potential in identifying a novel protein with direct implications in the spatial regulation of the EGFR.

\section{E. Signal Transducer and Activator of Transcription 3 (STAT3)}

Signal Transducer and Activator of Transcription (STAT) proteins were initially discovered as a family of cytoplasm-bound transcription factors, which mediate normal cellular responses to growth factors, cytokines, and ligands [87, 88]. STAT activation is critical for the mediation of certain biological processes, including cell proliferation, survival, differentiation, development and inflammation [89] (Fig. 1.5). To date, there are seven known members of the STAT family expressed in mammalian tissue: STAT1, 2, 3, 4, 5a, 5b, and 6. During activation, STAT proteins become phosphorylated at their unique critical tyrosine residues (Tyr705 for STAT3). This phosphorylation/activation process can be mediated directly by growth factor receptor tyrosine kinases [90], or via cytokine receptors through Janus Kinase (Jak) mediation [87, 88, 91] (Fig. 1.5). Phosphorylation occurs at the cytoplasm, which induces STAT: STAT dimer formation between two monomers via SH2 domain interactions. From the cytoplasm, the activated STATS accumulate in the nucleus, where they initiate and mediate gene transcription by binding to DNA response elements [87]. This results in either upregulation or downregulation of the biological processes discussed previously, which are critical for cellular homeostasis (Fig. 1.5). 


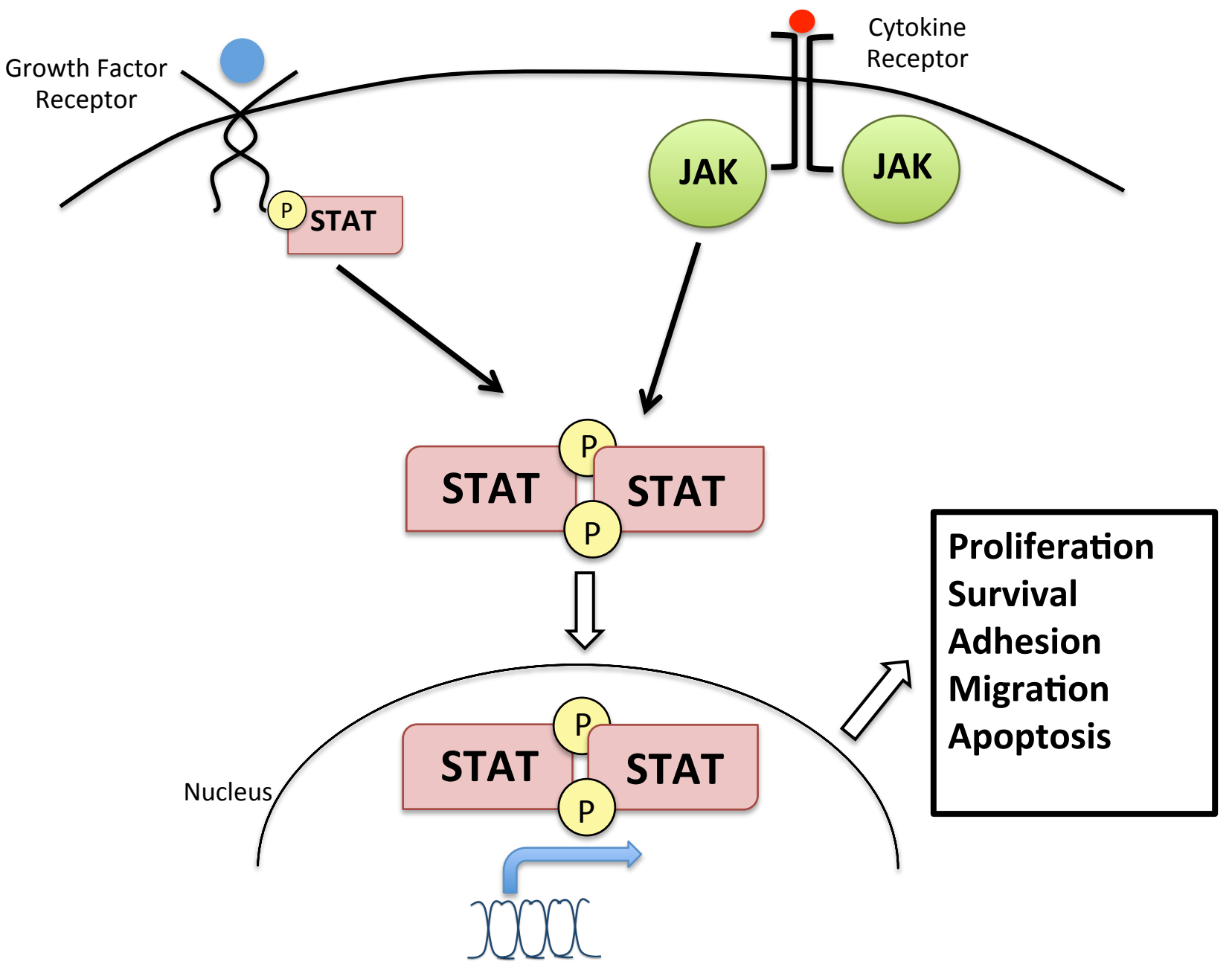

Figure 1.5. Schematic representation of STAT dimer formation and subsequent activation. STAT heterodimer formation and subsequent occurs at the cytoplasm, and can occur directly mediated through a receptor tyrosine kinase (i.e. EGFR), or conversely, through non-receptor tyrosine kinase mediation (i.e. JAK). 
Similarly to the EGFR, STAT proteins are implicated in cell growth and proliferation; however, they are upregulated in cancers and have been known to induce aberrant signaling in cancer cells. STAT3 has been reported to be constitutively phosphorylated in human cancer, and has been shown to promote tumor survival and cancer cell progression [89, 92]. Constitutive STAT3 activity has been reported in $30-60 \%$ of primary mammary malignancies [93]. One study reports that MDA-MB-468 cells exhibit constitutive activation of STAT3, and that upon inhibition using a pharmacological inhibitor (5,15-DPP), STAT3:DNA complexes decrease in a dose dependent manner of inhibitor [94]. These finding were not observed among the data described within this thesis.

Prior to being implicated in cancer, STAT3-programmed cellular death was found to be associated with and required for IL-6 induced cell death in myeloid leukemia [95] and mammary grand involution [96, 97]. After a woman is finished lactating, the involution process must occur in order to return the mammary gland to normal size of a "pre-pregnancy" state. This process is reliant on the post-translational upregulation of STAT3. This leads to downregulation of serine protease inhibitor $2 \mathrm{~A}(\mathrm{Spi} 2 \mathrm{~A})$, and upregulation of cathepsin $\mathrm{B}$. This upregulation of cathepsin B leads to the ultimate induction of apoptosis from the lysosome [98].

It appears as though STAT3 has been shown to play opposing roles in mammary tissue. In one instance, it has been shown to potentiate cell growth and invasion when constitutively active in cancer cells. Contrastingly, it has been implicated in cell death, being required for mammary gland involution, and even 
in leukemia. One of the focuses of this dissertation is to define the role of STAT3 activity in MDA-MB-468 cells.

It has been established that cGMP dependent protein kinase (PKG) plays critical roles in smooth muscle function and regulation. PKG activity has been implicated in breast and ovarian cancer. More importantly, PKG activity has been shown to induce apoptosis in a dose dependent manner of a PKG agonist in MDA-MB-468 cells [99]. Identifying a correlation between PKG-mediated and EGFR-mediated apoptosis is therefore of interest for the progression of this research project. Additionally, STAT3 has also been implicated in cancer. Although this protein is often associated with cell growth and survival, it is constitutively active in certain breast cancers, and required for cell death in certain contexts, such as post-lactation mammary gland involution [98]. The research within the dissertation entails determining if PKG and STAT3 participate in the mediation of EGF-induced apoptosis in MDA-MB-468 cells. This determination, as well as the identification of the exact role of each effector in this biochemical process, has great potential in improving therapeutic treatments that target cancers characterized by hyperexpression of receptor tyrosine kinases.

\section{F. Significance and Statement of Specific Aims}

It has been well established that receptor tyrosine kinases (RTK) inhibitors insufficiently attenuate cancer cell growth over prolonged periods of time [100], which is due to either acquired or intrinsic resistance of the malignant tissue 
[101]. Therefore, targeting the employed molecular pathways that promote or attenuate EGFR-mediated cell growth may elucidate more efficacious therapeutic options for EGFR-associated cancers. Given that EGFR-mediated apoptosis occurs preferentially in cells with high-level receptor expression, we elected to use this information advantageously by identifying effectors that had direct implications in receptor-mediated cell death in a cell line with high EGFR expression (MDA-MB-468 cells). We identified PKG and STAT3 as potential candidates of EGF-induced mediators of apoptosis in MDA-MB-468 cells. These were identified through thorough literature searches, and also through preliminary data that exhibited that PKG and STAT3 were both preferentially upregulated with high ligand stimulation, stimulation that coincidently induces cell death. Therefore, we developed and assessed the following specific aims, and their respective hypotheses:

\section{Specific Aim 1: Establish the temporal relationship between the EGFR and PKG activity in the induction of apoptosis in MDA-MB-468 cells.}

\section{Aim 1A: Determine if PKG-mediated apoptosis is EGFR dependent.}

We hypothesized that EGFR activation induced downstream PKG activation, resulting in the induction of apoptosis. To assess this hypothesis, we employed RNAi targeting PKG, just prior to activating the EGFR in MDA-MB-468 cells. Observing an increase in cell viability, coincident with a reduction in apoptosis would further support our hypothesis and define PKG is a required mediator of EGF-induced apoptosis. 


\section{Aim 1B: Determine if EGFR-mediated apoptosis is PKG dependent.}

We could not abnegate the possibility that our current hypothesis may be incorrect in regard to the sequence of PKG signaling events. In order to address this possibility, we elected to assess an alterative hypothesis as well, which was that within the MDA-MB-468 cell line, PKG activation signals to the accumulating EGFRs at the endosomes, which then results in the induction of apoptosis. To assess this hypothesis, we assessed PKG activity within MDA-MB-468 cells upon cell stimulation with increasing concentrations of EGF. Further, we intended to antagonize EGFR activity via pharmacological inhibition, stimulate of PKG activity with PKG agonists before ultimately assessing the outcome on cell viability and apoptosis. Observing an increase in cell viability, coincident with a reduction in apoptosis would further support our alternative hypothesis and define PKG as mediator apoptosis in MDA-MB-468 cells, that functioned via EGFR activation.

\section{Specific Aim 2: Determine the role of STAT3 in EGFR-mediated apoptosis in MDA-MB-468 cells.}

Similar to our studies entailing PKG, we elected to confirm or refute the role of STAT3 in either EGFR-mediated cell growth or cell death. In doing so, we antagonized STAT3 activity via pharmacological inhibition and RNAi-induced reduction of STAT3 expression. Upon successful STAT3 inhibition and EGFR activation, observing a reduction in apoptosis would be indicative of a proapoptotic role of STAT3. On the contrary, enhanced apoptosis accompanied with 
an enhanced reduced viability would be indicative of a pro-proliferative, compensatory EGF-induced cell growth mechanism. 


\section{CHAPTER II}

\section{MATERIALS AND METHODS}

\section{Cell Lines}

MDA-MB-468, A431, and HeLa cell lines were acquired from the American Type Culture Collection (ATCC). PC3 cells were generously gifted from Dr. Geoffrey Clark (University of Louisville, Louisville, KY). MDA-MB-468, A431, and PC3 cells were maintained in Dulbecco's Modified Eagle Medium (DMEM) supplemented with 10\% Fetal Bovine Serum (FBS), 1\% penicillin, 1\% streptomycin, and $2 \mathrm{mM}$ glutamine. HeLa cells were propagated in similar conditions, except with less FBS (5\%). The cells were maintained at incubation conditions of $37^{\circ} \mathrm{C}$ in $5 \% \mathrm{CO}_{2}$.

All cell lines were serum starved prior to any experimental procedure. Serum deprivation removes proteins and ligands from serum that could introduce analytical interference, providing experimental conditions that yield higher reproducibility $[102,103]$. MDA-MB-468 cells were serum starved overnight in serum free (SF) DMEM (unless otherwise specified in figure legends). PC3 and HeLa cells were serum starved in SF DMEM for 2 hours prior to beginning of all experiments. All reagent treatments for MDA-MB-468, HeLa and PC3 cell lines were prepared in SF DMEM. Preliminary data in the A431 cell line exhibited that 
A431 cells do not retain viability in SF DMEM over prolonged periods of time. Therefore, A431 cells were always serum "starved" in reduced serum, DMEM supplemented with $1.25 \%$ FBS. A431 cells were subjected to reduced serum for 2 hours prior to beginning all experimental procedures. All reagent treatments for A431 cell lines were prepared in DMEM supplemented with 1.25\% FBS.

\section{Cell Viability Analyses}

\section{MTT assay}

MTT assays were conducted in order to assess cell viability of MDA-MB468-cells upon exposure to agonists of PKG. The MTT assay assesses mitochondrial dehydrogenase activity based on its ability to cleave the tetrazolium ring of the MTT reagent (Sigma Aldrich), and subsequently produce formazan. Only mitochondria of viable cells are capable of such cleavage. Cells were plated at a density of $5,000-10,000$ cells with DMEM supplemented with $10 \%$ FBS in a 96 well plate. After a 24 -hour incubation period, the cells were washed with PBS and serum starved for 3 hours in DMEM supplemented with $0.2 \%$ BSA. The cells were then treated with various ligands and reagents in order to induce cell death. After appropriate incubation periods, the MTT reagent (5 $\mathrm{mg} / \mathrm{mL}$ in PBS) was added to each sample within the 96-well plate. The cells were then incubated for 2 hours at $37^{\circ} \mathrm{C}$ in the absence of $\mathrm{CO}_{2}$. An extraction buffer $\left(20 \%\right.$ sodium dodecyl sulfate, $50 \% \mathrm{~N}$-dimethylformamide, $50 \% \mathrm{ddH}_{2} \mathrm{O}$, $80 \%$ Acetic Acid, $1 \mathrm{M} \mathrm{HCl}$ ) was then added to all samples of the 96 -well plate in order to extract and solubilize the formazan crystals. After an additional 30- 
minute incubation with extraction buffer at $37^{\circ} \mathrm{C}$ in the absence of $\mathrm{CO}_{2}$, the 96 well plate was then analyzed on a BioTek Synergy HT plate reader and Gen5 BioTek software, at a wavelength of $570 \mathrm{~nm}$.

\section{Alamar Blue Assay}

Alamar Blue assays were also conducted in order to assess cell viability within the MDA-MB-468 cells. Resazurin, the active ingredient in the alamarblue reagent, is reduced to Resorufin in viable cells. Resorufin is highly fluorescent and viable cells enhance this fluorescence, which can be analyzed and quantified on a plate reader. Cells were plated at a density of 10,000 cells in DMEM supplemented with $10 \%$ FBS in a 96 -well plate. After a 24 -hour incubation period, the cells were washed with PBS and subjected to serum starvation conditions described in the previous section. The cells were then treated with reagents in order to induce either cell growth or death. The cells were then incubated in the presence of the various reagents for 24-48 hours. The Alamar Blue reagent was then added as $10 \%$ of the sample volume prior to a 2 -hour incubation period. The 96-well plate was then analyzed for fluorescence on a BioTek Synergy HT plate reader and Gen5 BioTek software, at wavelengths of $530 \mathrm{~nm}$ (excitation) and $590 \mathrm{~nm}$ (emission).

\section{Agonists and Antagonists}

The following agonists of PKG were employed in the research summarized in Chapter III: 8-Bromoguanosine 3',5'-cyclic monophosphate (8-Br- 
cGMP; Sigma-Aldrich, St. Louis, MO), 8-(4-Chlorophenylthio)-guanosine 3',5'cyclic monophosphate (8-pCPT-cGMP; Biolog Life Science Institute, Bremen, Germany), and 8- (4- Chlorophenylthio)guanosine- 3', 5'- cyclic monophosphate, acetoxymethyl ester (8-pCPT-cGMP-AM; Biolog Life Science Institute, Bremen, Germany).

STAT3 antagonists, Stattic and S3I-201, were both acquired from SigmaAldrich, and were employed at concentrations specified in the figure legends. The Oncostatin M (OSM) cytokine was employed as a STAT3 agonist, and was acquired from PeproTech (Rocky Hill, NJ). EGF ligand was acquired from ProSpec Protein Specialist (East Brunswick, NJ). Staurosporine (STS) was used as a positive control for apoptosis, and was acquired from Sigma-Aldrich.

\section{Cell Lysate Preparation and Immunoblot Analyses.}

Cell lysates were acquired by washing the cells twice in PBS prior to the equilibration to $4{ }^{\circ} \mathrm{C}$ and addition of RIPA lysis buffer for cell solubilization (150 $\mathrm{mm} \mathrm{NaCl}, 1 \%$ Nonidet P-40, $0.5 \%$ deoxycholate, $0.1 \%$ SDS, $50 \mathrm{~mm}$ Tris $(\mathrm{pH}$ 8.0), $10 \mathrm{~mm}$ sodium pyrophosphate, $100 \mathrm{~mm}$ sodium fluoride, $2 \mathrm{~mm}$ phenylmethyl sulfonyl fluoride). The lysis buffer/cell mixture was then rotated end-over-end for 10 min at $4{ }^{\circ} \mathrm{C}$, followed by a 10 minute centrifugation period at $15,000 \times \mathrm{g}$, at $4{ }^{\circ} \mathrm{C}$. The protein concentration of the supernatant from each sample was then assessed by a BCA assay (Pierce), and samples were subjected to a 1:3 dilution in SDS sample buffer. Equivalent amounts of protein 
(20-60 $\mu \mathrm{g})$ were separated by a $10 \%, 12 \%$, or $15 \%$ SDS-PAGE, prior to be being transferred to nitrocellulose membranes. After being washed in a blocking reagent to prevent non-specific antibody binding, the membranes were exposed to various primary antibodies overnight at $4{ }^{\circ} \mathrm{C}$ (All antibodies used are listed in Table 2.1). After a 1-hour incubation period with HRP-conjugated secondary antibodies, the membranes were washed in TBS-Tween and visualized by ECL reagent using a Fotodyne imaging system. All western blot data were analyzed and quantified using ImageJ software.

\section{siRNA knockdown in MDA-MB-468 cells}

Small Interfering RNA (siRNA) targeting PKG-I was acquired from Dharmacon (Lafayette, CO). Two siRNA oligonucleotides targeting STAT3 (5'GGAGAAGCAUCGUGAGUGA-3') (5'- CCAUUUGGUGUUUCAUAA-3') were also acquired from Dharmacon. Scramble control siRNA (siCON) was acquired from IDITDNA (Coralville, IA). MDA-MB-468 cells were treated with final concentrations of 200 nM PKG siRNA, 200 nM STAT3 siRNA or 200 nM siCON along with INTERFERin (Polyplus Transfection, Strasbourg, France). Cells were exposed to PKG siRNA for 96 hours and STAT3 siRNA for 72 hours. Cells were then treated with EGF or STS for maximal time points of 24 or 48 hours, coincident with maximal siRNA exposure of either 96 hours (for PKGI siRNA) or 72 hours (for STAT3 siRNA). Details of each experiment and subsequent knockdown verification can be found within the figure legends of the figure 


\begin{tabular}{|c|c|c|c|}
\hline Antibody & Animal Source & Company & Catalog \# \\
\hline pY1045 & Rabbit & $\begin{array}{l}\text { Cell Signaling } \\
\text { Technology }\end{array}$ & 2237 \\
\hline $\begin{array}{l}\text { pAKT } \\
\text { (Thr308) }\end{array}$ & Rabbit & $\begin{array}{l}\text { Cell Signaling } \\
\text { Technology }\end{array}$ & 9275 \\
\hline $\begin{array}{l}\text { pBAD } \\
\text { (Ser112) }\end{array}$ & Rabbit & $\begin{array}{l}\text { Cell Signaling } \\
\text { Technology }\end{array}$ & 5284 \\
\hline $\begin{array}{l}\text { Cleaved } \\
\text { Caspase-3 } \\
\text { (Asp175) }\end{array}$ & Rabbit & $\begin{array}{l}\text { Cell Signaling } \\
\text { Technology }\end{array}$ & 9664 \\
\hline $\begin{array}{l}\text { EGFR } \\
\text { (total) }\end{array}$ & Rabbit & $\begin{array}{l}\text { Santa Cruz } \\
\text { Biotechnology }\end{array}$ & SC-03 \\
\hline GAPDH & Mouse & $\begin{array}{l}\text { Santa Cruz } \\
\text { Biotechnology }\end{array}$ & SC-365062 \\
\hline $\begin{array}{l}\text { pMAPK } \\
\text { (Thr202/Tyr204) }\end{array}$ & Rabbit & $\begin{array}{l}\text { Cell Signaling } \\
\text { Technology }\end{array}$ & 9101 \\
\hline PARP & Rabbit & $\begin{array}{l}\text { Cell Signaling } \\
\text { Technology }\end{array}$ & 9542 \\
\hline $\begin{array}{l}\text { pSRC } \\
\text { (Tyr416) }\end{array}$ & Rabbit & $\begin{array}{l}\text { Cell Signaling } \\
\text { Technology }\end{array}$ & 6943 \\
\hline $\begin{array}{l}\text { pSTAT3 XP } \\
\text { (Tyr705) }\end{array}$ & Rabbit & $\begin{array}{l}\text { Cell Signaling } \\
\text { Technology }\end{array}$ & 9145 \\
\hline
\end{tabular}

Figure 2.1 Compilation of all western blot antibodies employed. 


\begin{tabular}{|l|l|l|l|}
\hline Antibody & Animal Source & Company & Catalog \# \\
\hline $\begin{array}{l}\text { STAT3 } \\
\text { (79D7) }\end{array}$ & Rabbit & $\begin{array}{l}\text { Cell Signaling } \\
\text { Technology }\end{array}$ & 4904 \\
\hline $\begin{array}{l}\text { pVASP } \\
\text { (Ser239) }\end{array}$ & Rabbit & $\begin{array}{l}\text { Cell Signaling } \\
\text { Technology }\end{array}$ & 3114 \\
\hline $\begin{array}{l}\text { VASP } \\
\text { (total) }\end{array}$ & Rabbit & $\begin{array}{l}\text { Cell Signaling } \\
\text { Technology }\end{array}$ & 3112 \\
\hline
\end{tabular}

Figure 2.1 Compilation of all western blot antibodies employed (continued) 
containing the respective experiment. Knockdown efficiencies were calculated to be $55 \%$ for PKG siRNA, and $78 \%$ for STAT3 siRNA.

\section{EGF-Bead Synthesis}

Polystyrene beads of $0.9 \mu \mathrm{M}$ size (Sigma) were covalently conjugated to recombinant human EGF (Invitorgen) as previously described [104]. In short, EGF molecules are conjugated to carboxylate modified, polystyrene beads via zero length crosslinker, $\mathrm{N}$-(3-Dimethylaminopropyl)-N'-ethylcarbodimide hydrochlorine (EDAC; Sigma). After rigorous washing, the EGF-beads were reconstituted and stored in PBS and glycerol. The beads were stored at $-20^{\circ} \mathrm{C}$ and were stable for up to 3 weeks.

\section{Statistical Analyses}

Treatment groups within each Alamarblue experiment were quantified to either untreated or vehicle controls in order to generate percent viabilities for each experimental condition. These percentages for 3 to 4 individual experiments were then averaged together. Data acquired from both assays are reported as the means of the percent viabilities \pm standard error mean (SEM; $n=3)$. An unpaired student t-test was then performed for the determination of significance. Each treatment group was compared to the untreated, serum free (SF), DMEM control. For the data within Chapter III, Protein Kinase G facilitates EGFRMediated Cell Death in MDA-MB-468 Cells, a $p$ value of less than 0.1 is 
designated significant, and is indicated by a single asterisk $\left(^{*}\right)$. A $p$ value of less than 0.05 is designated significant, and is indicated by two asterisks $\left({ }^{* *}\right)$. A $p$ value of less than 0.001 is designated very significant, and is indicated by three asterisks $\left({ }^{* * *}\right)$. A $p$ value of less than 0.001 is designated extremely significant, and is indicated by four asterisks $\left.{ }^{* * * *}\right)$. Within Chapter IV, A $p$ value of less than 0.05 is designated significant, and is indicated by a single asterisk $\left({ }^{*}\right)$. A $p$ value of less than 0.01 is designated significant, and is indicated by two asterisks $\left(^{* *}\right)$. A $p$ value of less than 0.001 is designated very significant, and is indicated by three asterisks $\left(^{(* *}\right)$. A $p$ value of less than 0.0001 is designated extremely significant, and is indicated by four asterisks $\left(^{(* * *}\right)$ 


\section{CHAPTER III}

\section{PROTEIN KINASE G FACILITATES EGFR-MEDIATED CELL DEATH IN MDA-MB-468 CELLS}

\section{Introduction}

The Epidermal Growth Factor Receptor (EGFR) is a cell surface receptor that is expressed in almost every tissue of the body, and plays critical roles in development and tissue homeostasis $[8,105]$. In addition to these physiological roles, many cancers, such as lung [106], breast [43], and colon [107] malignancies, are characterized by hyper-activated EGFR signaling, either due to overexpression of the receptor or somatic activating mutations of the receptor $[43,47]$. Perturbations in EGFR expression and/or activation are associated with poor patient prognosis. There are a number of FDA-approved therapies that target the EGFR and attenuate cancer growth. These include small molecular inhibitors such as Erlotinib and Gefitinib, which has been approved for treatment of lung [17] and colon [108] cancers, and humanized monoclonal antibodies such as Cetuximab, which has been approved for treating colorectal cancers [109]. 
Despite the progress in using EGFR inhibitors as a mode of cancer treatment, these therapies are not failsafe. These drugs can have off-target effects (i.e. dermatitis, colitis, and corneal erosions) and some cancers become refractory to the drugs over time [110-112]. EGFR inhibition can also trigger autophagy in cancer cells, a degradative process that actually helps cancer cells withstand nutrient-poor conditions [46]. Thus, despite the therapeutic benefits of EGFR-inhibition, there remains a need for more aggressive and/or targeted treatments that will arrest cancer growth and progression.

A more comprehensive understanding of how EGFR signaling is regulated will facilitate the design of new agents. We hypothesize that one key to new therapies might lie within the cell itself. Paradoxically, cells that overexpress the EGFR naturally (i.e. A431 and MDA-MB-468 cells $[113,114]$ ) or through bioengineering [115], undergo apoptosis in response to EGF treatment. By utilizing this endogenous signaling mechanism we predict that this will specifically target EGFR-overexpressing cells with minimal side effects to healthy cells. However, to most effectively utilize these pathways, we need to fully understand the mechanisms that regulate their signaling.

The goal of this study was to determine the signaling events that occur downstream of EGFR activation that lead to apoptosis. By determining how EGFR-mediated apoptosis occurs in cell lines that overexpress the EGFR, we predict this pathway can be used to halt cancers that express high levels of EGFR. These studies were conducted primarily in MDA-MB-468 cell line, a metastatic, breast, epithelial cell line [41]. These cells express approximately 1.3 
$X 10^{6}$ EGFR per cell [42], and have a well documented induction of apoptosis in response to EGF ligand ( $\geq 10 \mathrm{ng} / \mathrm{mL})[43]$

One candidate regulator of EGFR-mediated apoptosis is Cyclic guanosine monophosphate (cGMP)-dependent protein kinase (PKG). PKG exists in two functionally indistinguishable forms: PKG I and PKG II. PKG I is localized within the cytoplasm whereas PKG II is generally associated with the cell membrane [81]. Additionally, there are two isoforms of the type I PKG homologue: PKGI $\beta$ and PKGla. These two isoforms are closely related, except in the $\mathrm{N}$-terminal domain of the PKGla isoform, which has 16 fewer residues than the PKGI $\beta$ isoform [81]. PKG1 has been demonstrated to be sufficient to induce apoptosis in MDA-MB-468 cells [99]. PKG is activated by cGMP, a second messenger produced by the conversion of GTP by guanylyl cyclase (Fig. 1.4). PKG mediates downstream signaling through interactions with intracellular phosphoproteins [116], including VASP [117] and Phosphodiesterase type 5 (PDE5) [118]. The activity of these proteins includes regulating smooth muscle tone, bone growth, platelet aggregation, and electrolyte and fluid homeostasis. [77-79].

Given that stimulation of PKGI but not PKGII was sufficient to induce apoptosis [86], we developed the hypothesis that the EGFR mediates apoptosis though PKGI activity. We find that MDA-MB-468 cells have a reduction in cell viability and an increase in apoptosis in response to both EGF and PKG agonists. Further, stimulation of the EGFR leads to enhanced PKG activity in MDA-MB-468, A431, and HeLa cell lines, as measured by Vasodilator Stimulated Phosphoprotein (VASP) phosphorylation. PKG stimulation does not enhance 
EGFR phosphorylation in MDA-MB-468 cells, indicative that PKG is downstream of the EGFR. Further, knock down of PKG decreases the dose dependent EGFR-mediated cell viability and reduces apoptotic pathways. From these data, we conclude that in MDA-MB-468 cells, the EGFR utilizes PKG to promote cell death via apoptotic pathways.

\section{Results}

It is well documented that cell lines that hyperexpress the EGFR, such as MDA-MB-468 cells $[43,119,120]$, undergo EGFR-mediated apoptosis. This is demonstrated with the dose-dependent decrease in MDA-MB-468 cell viability (Fig 3.1A). How a mitogenic growth factor receptor mediates cell death has studied for a number of years, with no clear resolution of the molecular mechanism. Determining the effectors that are necessary for EGFR-mediated apoptosis is a critical first step understanding the underlying molecular mechanism.

Based on previous studies linking Protein kinase G (PKG) activity to apoptosis in MDA-MB-468 cells, we tested whether PKG was downstream of EGFR activity (Fig 3.1B). Following treatment with EGF, there was a dosedependent increase in EGFR phosphorylation [measured as a function of phosphorylation of tyrosine 1045 (pY1045)] (Fig. 3.1C). Active PKG phosphorylates VASP specifically at Serine239 [121]; serine phosphorylation of VASP is accompanied by a slowed electrophoretic mobility of the protein on SDS-PAGE resulting in two bands on both phosphorylated VASP (pVASP) and total VASP immunoblots [122-124]. 

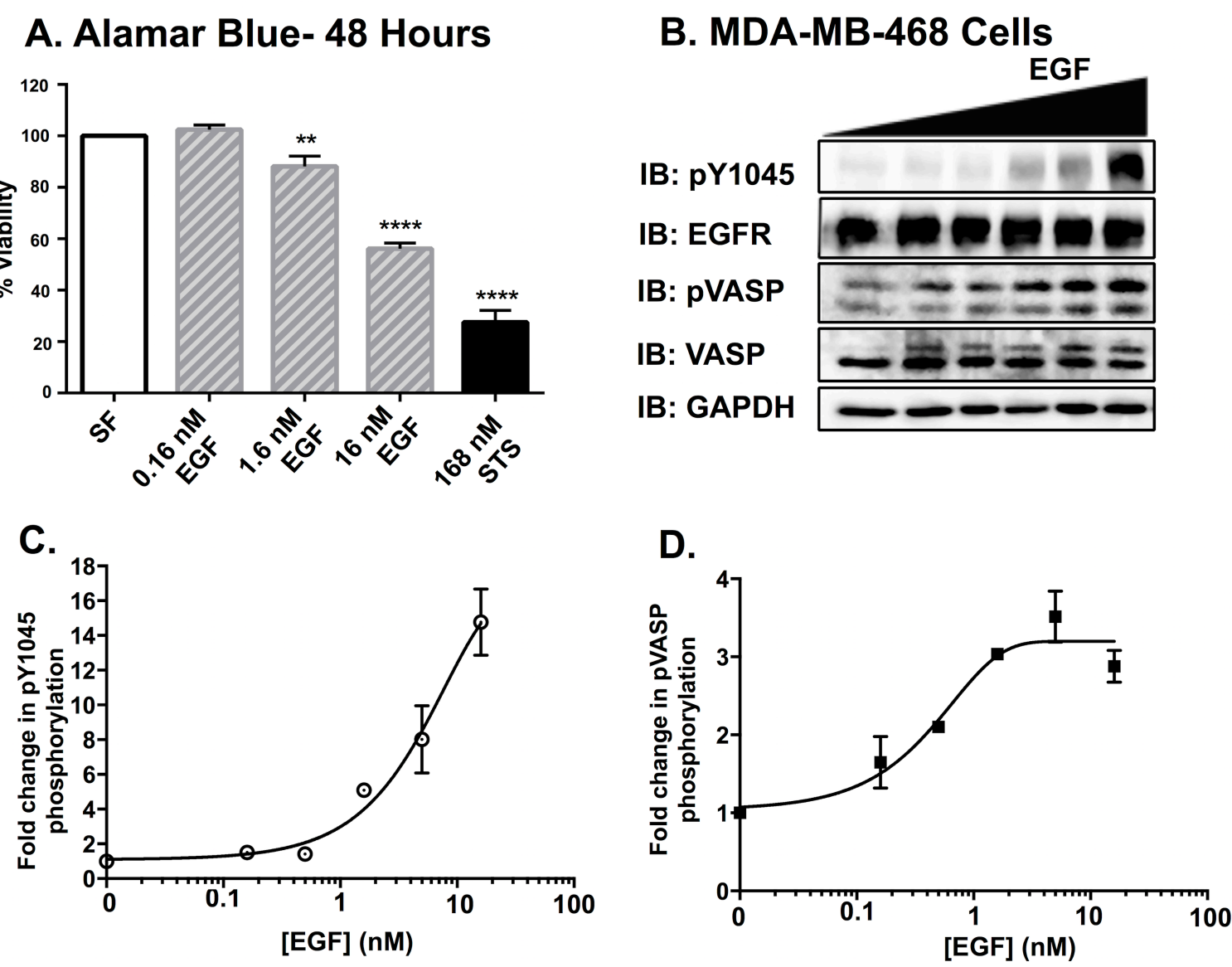

Figure 3.1 
Figure 3.1. Increases in EGF ligand concentration elicit a dose dependent increase in pVASPSer239 phosphorylation in MDA-MB-468 cells. A. MDAMB-468 cells were seeded into 96-well dishes prior to being serum starved overnight. The cells were treated for 48 hours prior to AlamarBlue, cell viability analyses. Data are reported as the mean \pm SEM $(n=3)$. B. Serum-starved MDAMB-468 cells were treated with varying concentrations of EGF $(0,0.16,0.5,1.6$, 5 and $16 \mathrm{nM}$ ) for 30 minutes. Cell lysates were prepared, and equivalent amounts of protein $(20 \mu \mathrm{g})$ were resolved by $12 \%$ SDS-PAGE and transferred to nitrocellulose. Membranes were probed for EGFR phosphorylated at tyrosine 1045 (pY1045), total EGFR (EGFR), VASP phosphorylated at serine 239 (pVASP), total VASP (VASP), and GAPDH as a loading control. Quantification of EGFR phosphorylation (pY1045) (C.) and VASP phosphorylation (pVASP) (D.) immunoblots using ImageJ software. Data are plotted as the mean \pm Standard Error of the Mean (SEM) $(n=3)$. 
Using a phosphoVASP immunoblot to monitor activation of PKG, we found that, co-incident with receptor phosphorylation, there was a dose-dependent increase in PKG activity (Fig 3.1B). Comparison of the $\mathrm{EC}_{50}$ of EGF-mediated EGFR and VASP phosphorylation (4.7 nM and $0.49 \mathrm{nM}$, respectively) indicates that the processes are tightly coupled; only low levels of EGFR activity are needed to stimulate PKG.

EGFR:PKG communication is not unique to MDA-MB-468 cells [84]. A431 cells are a metastatic epidermoid cell line that also undergoes EGF-dependent apoptosis [120], and hyperexpresses EGFRs at levels $\left(1.5 \times 10^{6}\right.$ EGFR/cell [125]) comparable to MDA-MB-468 [42]. When treated with EGF, A431 cells had a similar dose-dependent induction of EGFR and VASP activity (Fig. 3.2A). EGF induced EGFR phosphorylation in A431 cells with a similar efficacy and potency as seen in MDA-MB-468 cells (Fig. 3.2B). A431 and MDA-MB-468 cells had comparable levels of pVASP activity ( 2-3-fold over basal), and comparable $\mathrm{EC}_{50}$ 's to stimulate pVASP $(0.56 \mathrm{nM}$ and $0.66 \mathrm{nM}$, respectively). Further, in HeLa cells that expresses much lower levels of EGFR ( 50,000 EGFRs/cells [126], despite a smaller dynamic range of EGFR phosphorylation (Fig. 3.2D), the $E_{50}$ was comparable (0.66 nM). Thus, in multiple EGFR-expressing cell lines, there was an EGF-dependent PKG activation.

Having established that EGFR could activate PKG, we wanted to determine if direct activation of PKG was sufficient to induce cell death. MDAMB-468 cells were treated with three commercially available agonists of PKG 8-Bromoguanosine 3',5'-cyclic monophosphate (8-Br-cGMP), 

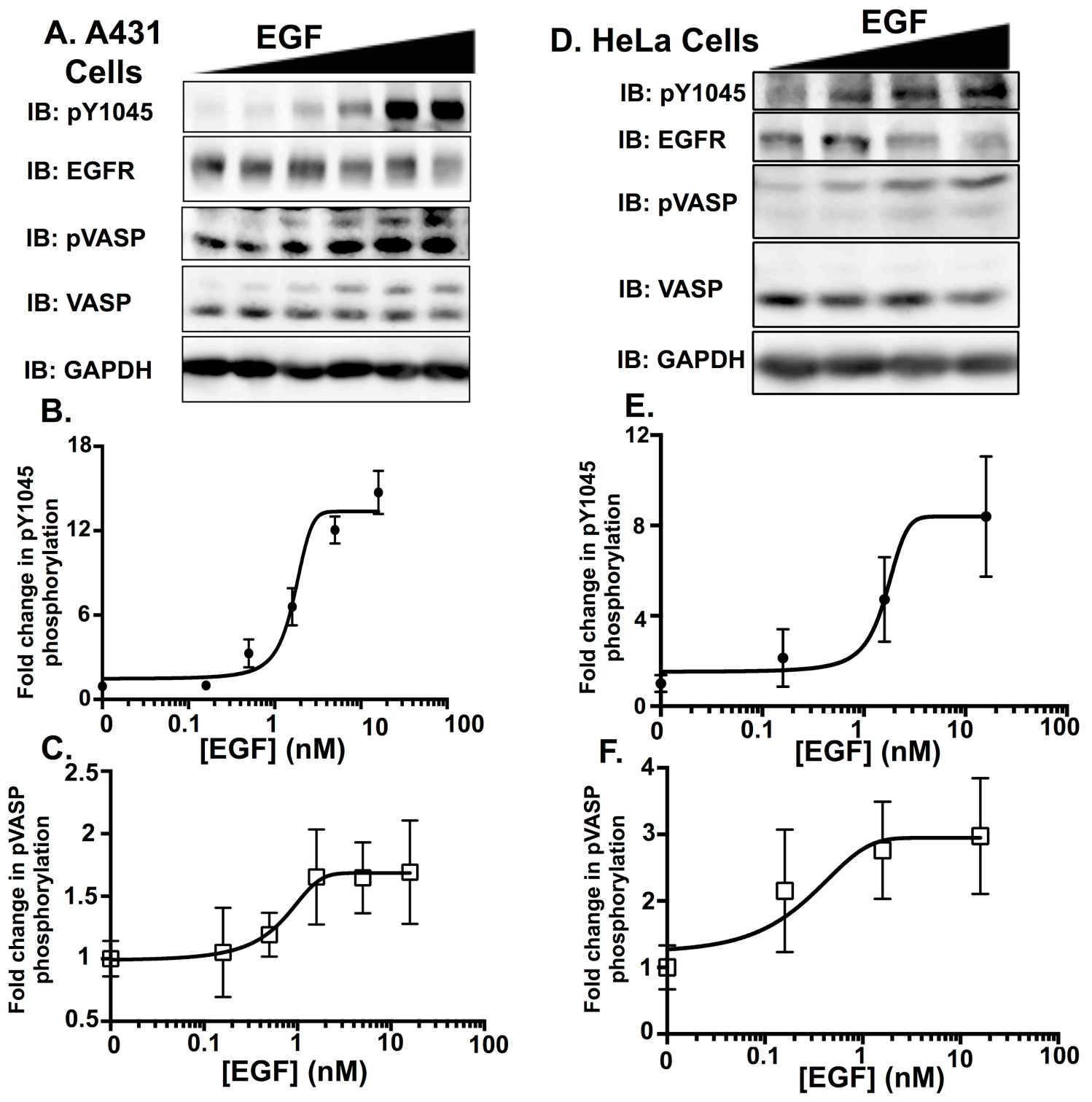

Figure 3.2 
Figure 3.2. Increases in EGF ligand concentration elicit a dose dependent increase in pVASPSer239 phosphorylation in A431 and HeLa cell lines.

A. A dose response was conducted in A431 cells using $0,0.16,0.5,1.6,5$ and $16 \mathrm{nM}$ concentrations of EGF ligand. Cells were serum starved for 2 hours, and then exposed to the various ligand concentrations for 60 minutes. Forty $\mu g$ of protein per sample were then resolved on a 10\% SDS-PAGE. Western blot data of pY1045 (B.) and pVASPSer239 (C.) from three independent dose response experiments in A431 cells were quantified to blots of total protein (EGFR and VASP, respectively) using ImageJ software. Error bars are expressed as \pm SEM. D. A dose response was conducted in HeLa cells using 0, 0.16, 1.6 and $16 \mathrm{nM}$ concentrations of EGF ligand. Cells were serum starved for 2 hours, and then exposed to the various ligand concentrations for 60 minutes. HeLa cell lysates $(60 \mu \mathrm{g})$ were then resolved on a 10\% SDS-PAGE. Western blot data of pY1045 (E.) and pVASPSer239 (F.) from three independent dose response experiments in HeLa cells were quantified to blots of total protein (EGFR and VASP, respectively) using ImageJ software. Error bars are expressed as \pm SEM $(n=3)$. 
8-(4-Chlorophenylthio)-guanosine 3',5'-cyclic monophosphate (8-pCPT-cGMP), and 8- (4- Chlorophenylthio) guanosine- 3',5'- cyclic monophosphate, acetoxymethyl ester (8-pCPT-cGMP-AM). 8-Br-cGMP is a brominated derivative cGMP analog and is cell permeant [127]. 8-pCPT-cGMP and 8-pCPT-cGMP-AM are both PKG agonists that only differ by the presence of an acetoxymethyl ester; the addition of the acetoxymethyl ester makes 8-pCPT-cGMP-AM more cell permeant, and resistant to metabolic turnover [128]. MDA-MB-468 cells were treated with varying concentrations of these compounds and found to activate PKG (measured by VASP phosphorylation) (Figs. 3.3A and 3.3B), treatment with 8-pCPT-cGMP did not produce detectable levels of pVASP, likely due to limited cell permeability, and was not used in cell viability experiments. Importantly, none of the PKG activators were able to induce detectable levels of EGFR phosphorylation (Figs. 3.3A and 3.3B). Next, the effect of the PKG agonists on cell viability was examined. Both 8-Br-cGMP and 8-pCPT-cGMP-AM caused a modest, dose-dependent decrease in cell viability (Figs. 3.3C and 3.3D).

To determine if the observed decreases in cell viability were a consequence of apoptosis, we examined caspase-3 and poly ADP-ribose polymerase (PARP) cleavage via immunoblot analysis. Caspase-3 is a critical executioner of apoptosis [129]; when active, executioner caspases cleave and activate various substrates, such as poly ADP-ribose polymerase (PARP), which ultimately cause the morphological changes associated with apoptotic cells [50, 71]. MDA-MB-468 cells were treated with 8-Br-cGMP, 8-pCPT-cGMP-AM 


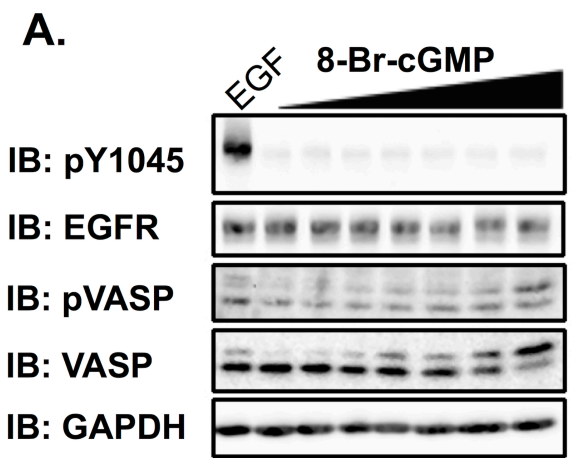

C. MTT- 48 Hours

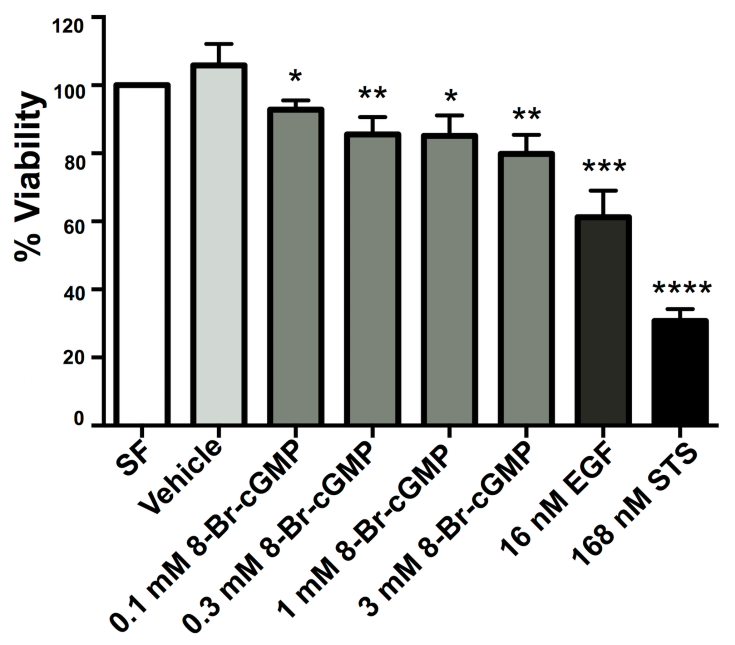

B. 8-pCPT-cGMP-AM 8-pCPT-cGMP

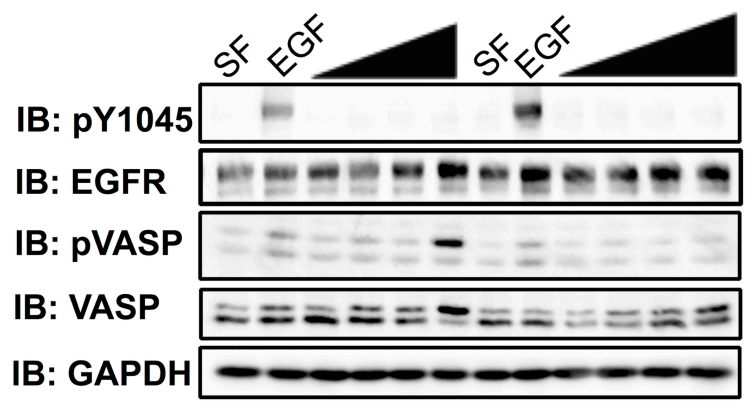

D. Alamar Blue- 48 Hours

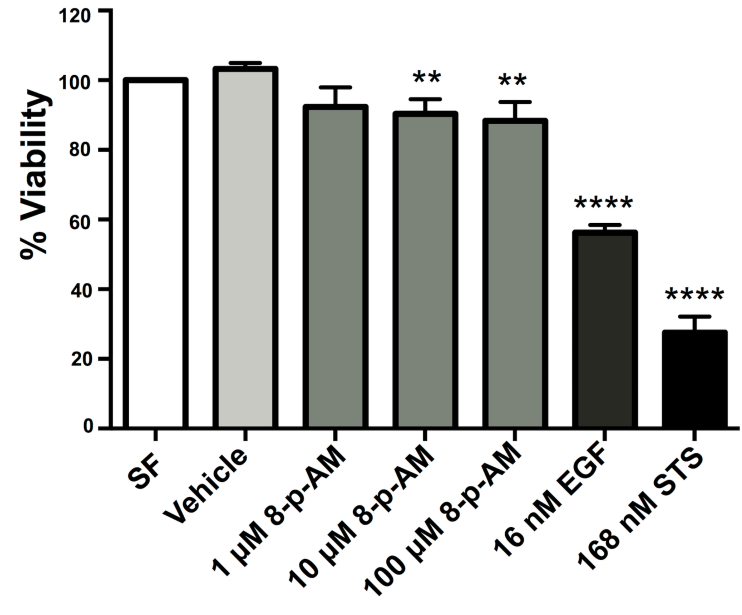

Figure 3.3 
Figure 3.3. PKG agonists do not elicit EGFR phosphorylation, but do induce dose dependent decreases in MDA-MB-468 cell viability. A. The PKG agonist, 8-Br- cGMP, was used at 0.1, 0.3, 1, 1.3, 2 and $3 \mathrm{mM}$ concentrations. This treatment was accompanied with a positive control for EGFR phosphorylation, $16 \mathrm{nM}$ EGF. The cells were exposed to the various conditions for 1 hour prior to the harvesting of each cell lysate. Forty $\mu g$ of protein per sample were then resolved on a 12\% SDS-PAGE. B. The PKG agonist, 8-pCPTcGMP-AM (8-p-AM), was employed at 1, 10, and $100 \mu \mathrm{M}$ concentrations. The other PKG agonist in use, 8-pCPT-cGMP, was employed at 100, 250, and 500 $\mu \mathrm{M}$ concentrations. Cells treated with serum free DMEM (SF) served as a negative control for both pVASP and EGFR phosphorylation. Cells treated with $16 \mathrm{nM}$ EGF served as a positive control for EGFR and pVASP-SER239 phosphorylation. C. Results from an MTT (3-(4,5-dimethylthiazol-2-yl)-2,5diphenyltetrazolium bromide) cell viability assay. Cells were serum starved overnight, and then subjected to each experimental condition for 48 hours total prior to MTT analyses. A vehicle control of $6.7 \%$ deionized water in DMEM was used to accompany the $3 \mathrm{mM}$ 8-Br-cGMP treatment. Data are expressed as means of percent viability \pm SEM $(n=3)$. D. Results from an AlamarBlue cell viability assay. Cells were serum starved overnight, and then subjected to each experimental condition for 48 hours total prior to AlamarBlue analyses. Cells treated with the PKG agonist, 8-p-AM, were quantified to their respective vehicle control (cells treated with $0.2 \%$ DMF). All other data were quantified to the serum free control. All data are plotted as the average of percent viability \pm SEM $(n=4)$. 
(8-p-AM) and 16 nM EGF. Cells were collected and analyzed by immunoblot for the presence of cleaved PARP and caspase 3 (Fig. 3.4). Cells were incubated in serum free media (SF) and vehicle alone as a negative control and with Staurosporine (STS) as a positive control. The PKG activators and EGF induced PARP and caspase-3 cleavage (Fig. 3.4A). Consistent with the cell viability assays, EGF treatment was more effective than PKG activation (Figs. 3.4B and $3.4 C)$.

Finally, to determine if PKG is a signaling intermediate in EGFR-mediated apoptosis, we examined EGFR-mediated signaling with attenuated PKG expression (Fig. 3.5). Cells were transfected with control (siCON) or PKG specific siRNA, treated with EGF for 24 or 48 hours, and assayed for cell viability (Figs. 3.5A and 3.5B). PKG knockdown was verified by immunoblot (Fig 3.5C) and was quantified using Image $\mathrm{J}$ software to be $55 \%$, consistent with previous reports [130]. In the absence of PKG, EGF treatment was not as effective at decreasing cell viability. This was statistically significant after 48 hours of EGF treatment and at high EGF doses (i.e. $16 \mathrm{nM}$ ), however, this trend is observed at all three EGF concentrations. When PKG knock down cells were treated with EGF, there was a trend of reduced activity in apoptotic markers (PARP and Caspase-3 cleavage) (Figs. 3.6B- D), but this was not statistically significant. 

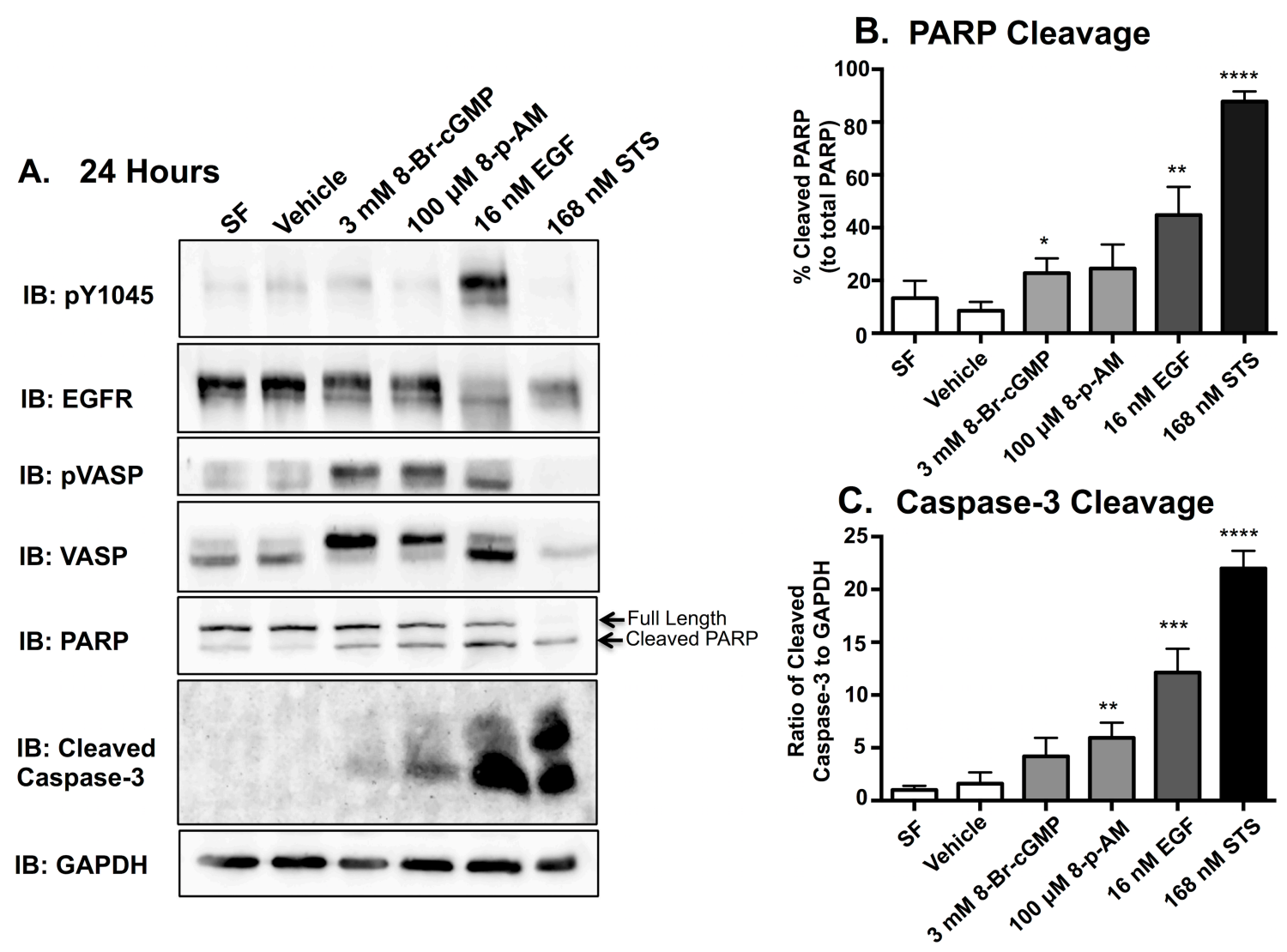

Figure 3.4 
Figure 3.4. PKG agonists induce apoptosis in the MDA-MB-468 cell line.

A. MDA-MB-468 cells were serum starved overnight. With the exception of Staurosproine (STS), the cells were then subjected to each experimental condition for 24 hours. MDA-MB-468 cells were treated with STS for 3 hours prior to being harvested. This was done in order to induce a robust response without inducing catastrophic damage to the cell. The induction of apoptosis was determined by using PARP and Cleaved Caspase-3 antibodies. With the exception of STS, $40 \mu \mathrm{g}$ of protein per sample were then resolved on a $15 \%$ SDS-PAGE. Fifteen $\mu \mathrm{g}$ of protein from the STS sample were resolved on the $15 \%$ SDS-PAGE. This was done in order to ensure that our positive control was within the dynamic range. Quantification of western blot data from cleaved PARP (B.) and Caspase-3 (C.) from three independent experiments. Band intensities were determined using Image $\mathrm{J}$ software and plotted relative to total PARP (\% cleaved PARP) or GAPDH (ratio of cleaved Caspase-3/GAPDH), respectively. Data are plotted as the average \pm SEM $(n=3)$. 

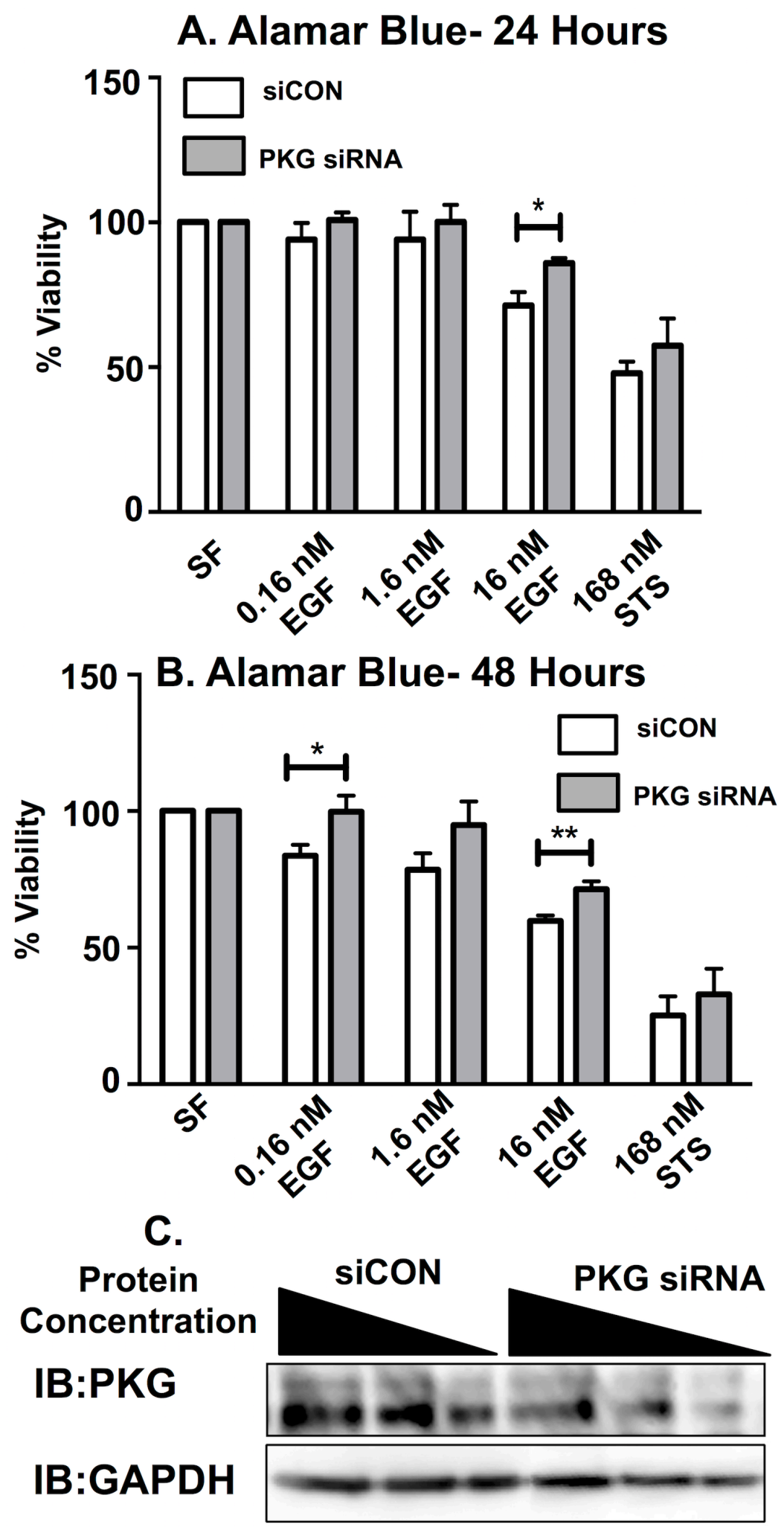

Figure 3.5 
Figure 3.5. Reduction in PKG activity yields a significant increase in MDAMB-468 cell viability upon exposure to EGF ligand. MDA-MB-468 cells were subjected to either $200 \mathrm{nM}$ control siRNA (siCON) or $200 \mathrm{nM}$ of siRNA targeting PKG for a total of 96 hours. The day after initial siRNA transfection, MDA-MB468 cells were seeded into 96-well dishes and were then subjected to various concentrations of EGF ligand for either 24 hours (A) or 48 hours (B). Data are plotted as the average of percent viability \pm SEM $(n=3)$ C. Representative western blot image of $200 \mathrm{nM}$ siCON and 200 nM PKG siRNA exposed MDAMB-468 cells at 96 hours. Cell lysates were loaded in volumes of decreasing protein concentration $(20,10$, and $5 \mu \mathrm{g})$ and then resolved on a $12 \%$ SDS-PAGE. Blots were then quantified using ImageJ software in order to determine the percentage of PKG knockdown (55\%). 
A.

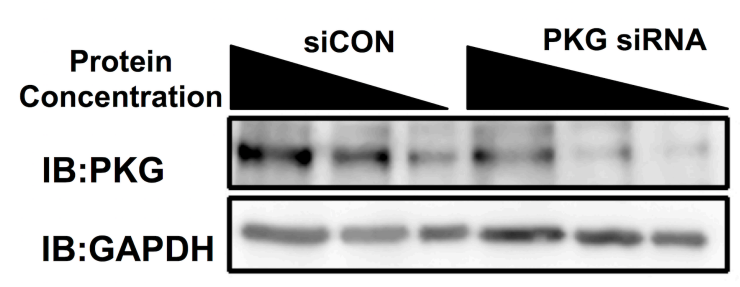

C.

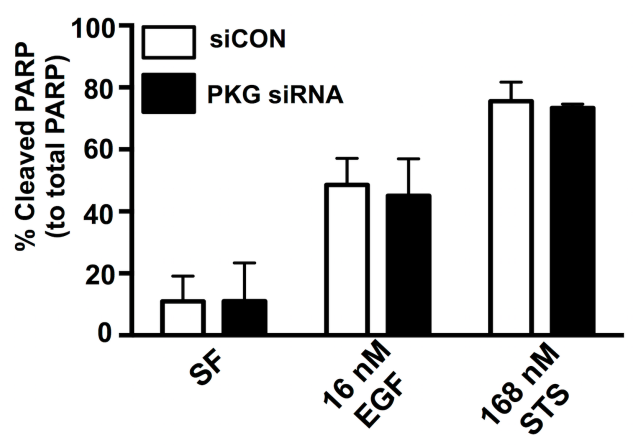

B.

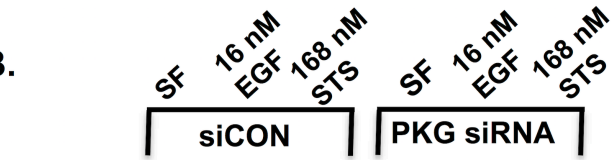

IB: PARP

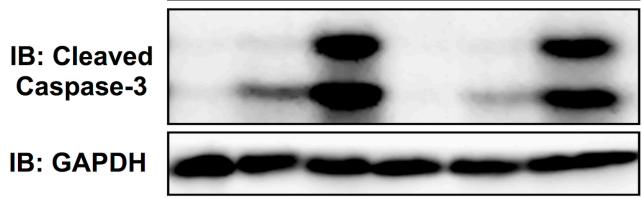

D.

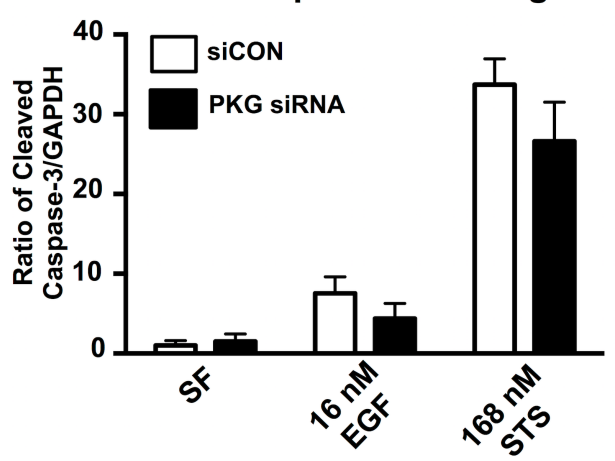

Figure 3.6 
Figure 3.6. Reduction in PKG activity yields less apoptosis in MDA-MB-468 cells. A. Representative western blot image of $200 \mathrm{nM}$ siCON and $200 \mathrm{nM}$ PKG siRNA exposed MDA-MB-468 cells at 96 hours. Cell lysates were loaded in volumes of decreasing protein concentration $(20,10$, and $5 \mu \mathrm{g})$ and then resolved on a $12 \%$ SDS-PAGE. Blots were then quantified using ImageJ software in order to determine the percentage of PKG knockdown (55\%). B. Representative western blot image of western blot analyses of PKG knockdown and siCON MDA-MB-468 cells. Cells were treated with $200 \mathrm{nM}$ siCON or $200 \mathrm{nM}$ PKG siRNA for 96 hours. The cells were also exposed to either serum free media (SF), EGF, or Staurosporine (STS) for 48 hours. Cell lysates were then harvested and resolved on a 15\% SDS PAGE. Immunoblot images for PARP and Cleaved Caspase-3 were used as indicators of apoptosis. Quantification of western blot data from cleaved PARP (C.) and Caspase-3 (D.) from three independent experiments. Band intensities were determined using Image $\mathrm{J}$ software and plotted relative to total PARP ( $\%$ cleaved PARP) or GAPDH (ratio of cleaved Caspase-3/GAPDH), respectively. Data are plotted as the average \pm $\operatorname{SEM}(n=3)$. 


\section{Discussion}

The purpose of this study was to identify effectors downstream of EGFR activation that are actively mediating apoptosis in MDA-MB-468 cells. Using a combination of immunoblot assays, pharmacological activators, and RNAi, we tested the hypothesis that the EGFR is signaling via PKG to induce apoptosis. The ligand-dependent activation of the EGFR corresponded with phosphorylation of the PKG substrate VASP (Fig. 3.1B). The directionality of this signaling was confirmed by the observation that direct activation of PKG with the agonists 8-BrcGMP and 8-p-AM (Figs. 3.3A and 3.3B) failed to stimulate the EGFR. Finally, when PKG was knocked down, there was a statistically significant reduction in EGFR-mediated cell viability and a decrease in caspase-3 cleavage.

PKG is not normally associated with a downstream effector of the EGFR. However, it is not unprecedented; EGF stimulation in an ovarian cancer cell line, OV2008, leads to an EGFR-dependent VASP phosphorylation as well [84]. In addition to MDA-MB-468 cells, EGF treatment of A431 and HeLa cells, leads to a dose-dependent induction of phosphoVASP (Fig. 3.2). It should be noted that in cell lines which express physiological levels of EGFR, exposure to higher levels of ligand often elicit total receptor degradation [44] (Fig. 3.2D). EGFR:PKG communication can occur independent of receptor expression. However, the cytotoxicity associated with EGFR-mediated PKG activity may be a function of the kinase's subcellular distribution, the duration of receptor:effector communication, or the presence of downstream substrates. 
While A431 cells undergo EGFR-mediated apoptosis [120, 131], EGF is not as potent in its induction of apoptosis as what has been observed in MDAMB-468 cells. For instance, it has been reported that A431 cells are capable of surviving EGF treatment for several days, and can become resistant to the induction of apoptosis in the presence of EGF [132]. Further, the initial reports of PKG-mediated apoptosis were in MDA-MB-468 cells [86, 99]. We therefore elected to pursue subsequent experiments in a cell line with the greatest dynamic range.

PKG activity is often associated with cytoprotective biology (i.e. heart cells [133], neurons, and glia cells $[134,135])$ rather than a mediator of apoptosis. However, there is other evidence linking PKG to other proapoptotic effects in breast [86], ovarian [84], and colon cancer. Activation of PKGI in colon cancer cells induces apoptosis in a c-Jun $\mathrm{NH}_{2} \mathrm{NH}_{2}$-terminal kinase 1 (JNK1) pathway dependent manner [136]. Many of the roles of cGMP and PKG signaling are well understood; however, a lack of clarity remains in terms of the role of PKG in cancer. This research aims to provide more information about PKG and it's association with EGFR, and other receptor tyrosine kinases with implications in human malignancies.

By most accounts, apoptosis is an aberrant EGFR-mediated signaling event for a receptor that typical promotes cell growth. It is a challenge to decipher the molecular events that specifically promote apoptosis in the context of receptor- and cell stress-mediated pro-growth signaling. As a result, the molecular details of EGFR-mediated apoptosis remain controversial. The signal 
transducers and activators of transcription (STAT) pathway is one of the most intensively studied mechanism entailed in EGFR-mediated apoptosis in cancer [137]. Studies have shown that in cell lines that hyper-express EGFR, the EGFR activates STAT1, which recognizes responsive elements of and upregulates p21 $[138,139]$. When active, $p 21$ is a cyclin-dependent kinase inhibitor that suppresses reduces cell proliferation and induces apoptosis [140]. More recent studies have shown that in cell lines with elevated EGFR expression, EGF stimulation suppresses activity within the phosphoinositide 3-kinase/protein kinase $\mathrm{B} /$ mammalian target of rapamycin (PI3K/AKT/mTOR) pathway, suggesting that inhibition of the PI3K/AKT/mTOR pathway might be required for EGFR-mediated apoptosis to occur [141].

This report provides data indicating that in MDA-MB-468 cells, PKG contributes to EGFR-mediated cell death, likely through apoptotic signaling pathways. Although the contribution of PKG to EGFR-mediated apoptosis appears modest, this is likely a consequence of partial PKG knock down ( 55\% knock down). It remains unclear how a mitogenic growth factor receptor and a cytoprotective effector collaborate to induce apoptosis. One possible explanation is that hyperstimulation of cell viability pathways leads to cell catastrophe over time. Several pieces of evidence support this model. First, cell lines that have low levels of EGFR and more rapid receptor turnover do not induce apoptosis [45]. Second, low levels of EGF ligand do not induce MDA-MDA-468 cell apoptosis [43]. Third, the slowed kinetics of cell death following EGFR or PKG activation argue that the induction of apoptosis does not occur as a direct activation of an 
enzymatic pathway. Nevertheless, the EGFR:PKG communication shows promise as a new pathway for selectively mediating cytotoxicity in cells that overexpress the EGFR. 


\section{CHAPTER IV \\ EGFR-MEDIATED APOPTOSIS VIA STAT3}

\section{Introduction}

The Epidermal Growth Factor Receptor (EGFR) is a transmembrane receptor tyrosine kinase that plays critical roles in cell growth, tissue development, and overall cellular homeostasis $[8,105]$. Despite these critical physiological roles, there are a myriad of human malignancies $[43,106,107]$ that are characterized by hyper-activated EGFR signaling. This is due to either receptor overexpression or activating mutations of the receptor $[43,47]$. The FDA has approved pharmacological agents that antagonize ligand binding and inhibit EGFR kinase activity for the treatment of patients with cancers characterized by hyper-activated EGFR signaling [17, 108, 109]; however, these drugs have offtarget effects (i.e. colitis, corneal erosions and dermatitis) and cancers often become desensitized to these agents over time [110-112]. Thus, there remains a need to develop drugs that more aggressively and specifically target those cancers with enhanced EGFR signaling, but allow normal, healthy cells to perform biological roles. 
One potential strategy for doing this is to hijack intrinsic signaling pathways and exploit them to compromise the cell's health. Cell lines with EGFR overexpression either naturally (A431 and MDA-MB-468 cells $[113,114])$ or via bioengineering (Rat-1 fibroblasts) [115], undergo EGF-induced apoptosis [43, $119,120]$. Understanding the molecular mechanism by which this occurs will identify new potential pharmacological targets that can induce death in cells that overexpress the EGFR (i.e. cancer cells).

Through an effector screen, STAT3 was identified as a plausible mediator of EGFR-induced apoptosis. Signal Transducer and Activator of Transcription 3 (STAT3) is one of seven members of the STAT family of transcription factors, namely, STAT1, STAT2, STAT3, STAT4, STAT5a, STAT5b, and STAT7. STAT activation is critical for a number of biological processes, including cell proliferation, survival, differentiation, development and inflammation [89]. STAT3 is a DNA-binding transcription factor that is known to mediate normal cellular processes upon activation by growth factors, ligands and cytoplasmic cytokines, such as cytokine receptor-associated Janus kinases (JAKs) [87, 88, 142, 143]. These upstream protein components phosphorylate STAT3 at its unique, critical tyrosine residues, primarily Tyr705 [87, 88]. The EGFR has also been reported to directly tyrosine phosphorylate STAT3 $[93,144]$. STAT phosphorylation occurs at the cytoplasm, which induces STAT homo and heterodimer formation between two monomers via their Src homology 2 (SH2) domain interactions. From the cytoplasm, activated STAT dimers translocate and accumulate in the nucleus, where they initiate and mediate gene transcription by binding to DNA response 
elements [87]. This results in either upregulation or downregulation of the biological effectors and subsequent cellular processes that are critical for cellular homeostasis.

STAT3 has been implicated in the post-transcriptional modification of cellular processes, positively and negatively affecting cell growth and proliferation. Aberrant STAT3 signaling and constitutive activity has been reported in a number of cancers $[89,92]$. Elevated basal STAT3 activity has been reported in $30-60 \%$ of primary mammary malignancies, with reports of it being required for tumor cell progression and metastasis [93]. However, prior to being implicated in cancer, STAT3-mediated programmed cellular death was found to be associated with and required for mammary gland involution [96, 97]. Additionally, STAT3 has been previously implicated as a key mediator of apoptosis in murine pro-B cells [145], myeloid leukemia [95], and prostate cancer [146]. These conflicting roles for STAT3 in the context of normal and malignant cellular biology highlight the need for a better understanding of this protein in EGFR signaling mechanisms.

The overarching goal of this study was to identify mediators of EGFRmediated apoptosis. STAT3 was identified as being specifically activated under apoptosis-inducing conditions. Based on this finding, we develop two mutually exclusive hypotheses. First, STAT3 was acting as an active intermediate and promoting cell death, or second, STAT3 was upregulated as a compensatory mechanism in an attempt to promote cell survival during EGFR-induced cell stress. Utilizing siRNA targeting STAT3 resulted in a significant attenuation of 
EGF-induced apoptosis. Additionally, EGFR-independent activation of STAT3 through cytokine stimulation promoted apoptosis, as measured by PARP and Caspase-3 cleavage. From these findings, we conclude that STAT3 is required for EGFR-mediated cell death via PARP cleavage and subsequent activation.

\section{Results}

It is known that cell lines that hyperexpress the EGFR, such as MDA-MB468 and $A 431$, undergo EGFR-mediated apoptosis $[43,119,120]$; however, the molecular mechanism(s) by which this occurs have not yet been fully elucidated. Previously, it has been documented that in MDA-MB-468 cells, lower concentrations of EGF (0.16 nM) promote cell growth, whereas higher concentrations (16 nM) induce apoptosis [43]. With this in mind, we screened MDA-MB-468 cells for the ability to activate five effector proteins that have been previously associated with cell growth and or apoptosis in cancer: MAPK [147, 148], SRC [149, 150], AKT [147], BAD [151], and STAT3 [95, 152] (Figs. 4.1 and 4.2). MDA-MB-468 cells were treated with either low ( $0.16 \mathrm{nM})$ or high (16 nM) concentrations of EGF for 0-120 minutes, and assessed the phosphorylation status (activity) of these effectors by immunoblot (Fig. 4.1A and Fig 4.2A). MAPK, SRC, AKT, and BAD displayed no significant differences in phosphorylation patterns with the high and low concentrations of ligand (Figs. 4.1B- E). However, STAT3 phosphorylation 
A.

0.16 nM EGF

16 nM EGF

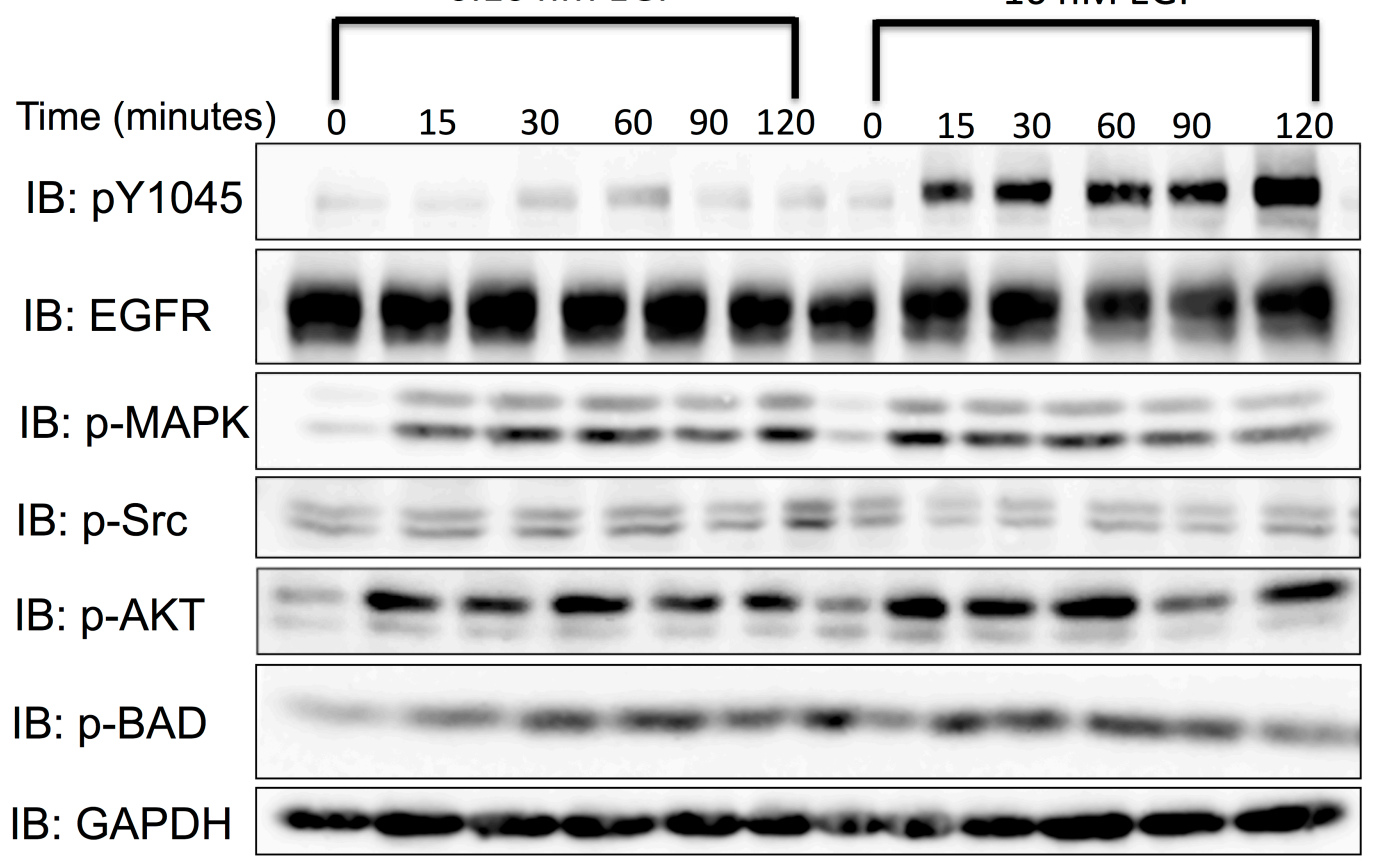

B.

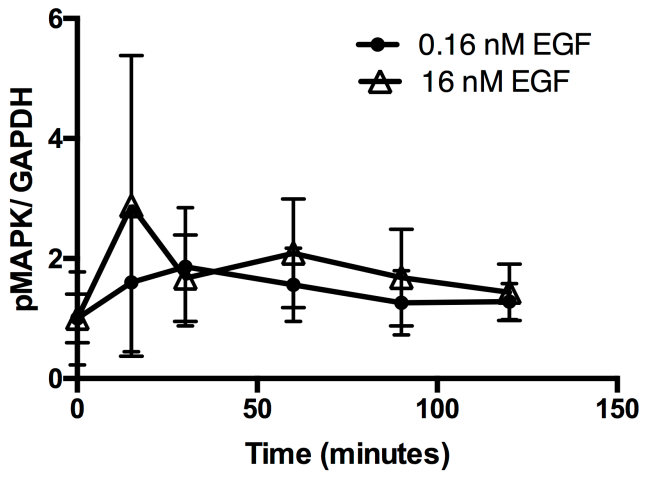

D.

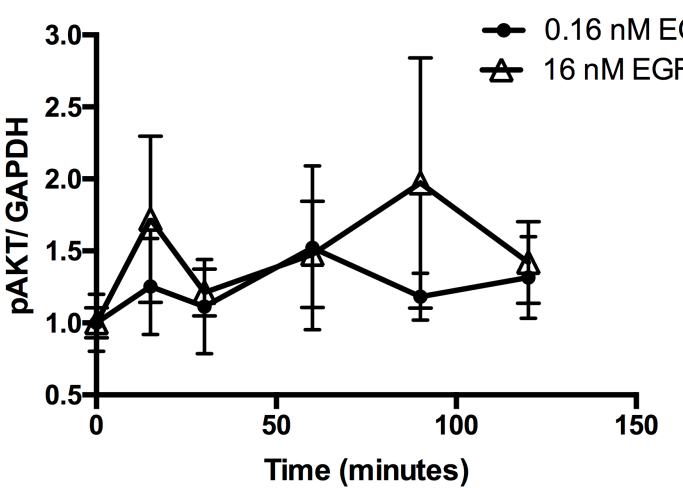

C.

pSRC

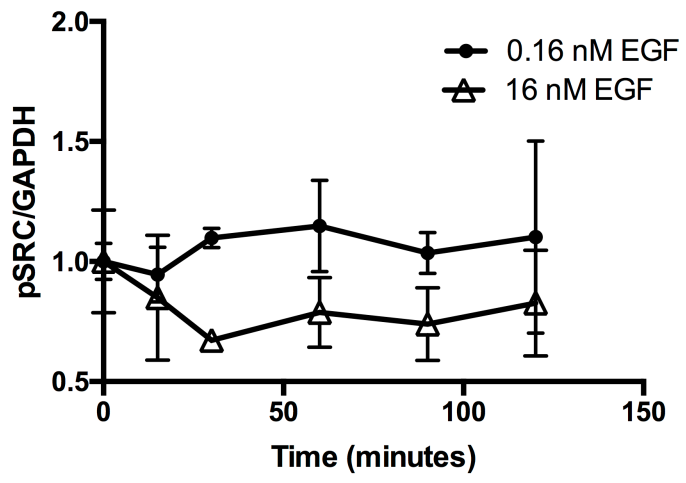

E.

PBAD

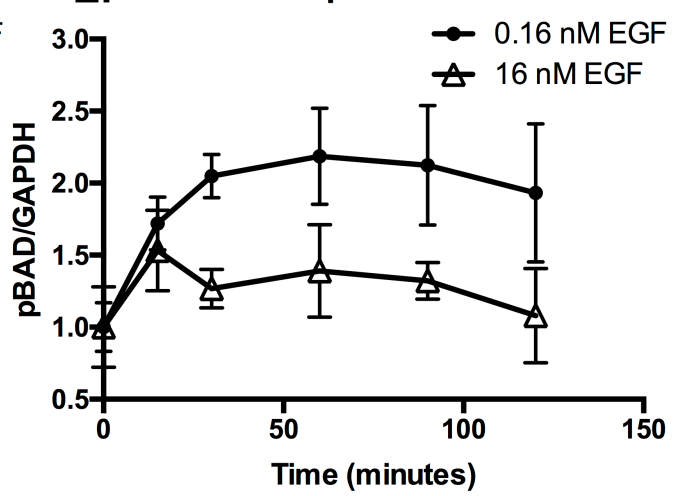

Figure 4.1 
Figure 4.1. Phosphorylation of MAPK, SRC, AKT, and BAD in response to high and low EGF concentrations. A. Serum-starved MDA-MB-468 cells were stimulated with low $(0.16 \mathrm{nM})$ or high (16 nM) EGF ligand for 0-120 minutes. Cell lysates $(20 \mu \mathrm{g})$ were resolved by $12 \%$ SDS-PAGE and were assessed for the indicated proteins via immunoblot analysis. Band intensities from the immunoblot data of pMAPK (B.), pSRC (C.), pAKT (D.) and pBAD (E.) were quantified, normalized to GAPDH levels, and plotted as the relative level compared to cells with no treatment. Data are expressed as the average \pm Standard Error of the Mean (SEM; $n=3)$. 
(Tyrosine 705), was undetectable at all time points following stimulation with low concentrations of ligand, but was robustly increased over time following treatment with high levels of ligand (Figs. 4.2A and 4.2B).

To determine if STAT3 phosphorylation is cell type specific, A431 cells, a metastatic epidermoid cell line, were employed. MDA-MB-468 and A431 cell lines both induce apoptosis upon EGF stimulation [120] and express comparable levels of EGFR $[42,153]$. Like MDA-MB-468 cells, A431 cells treated with low concentrations of EGF did not yield significant increases in pSTAT3, but cells treated with high concentrations did (Figs. 4.2C and 4.2D).

Next, we monitored STAT3 phosphorylation in MDA-MB-468 and A431 cells following treatment with increasing concentrations of EGF ligand. Data from the dose-response experiments supported the findings of our time course experiments, displaying a dose-dependent increase in STAT3 phosphorylation in both cell lines (Fig. 4.3). These experiments, in two different cell lines, confirmed that higher concentrations of EGF were required for STAT3 phosphorylation. Importantly, the concentrations of EGF required for STAT3 phosphorylation were co-incident with the concentrations required to induce apoptosis. To further confirm this, EGF-beads were employed in the MDA-MB-468 cell line. Given previous reports of EGF-beads promoting cell growth within this cell line, we suspected that if STAT3 were mediating apoptosis in an EGFR dependent manner, we would observe preferential STAT3 phosphorylation with soluble EGF, and no phosphorylation with the EGF-beads. Our studies utilizing the beads resulted in a robust, dose-dependent increase in PSTAT3 with soluble 


\section{A. MDA-MB-468 Cells}

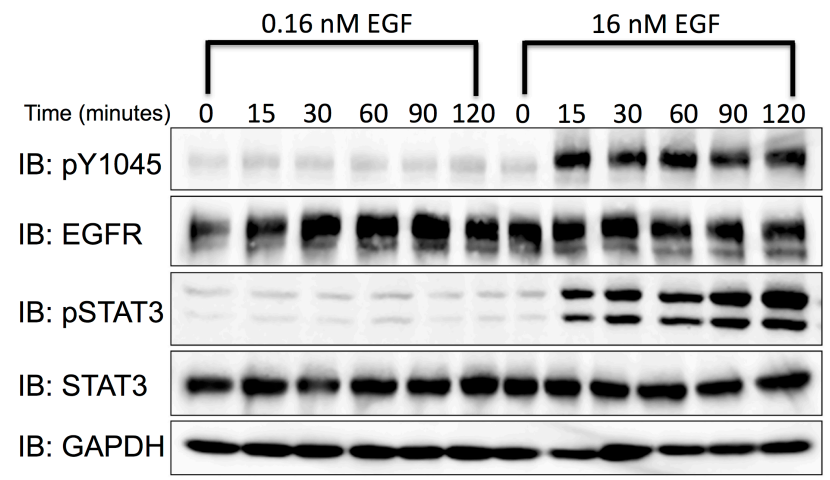

\section{A431 Cells}

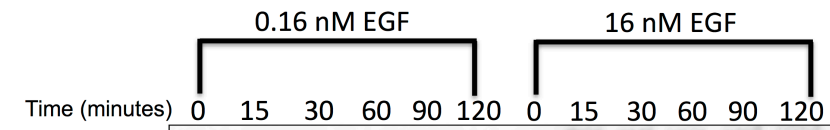

IB: pY1045

IB: EGFR

IB: pSTAT3

IB: STAT3

IB: GAPDH

\section{B. MDA-MB-468 Cells}

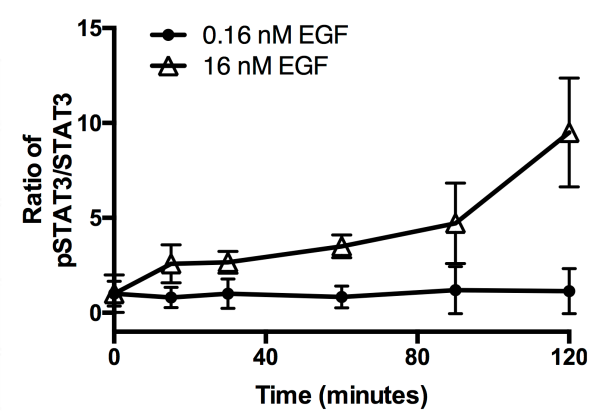

D. A431 Cells

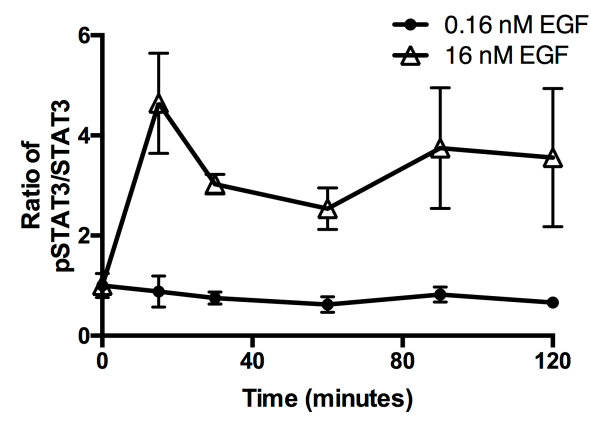

Figure 4.2. STAT3 is tyrosine phosphorylated in response to high, but not low, EGF concentrations. Serum-starved A. MDA-MB-468 and B. A431 cells were stimulated with $0.16 \mathrm{nM}$ and $16 \mathrm{nM}$ EGF ligand for 0-120 minutes. Cell lysates (20 $\mu \mathrm{g}$ and $15 \mu \mathrm{g}$, respectively) were resolved by $12 \%$ SDS-PAGE and were assessed for phospho-EGFR (pY0145), EGFR, pSTAT3 (Tyr705), STAT3 and GAPDH, via immunoblot analysis. C. MDA-MB-468 and D. A431 immunoblot data were quantified, and pSTAT3 was normalized to total STAT3. Data are expressed as the average $\pm \operatorname{SEM}(n=3)$ relative to untreated samples. 
A. MDA-MB-468 Cells

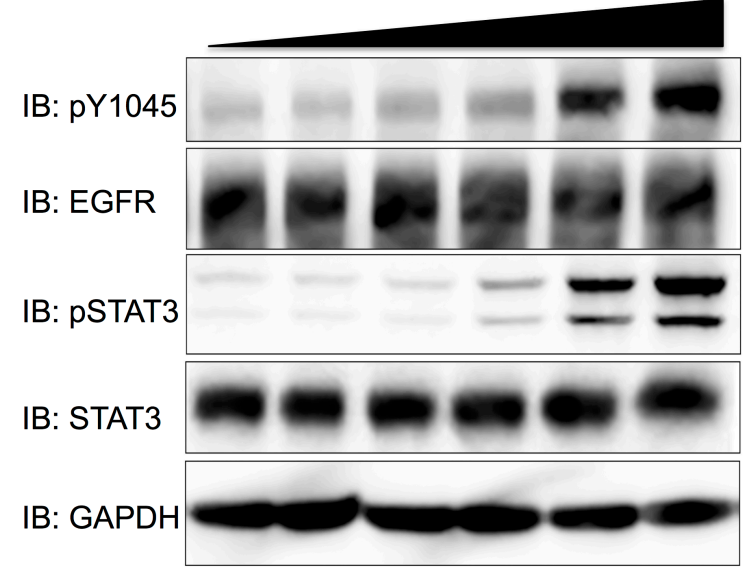

C. A431 Cells

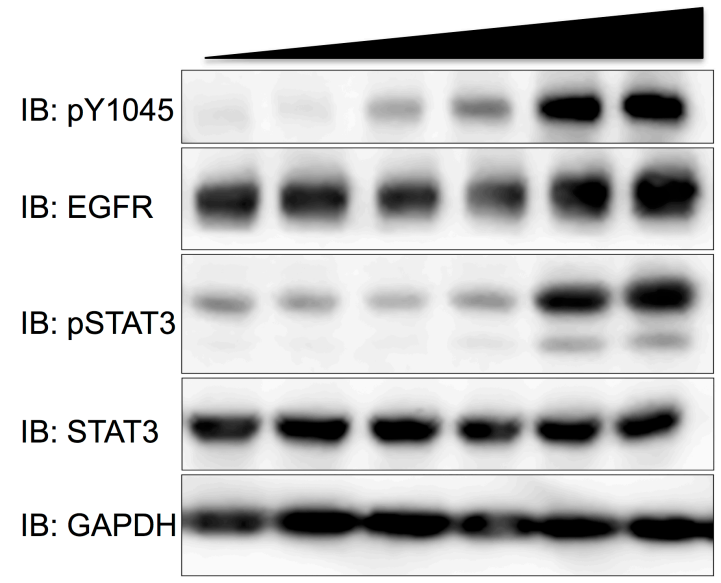

B. MDA-MB-468 Cells

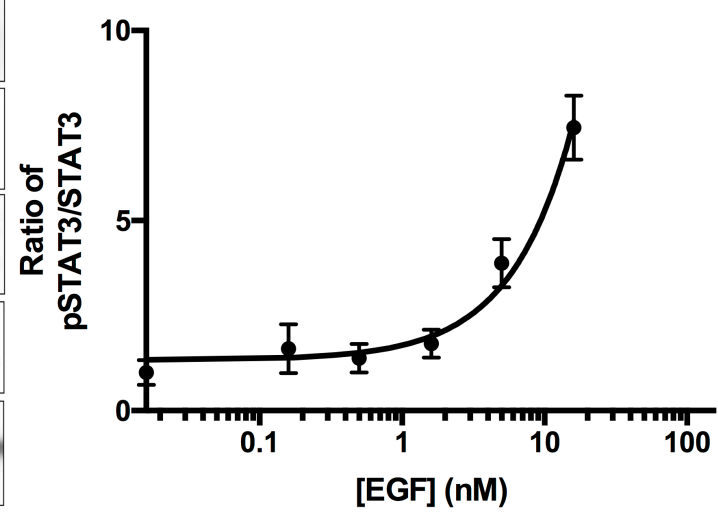

D. A431 Cells

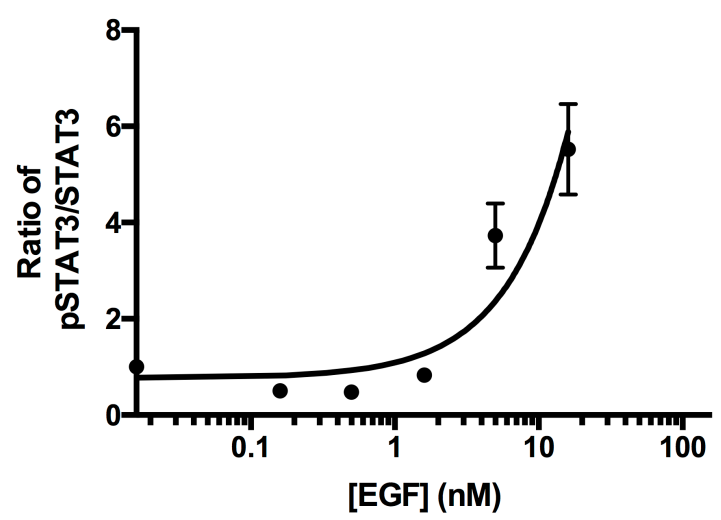

Figure 4.3. EGF phosphorylates STAT3 in a dose-dependent manner in MDA-MB-468 and A431 cell lines. Serum-starved MDA-MB-468 cells (A.) and A431 cells (B.) were treated with varying concentrations of EGF $(0,0.16,0.5$, $1.6,5,16 \mathrm{nM})$ for 30 minutes. Cell lysates $(40 \mu \mathrm{g})$ were resolved by $10 \%$ SDS PAGE and immunobloted for the indicated proteins. C. and D. Immunoblot data were quantified, and pSTAT3 was normalized to total STAT3. Data are expressed as the average $\pm \operatorname{SEM}(n=3)$ relative to untreated samples. 
EGF, but no pronounced pSTAT3 in response to increasing volumes of EGFbeads (Fig. 4.4). Our studies with the EGF-beads require us to conduct a doseresponse to determine a range of EGFR phosphorylation with the beads that induces comparable phosphorylation to that of soluble EGF. The bulky and larger size of the polystyrene bead inevitably causes steric hindrance, making it unfeasible to induce phosphorylation of EGFR comparable to $16 \mathrm{nM}$ of soluble EGF. However, data from Figure 4.4 exhibit that $80 \mu \mathrm{L}$ of EGF-beads induces phosphorylation of the EGFR that's comparably to $1.6 \mathrm{nM}$ of EGF, a concentration of soluble ligand that is still capable of inducing apoptosis in the MDA-MB-468 cell line [43]. In comparison to one another, the pSTAT3 bands that corresponds with 1.6 nM EGF is slightly darker than the corresponding band generated from $80 \mu \mathrm{L}$ of EGF-beads (Fig. 4.4). These data further suggest that STAT3 is preferentially activated with soluble EGF, and might be associated with EGFR-mediated apoptosis specifically.

Next, to determine if the induction of STAT3 was unique for the EGFR, we examined another receptor family that stimulates STAT3 to see if it, too, promoted apoptosis. Oncostatin M (OSM) belongs to the Interleukin-6 (IL-6) family of cytokines [154]. Like the EGFR, it has established roles in promoting cancer and tumor formation in malignant prostate [155], lung, head and neck, and cervical [156] tissue. In addition, OSM has been shown in some cells to promote apoptosis [157-159]. MDA-MB-468 cells were stimulated with $100 \mathrm{ng} / \mathrm{mL}$ OSM over a course of 96 hours and were assessed for PARP and Caspase-3 


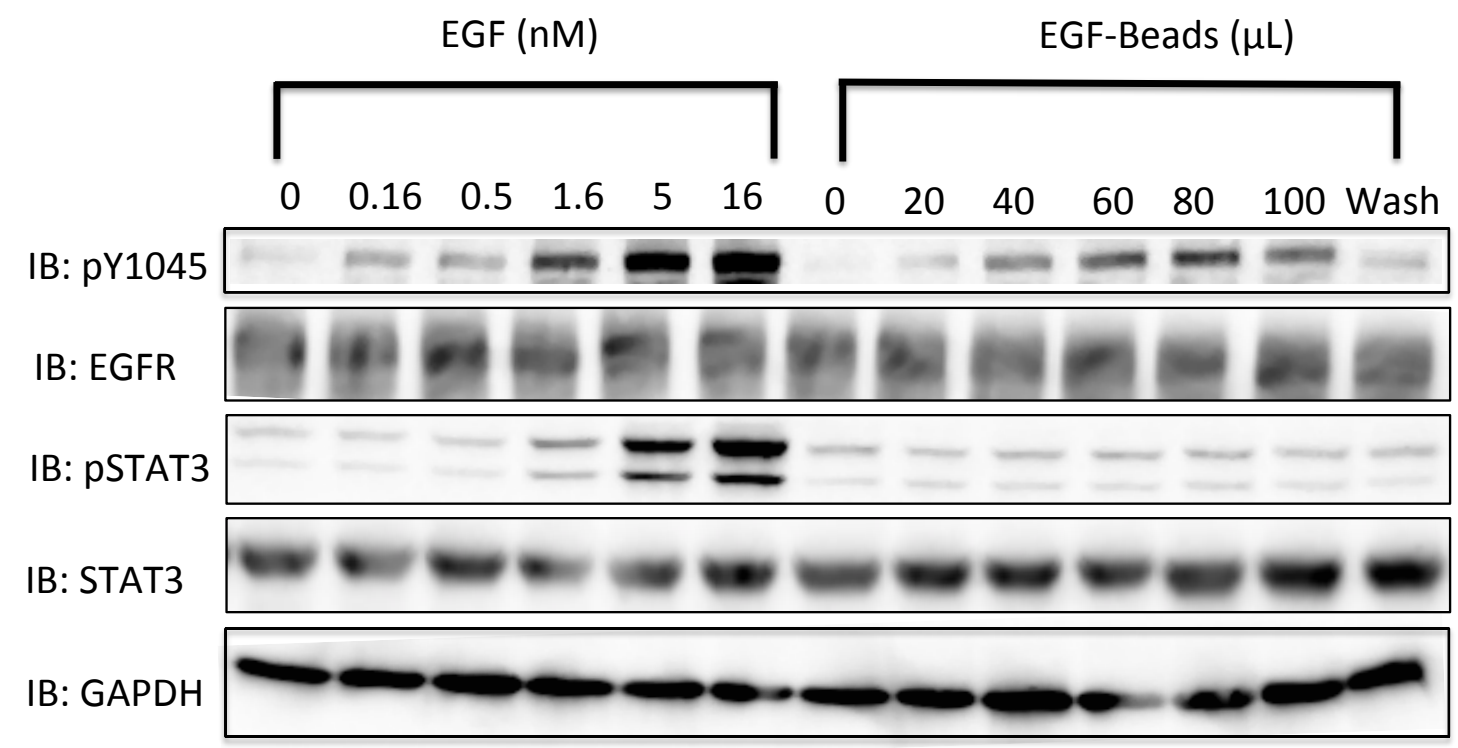

Figure 4.4 STAT3 is preferentially upregulated with soluble EGF, and not with EGF-beads. MDA-MB-468 cells were stimulated with the indicated concentrations of soluble EGF (nM) and volumes of EGF-beads $(\mu \mathrm{L})$ for 30 minutes. Cells were then rinsed and lysed as previously describe. Cell lysates $(20 \mu \mathrm{g})$ were then resolved on a $12 \%$ SDS PAGE and were assessed for pEGFR and pSTAT3. 
cleavage (Fig. 4.5). In addition to stimulating pSTAT3, OSM activated pVASP, a substrate of PKG as well as apoptotic pathways (as evident by increases in cleaved PARP and cleaved Caspase-3)(Fig. 4.5A). Quantification of multiple assays indicates that OSM-induced PARP cleavage (Fig. 4.5B) and Caspase-3 cleavage (Fig. 4.5C) is comparable to that induced by EGF. Upon exposure to STS, STAT3 activation was not induced (Fig. 4.5D). Together, these data are consistent with the hypothesis that multiple cell surface receptors induce STAT3 phosphorylation co-incident with apoptotic pathways.

Having established that STAT3 phosphorylation correlates with high concentrations of EGF ligand, and preferentially with soluble EGF ligand, we hypothesized that EGFR-mediated apoptosis occurred in a STAT3-dependent manner (Fig. 4.6A). On the contrary, STAT3 could have been have been upregulated with high ligand stimulation as a compensatory mechanism, in a failed attempt to rescue the cells from an EGFR-mediated apoptotic fate (Fig. 4.6B). To distinguish between these two possibilities, we antagonized STAT3 with pharmacological inhibitors, Stattic and S3I-201, and then stimulated MDAMB-468 and A431 cells with EGF (Figs. 4.7 and 4.8). These cells were assessed for cell viability and for their ability to induce apoptotic pathways. Caspase- 3 is a well-established executioner of apoptosis [129]. Upon its cleavage and subsequent activation, it cleaves and activates other downstream effectors that promote the induction of apoptosis (i.e. poly ADP-ribose polymerase or PARP). If STAT3 were in fact promoting apoptosis, we anticipated an attenuation of PARP 
A. OSM Time Course

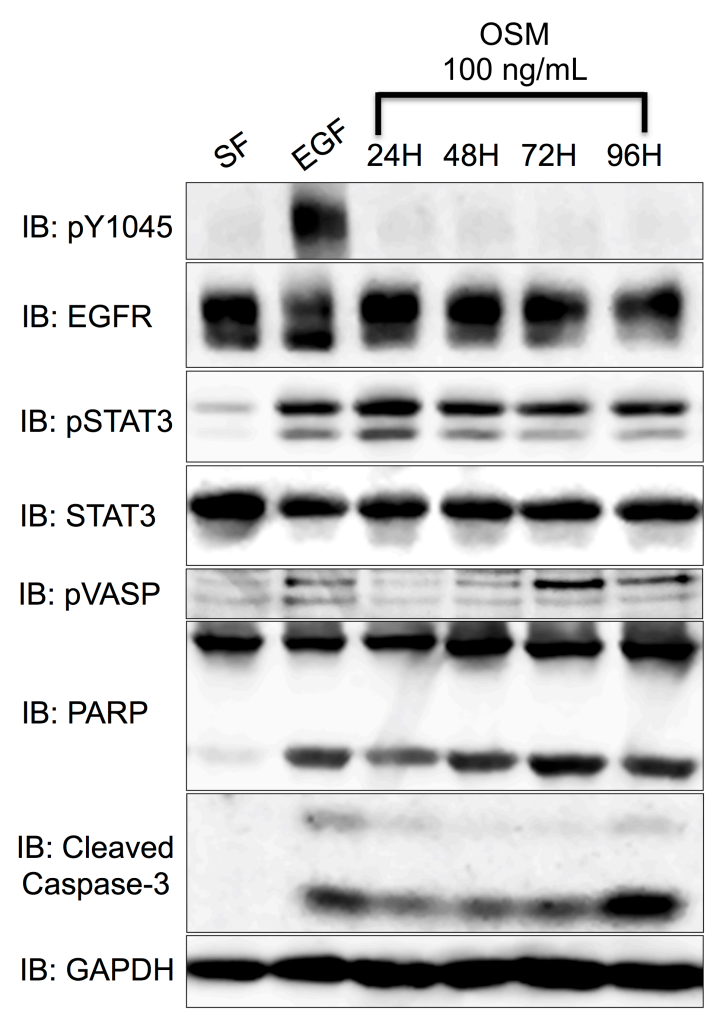

B. PARP Cleavage

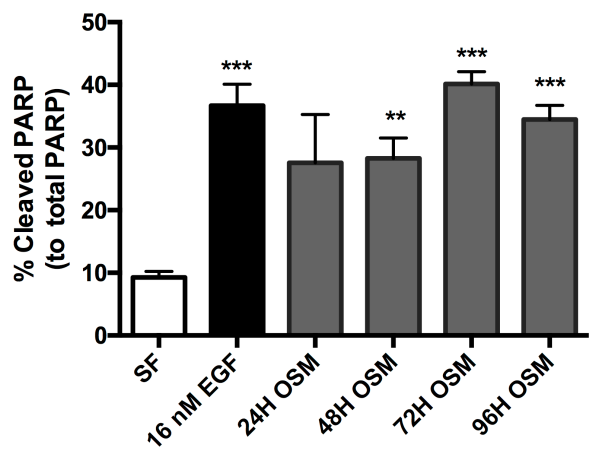

C. Caspase-3 Cleavage

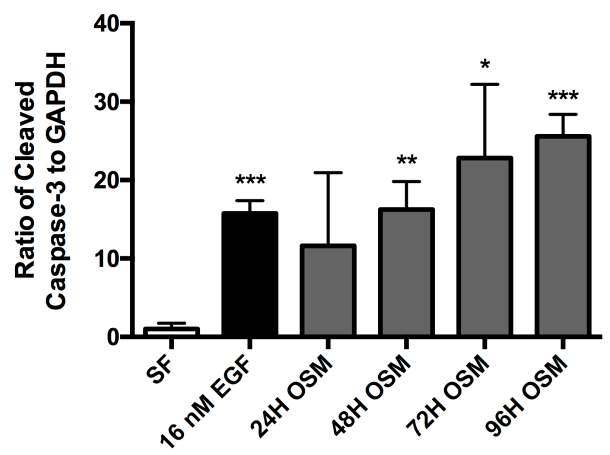

D. STS Dose Response

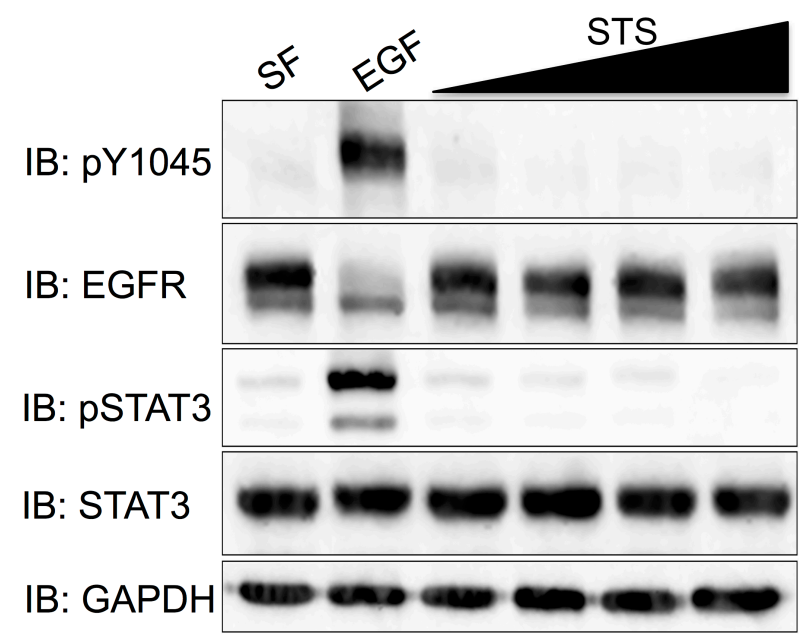

Figure 4.5 
Figure 4.5 EGFR-independent activation of STAT3 promotes apoptosis in MDA-MB-468 cells. A. Serum-starved MDA-MB-468 cells were stimulated with $100 \mathrm{ng} / \mathrm{mL}$ of Oncostatin M (OSM) for the indicated times. Control cells were exposed to serum free DMEM (SF) and or 16 nM EGF for 24 hours. After harvesting, the cell lysates $(40 \mu \mathrm{g})$ were resolved by SDS PAGE, and were immunoblotted for the indicated proteins. Densitometry quantification of western blot data of cleaved PARP (B.) and cleaved Caspase-3 (C.). The cleaved PARP band intensities were normalized to and plotted as a percentage of total PARP bands. Cleaved Caspase- 3 bands were quantified to total protein for each respective sample (GAPDH). Data are expressed as the average \pm SEM $(n=3)$. D. Serum-starved MDA-MB-468 cells were stimulated with 3, 10, 30, or $100 \mathrm{nM}$ Staurosproine (STS) for 4 hours. Control cells were exposed to serum free DMEM (SF) and or $16 \mathrm{nM}$ EGF for 4 hours. Cell lysates $(40 \mu \mathrm{g})$ were resolved by a $10 \%$ SDS PAGE, and were immunoblotted for the indicated proteins. 


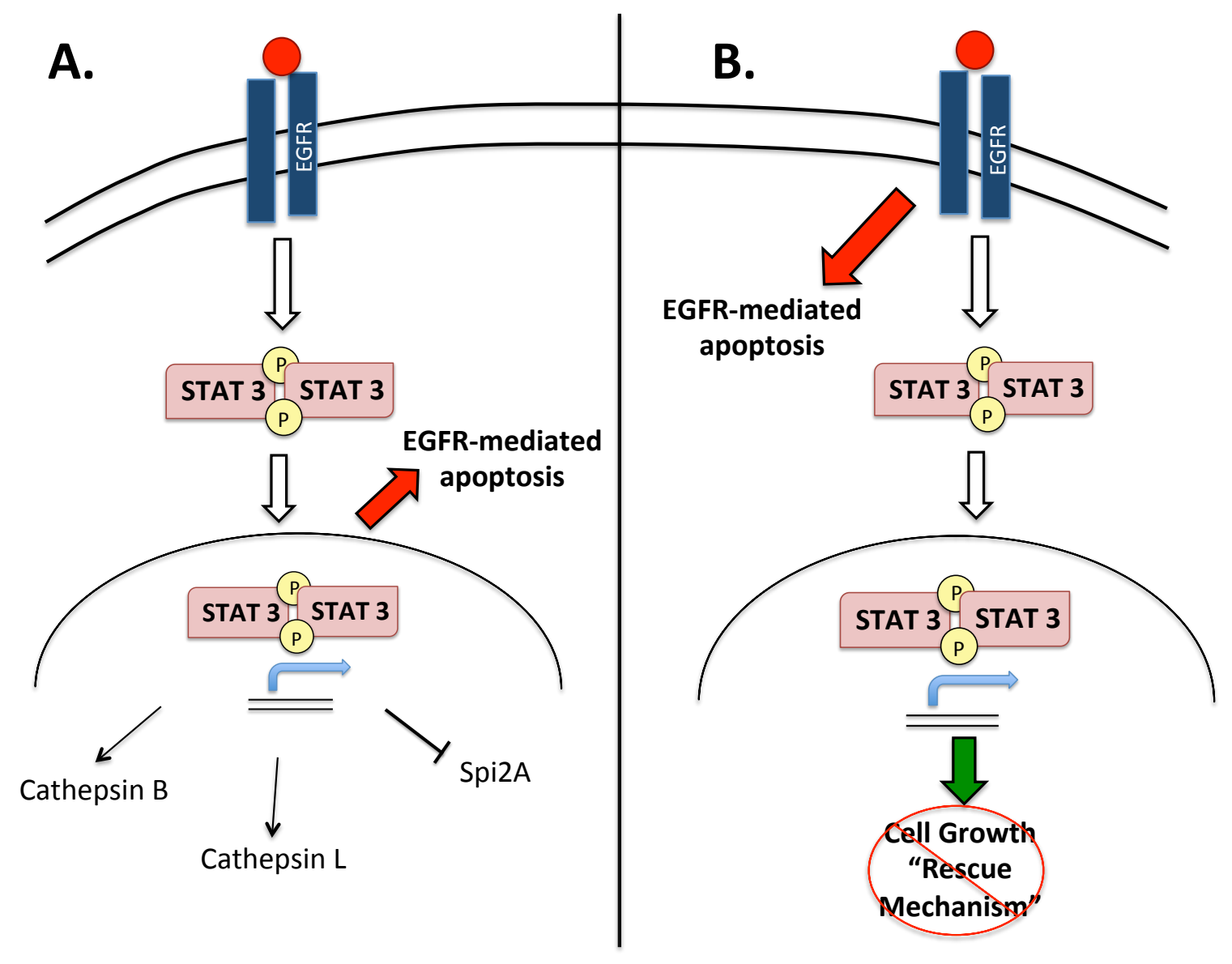

Figure 4.6. Models of STAT3 Activity and its potential role(s) in EGFR-

mediated Apoptosis. Model A depicts STAT3 playing a direct role in mediating EGF-induced apoptosis. Contrastingly, model B depicts STAT3 playing a compensatory role to promote cellular growth to prevent an EGFR-mediated apoptotic fate. 
and Caspase-3 cleavage, coincident with enhanced viability in STAT3 antagonized cells. Conversely, if STAT3 were being activated as a compensatory mechanism, inhibition of STAT3 would not affect induction of the apoptotic pathways and would likely further decrease cell viability.

Upon exposure to both inhibitors, cell viability analyses revealed a dosedependent decrease in viability in both MDA-MB-468 and A431 cells, independent of the presence of EGF (Figs. 4.7A, 4.7C, 4.8A, 4.8C). Although Stattic was more potent than S31-201, and MDA-MB-468 cells were more sensitive to inhibitor treatments than A431 cells, the trends held in both cell lines. Complementary with the viability data, we observed a dose-dependent increase in cleaved PARP and cleaved Capsase-3 phosphorylation. This finding was observed in both cell lines when cells were treated with 16 nM EGF in combination with the STAT3 inhibitors. However, coincident with a dosedependent decrease in phosphorylated STAT3, both cell lines displayed a corresponding decrease in EGFR phosphorylation (Figs. 4.7B, 4.7D, 4.8B, and 4.8D).

We wanted to determine whether these decreases in cell viability were due to STAT3 inhibition or from a toxicity mediated by the compounds themselves. To assess whether the compounds were inherently cytotoxic, we employed the PC3 cell line, a prostatic carcinoma cell line lacking STAT3 expression [146]. Our biochemistry analysis confirmed that PC3 cells do not express STAT3 and have very low levels of EGFR expression (Fig. 4.9A). PC3 cells exhibited a dose-dependent decrease in 


\section{STAT3 Inhibition in MDA-MB-468 Cells}

A. Stattic

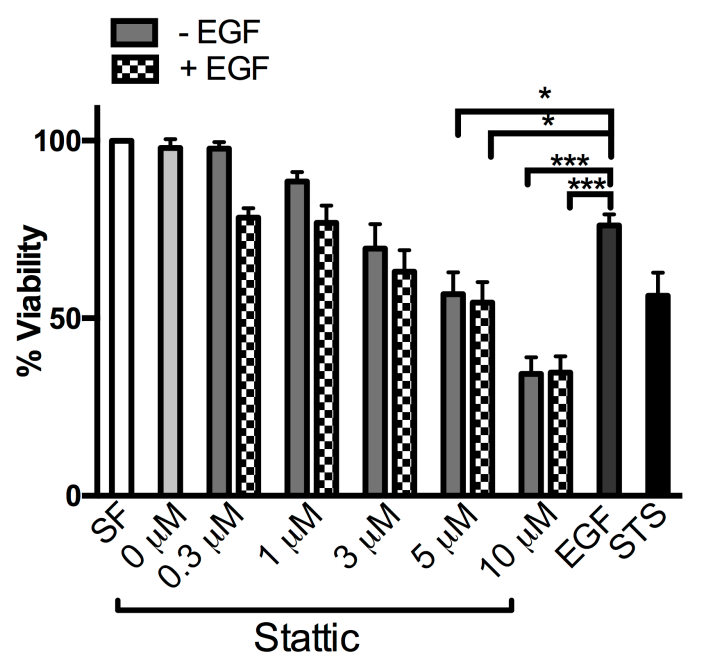

B.

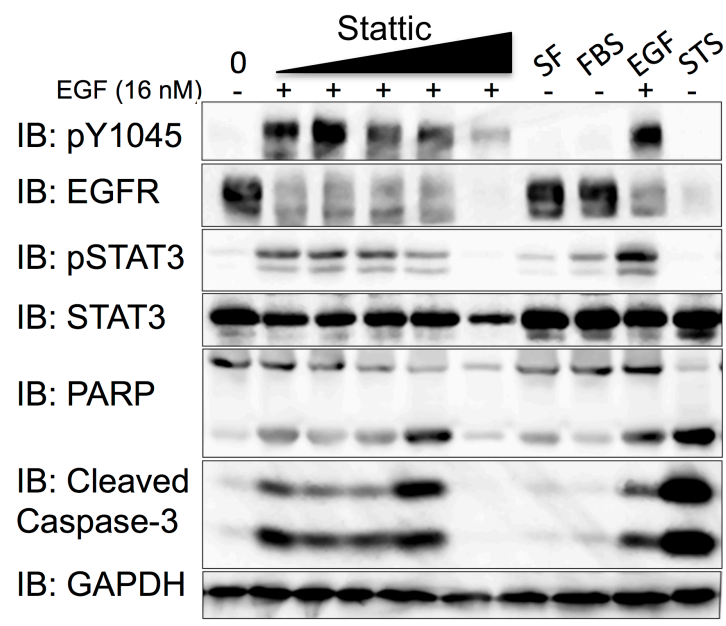

C. S3I-201

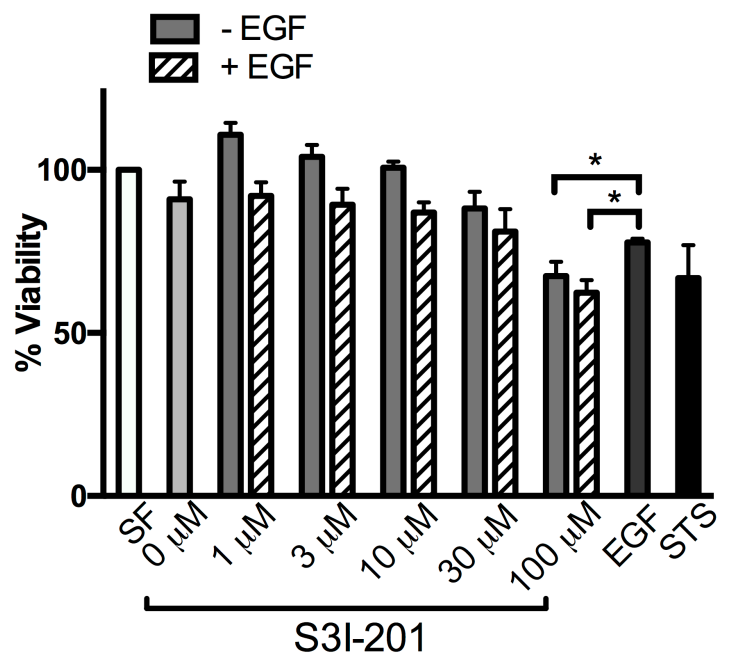

D.

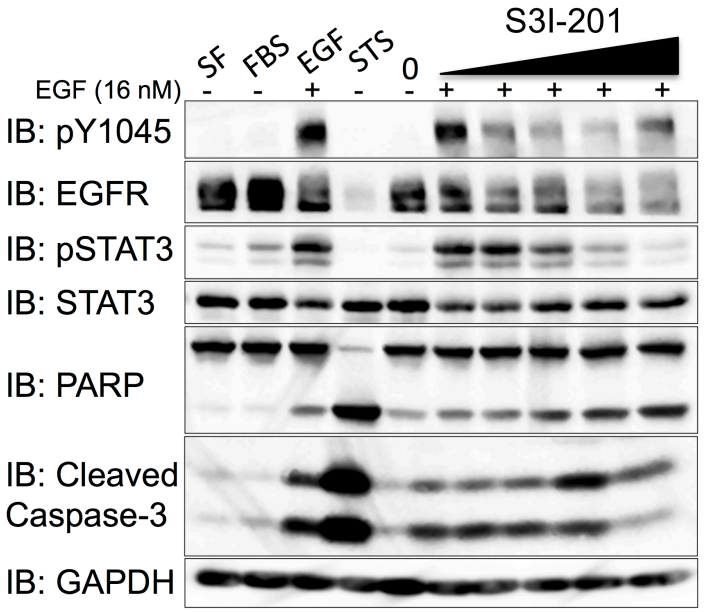

Figure 4.7 
Figure 4.7. STAT3 inhibitors attenuate cell viability and EGFR activity in MDA-MB-468 cells. MDA-MB-468 cells, plated and treated in parallel, were assessed for cell viability using an Alamar Blue assay. Data from A. Stattic or C. S31-201 treated cells are expressed as the average \pm SEM $(n=3)$ relative to cells treated without serum (SF). Serum-starved cells were pre-treated for 1 hour with $0\left(0.025 \%\right.$ DMSO), $0.3,1,3,5$, or $10 \mu \mathrm{M}$ Stattic $\left(\mathrm{IC}_{50}=5.1 \mu \mathrm{M}\right.$; panel B. $)$, or with 0 (0.5\% DMSO), 1, 3, 10, 30, and $100 \mu \mathrm{M}$ S3I-201( $\left(\mathrm{IC}_{50}=86 \mu \mathrm{M}\right.$; panel D.), followed by the addition of $16 \mathrm{nM} \mathrm{EGF} \mathrm{(+)} \mathrm{for} 24$ hours. Control cells were incubated with serum free media alone (SF), media containing $10 \%$ fetal bovine serum (FBS), or $16 \mathrm{nM}$ EGF (EGF) for 24 hours. As a positive control cells were treated with $1 \mu \mathrm{M}$ staurosporine (STS) for 4 hours. Cell lysates were prepared and $40 \mu \mathrm{g}$ were resolved by SDS-PAGE before being assessed for the indicated proteins. For STS treated samples, $15 \mu \mathrm{g}$ of cell lysates were loaded to keep the signals in the dynamic range. Shown is a representative experimental replicate of three. 


\section{STAT3 Inhibition in A431 Cells}

\section{A. Stattic}

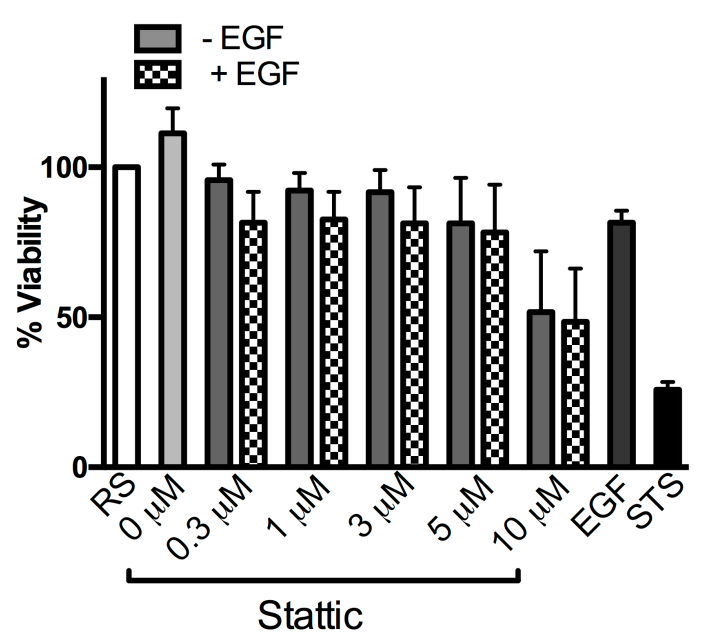

C. $\$ 3 \mid-201$

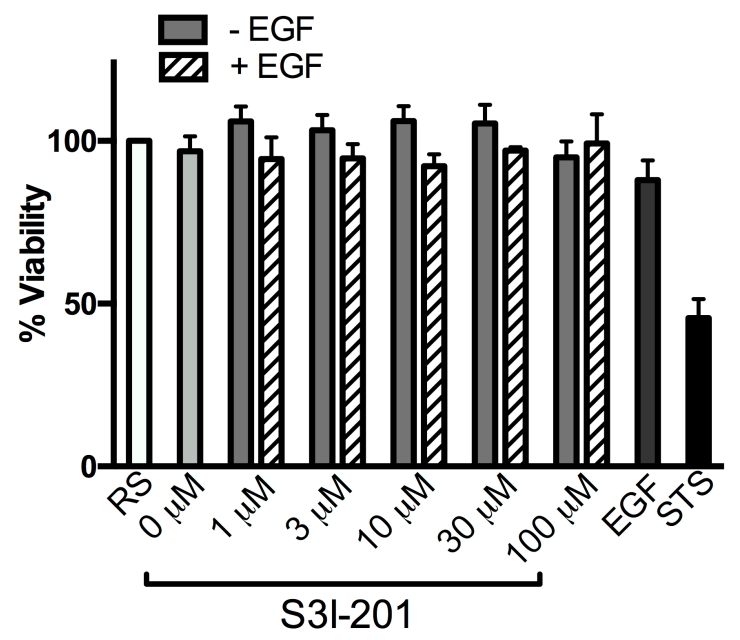

D.

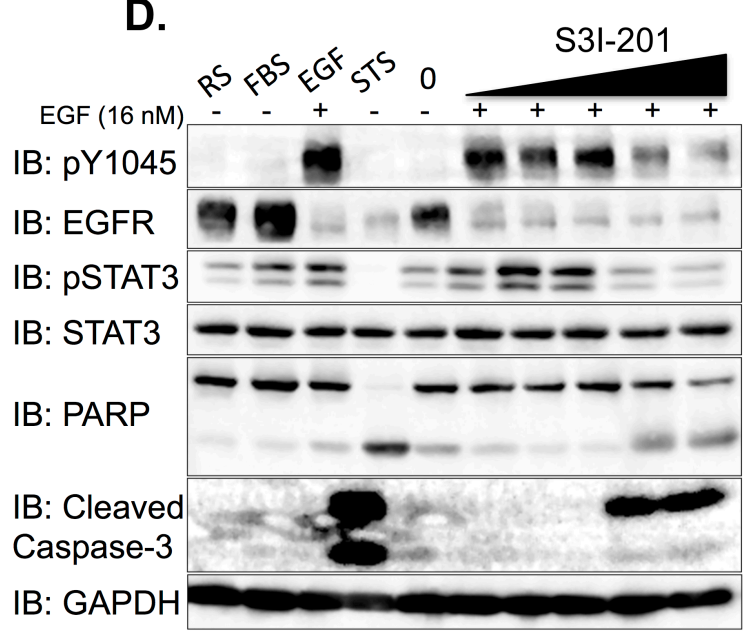

Figure 4.8 
Figure 4.8. STAT3 inhibitors attenuate EGFR activity in A431 cells. A431 cells, plated and treated in parallel, were assessed for cell viability using an Alamar Blue assay. Data from A. Stattic or B. S31-201 treated cells are expressed as the average \pm SEM $(n=3)$ relative to cells incubated in $1.25 \%$ FBS in DMEM (reduced serum - RS). Serum-starved A431 cells were pre-treated for 1 hour with $0(0.025 \%$ DMSO $), 0.3,1,3,5$, or $10 \mu \mathrm{M}$ Stattic $\left(\mathrm{IC}_{50}=5.1 \mu \mathrm{M}\right.$; panel A.), or with 0 (0.5\% DMSO), 1, 3, 10, 30, and $100 \mu \mathrm{M}$ S3I-201 $\left(\mathrm{IC}_{50}=86 \mu \mathrm{M}\right.$; panel C.), followed by the addition of 16 nM EGF (+) for 24 hours. Control cells were incubated with reduced serum media alone (RS), media containing $10 \%$ fetal bovine serum (FBS), or $16 \mathrm{nM} \mathrm{EGF} \mathrm{(EGF)} \mathrm{for} 24$ hours. As a positive control cells were treated with $1 \mu \mathrm{M}$ staurosporine (STS) for 4 hours. Cell lysates were prepared, $40 \mu \mathrm{g}$ were resolved by SDS-PAGE, and immunoblotted for the indicated proteins. Fifteen $\mu \mathrm{g}$ of the STS sample were used to keep the immunoblot analysis in the dynamic range. Shown is a representative experimental replicate of three. 
viability upon stimulation with Stattic and S3I-201 (Fig. 4.9B). These data indicate the STAT3 inhibitors had off-target activity, and an alternative method was needed to attenuate STAT3 activity and determine its ultimate role in EGFRmediated apoptosis.

Next, we employed STAT3 siRNA as a more selective mode of reducing STAT3 expression in the MDA-MB-468 cell line (Fig. 4.10). As compared to control siRNA (siCON), STAT3 reduced STAT3 expression by 78\% (Fig. 4.10A). STAT3 knock down cells were slightly more viable than control cells following treatment with the high concentrations of EGF required to induce apoptosis (Fig. 4.10B). Biochemically, STAT3 knock down cells had reduced EGF-induced cleaved PARP and Caspase-3 (Fig 4.10C- E). 
STAT3 Inhibition in PC3 Cells

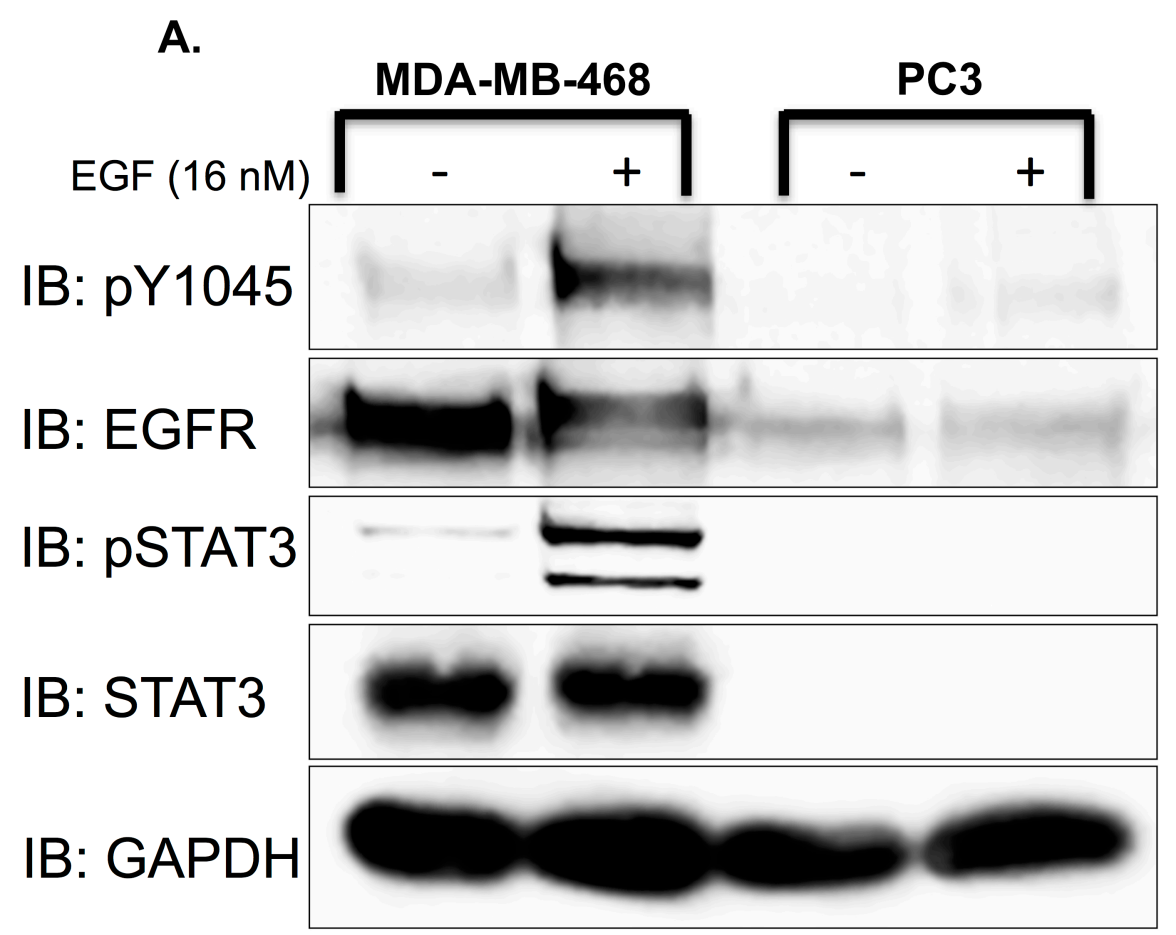

B. Alamar Blue- 24 Hours (PC3)

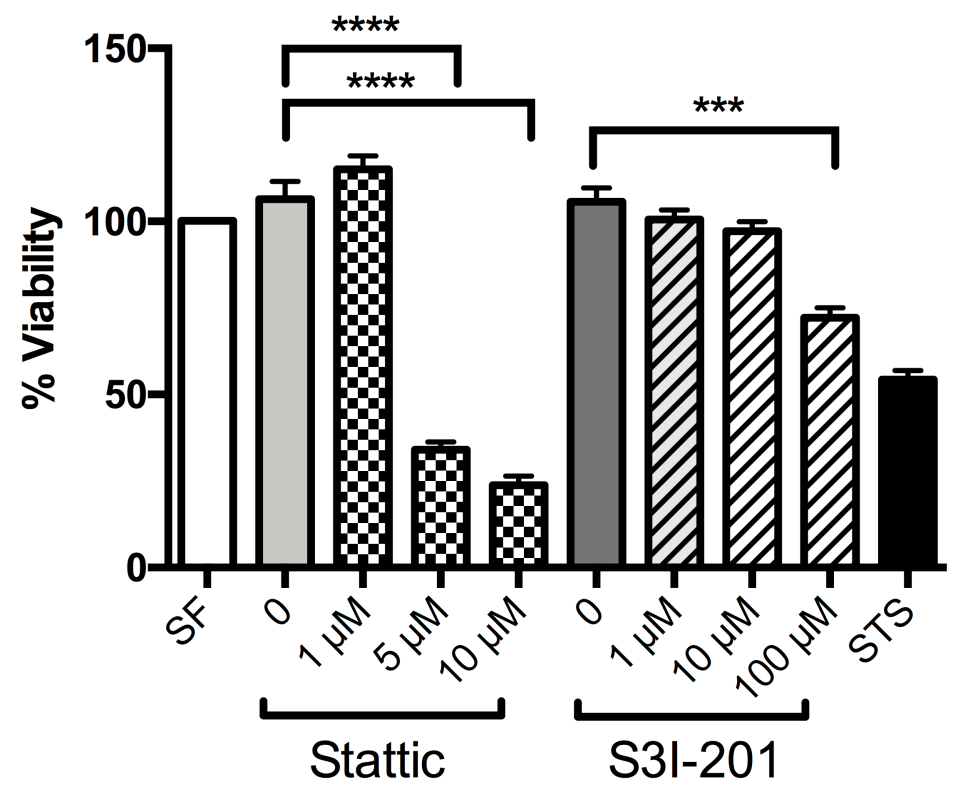

Figure 4.9 
Figure 4.9. STAT3 inhibitors reduce cell viability in STAT3-null, PC3 cells. A. Serum-starved MDA-MB-468 and PC3 cells were treated with either DMEM alone (-), or DMEM supplemented with 16 nM EGF (+) for 1 hour. Cell lysates (20 $\mu \mathrm{g}$ ) were resolved by $10 \%$ SDS PAGE, and immunoblotted for the indicated proteins. Shown is a representative experiment repeated three times. B. PC3 cells were exposed to treatments of serum free media (SF), DMEM with $0.025 \%$ DMSO (0), 1, 5, $10 \mu \mathrm{M}$ Stattic; 0.5\% DMSO (0), 1, 10, $100 \mu \mathrm{M}$ S31-201; or 168 nM Staurosporine (STS) for a total of 24 hours. Cell viability was assessed with an Alamar Blue assay. Data are normalized to cell viability in serum free media $(\mathrm{SF})$ and expressed as the average $\pm \operatorname{SEM}(n=3)$. 
A. STAT3 Knock Down Verification

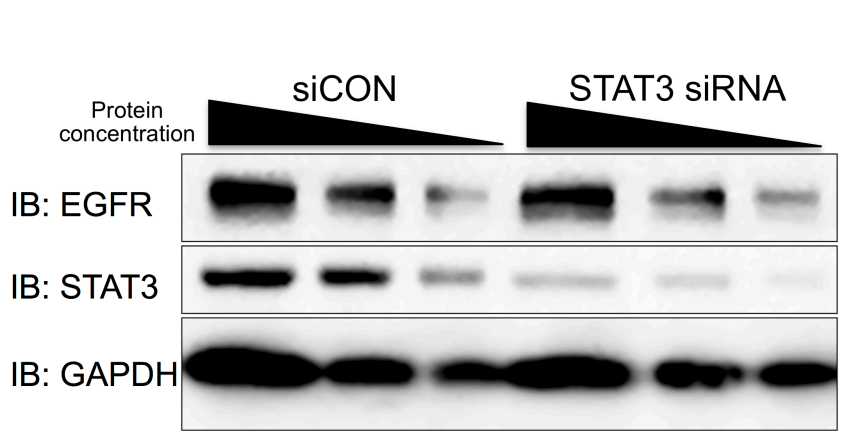

C.

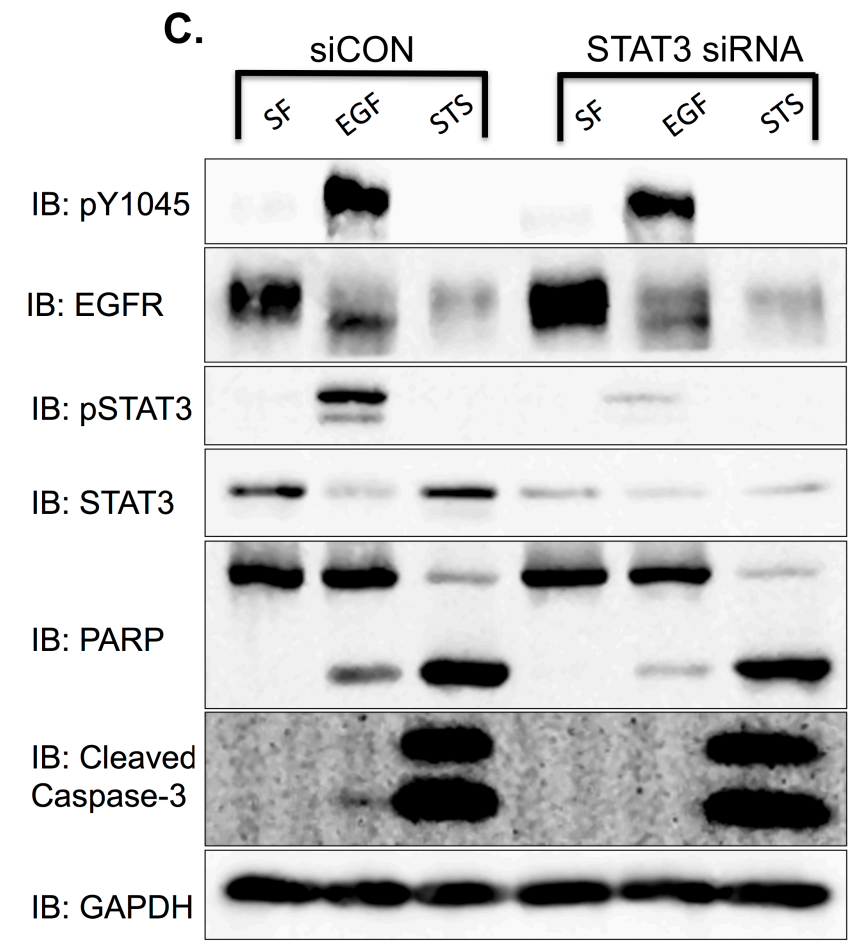

Figure 4.10
B. Alamar Blue- 24 Hours

口 STCON

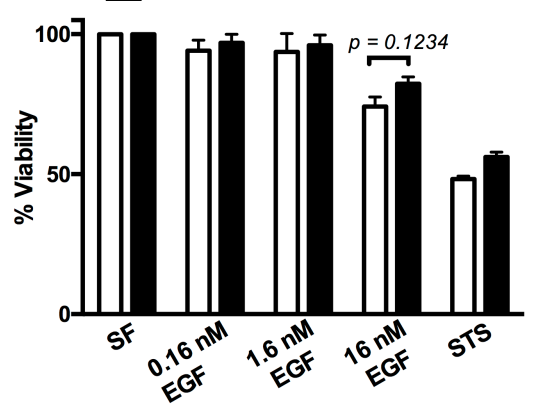

D. PARP Cleavage

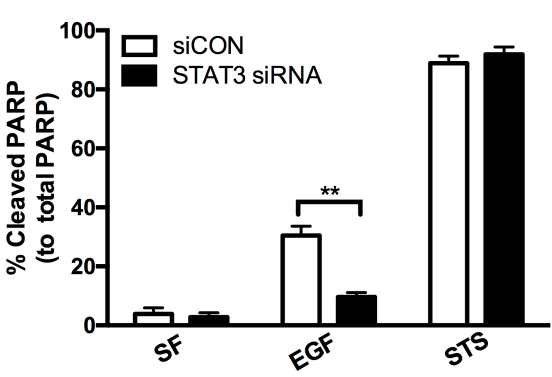

E. Caspase-3 Cleavage

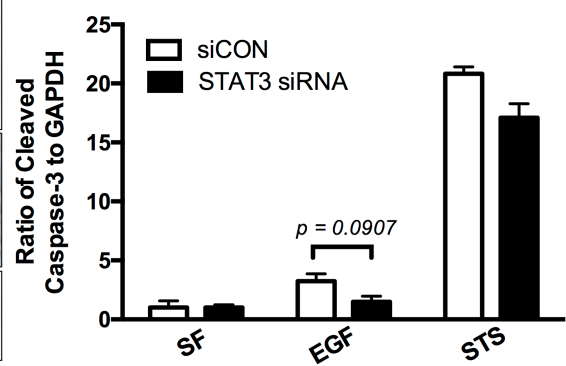


Figure 4.10. Knockdown of STAT3 attenuates EGFR-mediated apoptosis in MDA-MB-468 cells. A. MDA-MB-468 cells were transfected with either $200 \mathrm{nM}$ control siRNA (siCON) or 200 nM STAT3 siRNA for 72 hours. Cell lysates were prepared, and decreasing protein concentrations $(40,20$, and $10 \mu \mathrm{g})$ were resolved by $10 \%$ SDS PAGE and immunoblotted for EGFR, STAT3, and GAPDH. B. Fourty-eight hours post-transfection, siCON and STAT3 siRNAtransfected cells were treated for 24 hours with 0 (SF), 0.16, 1.6, 16 nM EGF or $168 \mathrm{nM}$ Staurosporine (STS) as a positive control. Cell viability was assessed by an Alamar Blue assay. Data are expressed as the average \pm SEM $(n=3)$. C. Cleaved PARP and cleaved Caspase-3 were assessed in siCON and STAT3 siRNA transfected cells. Seventy-two hours post-transfection, cells were coincidently exposed to SF DMEM and 16 nM EGF for 24 hours or $1 \mu \mathrm{M}$ STS for 4 hours prior to harvesting. Cell lysates $(40 \mu \mathrm{g})$ were resolved on either a $10 \%$ SDS PAGE (pY1045, PARP, and GAPDH) or a 15\% SDS PAGE (pSTAT3 and cleaved Caspase-3), and were assessed for the indicated proteins via immunoblot analysis. Densitometry quantification of western blot data of cleaved PARP (D.) and cleaved Caspase-3 (E.). The cleaved PARP band intensities were normalized to and plotted as a percentage of total PARP. The intensity of cleaved Caspase-3 was normalized to the levels of GAPDH. Data are expressed as the average $\pm \operatorname{SEM}(n=3)$. 


\section{Discussion}

EGFR-mediated apoptosis is a paradox for growth factor receptors. However, dissecting how a receptor that normally mediates cell growth and proliferation induces cell death when overexpressed provides an opportunity to understand receptor signaling and develop strategies for attenuating the growth of cancer cells with elevated EGFR levels. In this study, we assessed effector candidates with documented affiliation with EGFR activation $[147,150,160]$ and implication in human malignancies by either promoting proliferation [147, 148, $152,161]$ and/or attenuating it $[95,148,149,151]$. We assessed MAPK, SRC, AKT, BAD, and STAT3 for phosphorylation following treatment with low $(0.16$ $\mathrm{nM}$ ) versus high (16 nM) concentrations of EGF (Figs. 4.1 and 4.2). Among these, only STAT3 was activated when ligand concentrations were sufficient to induce the apoptotic pathways. This was not only true for the EGFR, but cytokine-mediated activation of STAT3 via OSM resulted in the induction of apoptosis as well (Fig. 4.5).

Pharmacological inhibitors of STAT3 were employed to ascertain the role of STAT3 on EGFR-mediated apoptosis. As expected, STAT3 inhibitors in MDAMB-468 and A431 cells resulted in a dose-dependent decrease in STAT3 phosphorylation. Unexpectedly, these inhibitors also antagonized EGFR phosphorylation and decreased cell viability (Figs. 4.7 and 4.8 ). This cytotoxicity cannot be attributed only to STAT3 inhibition; STAT3-null, PC3 cells were also less viable in response to these inhibitors (Fig. 4.9). RNAi proved to be a more 
useful tool for studying the role of STAT3. Knock down of STAT3 with siRNA significantly attenuated EGF-induced PARP cleavage and also reduced Caspase-3 cleavage and cell death (Fig. 4.10). These data provide evidence that support STAT3 as a direct mediator of EGF-induced apoptosis.

Since it was first reported by Armstrong et al in 1994 [162], the molecular mechanism by which EGFR-mediated apoptosis occurs has remained controversial. A number of signaling molecules have been reported to be involved in this process including Etk [163], STAT1 [164], Caspase-1 [48], and Protein Kinase G [165]. Dissecting the signaling events that emanate from a hyperexpressed receptor and culminate in cell death are challenging for a number of reasons. First, high levels of receptors are going to favor the formation of receptor:effector complexes that may not occur with physiological levels of receptor expression. Second, cells with elevated receptor expression have altered kinetics of receptor down regulation through the endocytic pathway [166, 167]. In cells with physiological levels of receptor expression, the EGFR will traffic to the lysosome for degradation; in MDA-MB-468 cells, the activated EGFR internalizes to the early endosome and can be retained there for 24 hours [168]. This increases the duration of total receptor activity, as well as any receptor:effector interactions in the early endosome. Finally, the kinetics of EGFR-mediated apoptosis provide a large window (0-16 hours) to monitor the many effectors activated by the receptor.

Despite these limitations to studying apoptosis, we were able to identify a role for STAT3. There are multiple lines of evidence that support this role. First, 
the concentrations of EGF needed to activate STAT3 in MDA-MB-468 and A431 cells (Fig. 4.3) are consistent with the concentrations of EGF required to induce apoptosis. Second, the kinetics of EGFR-mediated apoptosis (over the course of 16-48 hours $[44,165])$ are consistent with a transcriptionally regulated event. Third, STAT3 is a well-documented regulator of cell growth, albeit more frequently having a positive effect. STAT3 has been associated with proliferative activity in numerous malignancies, including glioblastoma [169], non-small cell lung [170], and colorectal cancer [171]. In addition, STAT3-induced tumorigenesis is linked to its constitutive activity in certain cancer cells [172-174]. Constitutive STAT3 activity was not observed in our MDA-MB-468 or A431 cells (Figs. 4.2 and 4.3). In addition, there are data, consistent with ours, which contradict these findings and implicate STAT3 as a mediator of cell death [175177].

The contradiction between our experimental results regarding STAT3 activity under pro-apoptotic conditions and the published data regarding the progrowth events of STAT3 led us to propose two opposing hypothesis. The first hypothesis was that STAT3 is a mediator of apoptosis and that inhibition of the protein would enhance cell viability. The second hypothesis was that the induction of STAT3 activity was a compensatory reaction to the induction of apoptosis promoted by another pathway (Fig. 4.6). Our subsequent experiments indicate that STAT3 mediates apoptosis and is not a compensatory mechanism.

Previous reports have shown that the EGFR kinase directly activates STAT3 [90], and that is likely the case in the MDA-MB-468 and A431 cells, 
particularly based on the kinetics of STAT3 phosphorylation. Given these interactions require high doses of EGF and high receptor levels, this is likely a pathological event rather than a physiological.

How STAT3 progresses to apoptosis is more ambiguous. It has been previously reported that STAT3 activity directly promotes apoptosis in some cancers $[95,146,178,179]$, and suppresses cancer cell colony formation and invasion [180]. One possibility is that in MDA-MB-468 cells, like LNCaP cells, STAT3 transcription is causing growth arrest and a block in cell cycle progression [146]. This, coupled with strong proliferative EGFR signals, may result in a signaling conflict for the cell that results in an apoptotic response. A second option is that the high levels of STAT3 phosphorylation may increase the magnitude and/or duration gene transcription that disrupts cell homeostasis and causes cell death. Alternatively, high levels of activated STAT3 may lead to aberrant STAT heterodimer formation. Previous studies have reported a role for STAT1 in the induction of apoptosis $[148,164,181]$. More specifically, STAT1 has been implicated in EGFR-mediated apoptosis in A431 cells $[138,164]$ and MDA-MB-468 cells [163]. Increased STAT3 activity may drive STAT1:STAT3 heterodimer formation which in turn allows STAT1 to drive apoptosis.

These changes in signaling may reflect mis-regulation of a normal physiological process. STAT3-mediated apoptosis occurs during mammary gland involution [96, 97], a complex process that returns mammary tissue to its prelactation, morphological state [182]. The initiation of this process is dependent on the presence of milk in the alveoli after weaning, which elicits the synthesis of 
cytokines and growth factors that activate the STAT3 pathway to then subsequently induce apoptosis [183-185]. The high concentrations of EGF ligand in milk [186] are indirect evidence that point to the EGFR's role within this process. EGF-induced STAT3 activity and the subsequent induction of apoptosis in MDA-MB-468 cells may therefore employ the same molecular mechanisms required for mammary gland involution. Kreuzaler et al. have reported that STAT3-mediated apoptosis in mammary gland involution entails enhancing cathepsin B and L activity, while also downregulating their endogenous inhibitor, serine protease inhibitor $2 \mathrm{~A}(\mathrm{spi} 2 \mathrm{~A})$, in a process that occurs independently of caspase 3,6 and 7 activity [187]. Similarly, our data indicate that caspase 3 is not a major factor in EGF-induced, STAT3-mediated apoptosis in MDA-MB-468 cells. Together, the cathepsin proteases, spi2A, and other effectors implicated in mammary gland involution may be worth assessing in the context of EGFinduced, STAT3-mediated apoptosis (Depicted in Fig. 4.6A).

Another plausible explanation for this phenomenon is the pathway in which cell death is induced. Caspase-1 activation promotes a particular form of cell death that results from inflammatory responses, in a process known as pyroptosis [188]. Pyroptosis has been documented to induce DNA fragmentation [189] and has also been shown to cleave and activate PARP [68]. Given that Caspase-1 inhibition is capable of blocking EGFR-mediated cell death in MDAMB-468 cells [48], pyroptosis may be an additional mode of cell death employed by the EGFR. In addition to eliciting STAT3 activity, the Interleukin family of cytokines has been well documented to promote inflammation and further 
progress inflammatory diseases [190-192]. Interferon-beta, a member of the interferon family of cytokines, promotes apoptosis in pro-B cells in a STAT3dependent manner [145]. Thus, EGF-induced STAT3 activation and the subsequent induction of pyroptosis would not be an unexpected finding.

These signaling differences must also be considered in the context of the subcellular location in which they occur. There has been a well-established role for spatial regulation of EGFR signaling by the endocytic pathway [193]. In MDAMB-468 cells, retention of the activated EGFR on the plasma membrane promotes cell proliferation whereas when the EGF:EGFR complex internalizes the cell undergoes apoptosis [44]. Further, the induction of apoptotic pathways is linked to the endosomal accumulation of the EGF:EGFR complex [168]. Since high concentrations of ligand are required for apoptosis, one must consider the contribution of different routes of EGFR internalization. Sigismund et al. have shown that low EGF ligand stimulation $(1.5 \mathrm{ng} / \mathrm{mL})$ primarily results in a clathrinmediated manner of EGFR internalization, whereas high ligand stimulation (20 $\mathrm{ng} / \mathrm{mL}$ ) promotes a clathrin-independent, lipid raft-mediated mode of endocytosis [22]. These differing routes may also impact the composition of EGFR-containing endosomes and which down stream signaling molecules are present.

Although all models are possible, in summarizing the literature, we favor the notion that apoptosis results from the convergence of multiple signaling events. Hyper-activated signaling, due to an increased number of active receptors coupled with slowed down regulation, results in increased metabolic and proliferative cell biology. The cell cannot accommodate these demands, 
resulting in a disrupted cellular homeostasis that cannot be restored. Ultimately, the cell succumbs due to the stress of the saturated endocytic pathway. While this does not identify a specific, pharmacological target, it suggests the potential benefit of a multi-faceted approach that employs several low level, non-toxic insults. 


\section{CHAPTER V \\ SUMMARY AND FUTURE DIRECTIONS}

\section{A. Restatement of Research Goals}

The goal of the work described throughout this dissertation was to

elucidate the underlying mechanisms required for EGFR-mediated apoptosis to occur. The paradox of EGFR-mediated cell growth versus EGFR-mediated apoptosis is uncertain, and has remained so for decades. Identifying the signaling effectors with direct implications in receptor-mediated apoptosis not only contributes to the discipline of cellular biology, but also establishes a new mode of therapeutically targeting cancers that are characterized by receptor hyperexpression.

\section{B. Summary of Findings}

We have identified two signaling molecules, which both have shown to promote EGF-induced apoptosis. In Chapter III, we assessed and defined PKG in this cellular process. Previous reports have implicated PKG activation as a mediator of cell death in MDA-MB-468 cells, generally [86, 99]. Given this information, we hypothesized that PKG might be mediating 
EGF-induced apoptosis, downstream, or possibly upstream of EGFR activation. To differentiate between these two possibilities, we stimulated MDA-MB-468 cells with agonists of PKG (8-Br-cGMP and 8-pCPT-cGMP-AM), and assessed for phosphorylated EGFR. We also stimulated cells with EGF and assessed for a substrate of PKG, phosphorylated VASP(Ser239). We found that the PKG agonists did not elicit EGFR phosphorylation, where on the contrary, EGF ligand induced PKG activity in a dose dependent manner. EGF-induced PKG stimulation was confirmed in multiple cell lines (A431 and HeLa), further supporting the notion that EGFR did in fact activate PKG, and PKG activity selectively occurred downstream of receptor activation.

RNAi targeting PKG, and subsequent stimulation of EGFR resulted in a significant attenuation of cell death, accompanied with a non-significant attenuation of apoptosis, as measured by PARP and Caspase- 3 cleavage. The modesty in these findings may be attributed to the transfection efficiency of the PKG siRNA (55\%), which is consistent with previous reports [130], but nonetheless marginal. From these data, we concluded that PKG is a mediator of EGF-induce apoptosis in MDA-MB-468 cells, but not a very critical one.

To identify effectors with more pertinent roles in EGFR-mediated apoptosis, we began in Chapter IV by subjecting MDA-MB-468 cells to a thorough effector screen, assessing the phosphorylation pattern of effectors that are well-established substrates of the EGFR (MAPK, Src, AKT, BAD, and STAT3). We subjected MDA-MB-468 cells to conditions in which the cells undergo EGFR-mediated cell growth, and conversely EGFR-mediated apoptosis, 
and assessed the phosphorylation patterns of these five effectors for their potential association with one of these two conditions, preferentially. STAT3 activity was the only effector with a preferentially robust increase in phosphorylation at conditions that coincidently induce apoptosis.

Our findings helped develop the hypothesis that STAT3 was a mediator of EGF-induced apoptosis. Given the many reports depicting STAT3 portraying a pro-proliferative role in cancer [169-171], we developed the alternative hypothesis that STAT3 upregulation was the result of a compensatory mechanism, in an attempt to rescue the cell from EGFR-mediated apoptosis. Logically, in order to assess both of these hypotheses, we needed to abrogate STAT3 activity and or gene expression, activate the EGFR, and subsequently assess the outcome of this on receptor-mediated apoptosis. A rise in viability and an ultimate attenuation of apoptosis would favor the notion of STAT3 as a mediator of EGF-induce apoptosis; similar to our findings with PKG. On the contrary, observing an increase in apoptosis, and a further reduction in viability would define the role of STAT3 in pro-proliferative, compensatory signaling cascade.

We began our investigation by employing commercially available antagonists of STAT3, Stattic and S3I-201. Inhibitor treatments in the presence of EGF resulted in a dose dependent decrease in MDA-MB-468 and A431 cell viability. Biochemical analyses of the inhibitor treatments in the presence of EGF resulted in a dose dependent increase in apoptosis, which appeared to be substantially greater than in cells treated with EGF alone. Together, these 
findings favored our "pro-proliferative, compensatory" STAT3 hypothesis. However, further assessment of the inhibitor biochemistry revealed that with a dose dependent decrease in STAT3 activity, EGFR phosphorylation was coincidently decreased as well. We concluded that this was due to one of two possibilities. Either the STAT3: EGFR complex entailed a tightly coupled relationship between the two proteins, resulting in a dual-inhibitory effect, or these STAT3 antagonists were exhibiting off-target, non-specific cytotoxicity. The first possibility was not favored, considering previous reports that have indicated a low affinity of STAT3 for EGFR in both A431 and MDA-MB-468 cells [194]. The second possibility seemed more likely, given that our viability data showed no attenuation of inhibitor with EGF treatment in comparison to EGF treatment alone. Therefore, we hypothesized that Stattic and S3I-201 were exhibiting offtarget effects, in vitro.

To determine if the STAT3 inhibitors were in fact non-specifically cytotoxic, we employed the PC3 cell line, which contains very low EGFR expression, and is completely void of STAT3. A cell line without STAT3 expression biochemically functions and maintains cellular homeostasis independent of STAT3 activity. Therefore, the addition of these STAT3 antagonists to the PC3 cells should result in no deleterious effects on cell viability. The PC3 cell line however did exhibit a dose dependent decrease in cell viability as a result of the STAT3 inhibitors. The Stattic inhibitor was shown to be very cytotoxic (consistent within the MDA-MB468 and A431 cell lines), more than our positive control for cell death, STS. Additionally, the lack of STAT3 expression and low level EGFR expression in 
PC3 cells further suggests that these inhibitors promote their cytotoxic effects through multiple, unknown pleiotropic mechanisms. Although these studies did not contribute any further insight to the cellular mechanism of STAT3 activity in EGFR-mediated apoptosis, they are a paramount contribution in terms of the use of the clinical use of STAT3 antagonists. STAT3 inhibitors have been well documented to be clinically beneficial in the treatment of cancer [195-197] and muscle degeneration $[198,199]$. In addition to proving their limitations, our reports of STAT3 antagonist-induced, off-target interactions suggest the use of caution in regard to their therapeutic administration.

Continuing on within our research, we elected to employ STAT3 siRNA as a more selective mode of abrogating STAT3 activity in the MDA-MB-468 cell line. STAT3 knock down cells displayed a significant reduction in EGFR-mediated apoptosis, as measured by PARP cleavage. Although Caspase- 3 cleavage was also attenuated, the results were however statistically insignificant. Nonetheless, these data strongly depicted STAT3 as a critical mediator of EGF-induced apoptosis, via PARP activation.

To further strengthen our findings, we decided to assess STAT3 activity independent of EGFR-activation. First, we subjected MDA-MB-468 cells to a cytokine (OSM) that has been documented to induce STAT3 activation. The results of these studies indicate that with a simultaneous activation of STAT3, a sustained increase in PARP and Caspase-3 cleavage was also observed over time. In addition to STAT3 activation, OSM induced a time-dependent increase pVASP stimulation. This further supported STAT3 as a mediator of apoptosis, 
while also suggesting it does so through activation of our initial effector candidate, PKG. In our final assessment if STAT3, we stimulated MDA-MB-468 cells with concentrations of STS capable of inducing cell stress without causing catastrophic cellular damage. Our goal was to establish whether or not STAT3 activity was induced in response to cell stress generally, and also to determine if STAT3 activation could be achieved independently of cytokine or growth factor mediation. The results displayed no induction of STAT3 activity with STS activation, suggesting that cytokine or growth factor activation is required to simulate STAT3 and promote its apoptotic effects. In summary of Chapter IV, our data provide evidence of a novel, molecular interaction between EGFR and STAT3, with EGFR requiring STAT3 to exert its apoptotic effects in MDA-MB-468 cells.

\section{Significance of Findings}

The significance among this research lies within the identification of key, molecular links in-between initial EGFR activation and the ultimate induction of apoptosis. PKG and STAT3 differ both structurally, and in terms of their physiological implications. However, both of these effectors contribute to an EGF-induced apoptotic fate in MDA-MB-468 cells. Although PKG has shown to play a more minor role in receptor-mediated cell death, preliminary data suggests that STAT3 may signal to and stimulates PKG and subsequent pVASP activity (Figure 4.4) Not only does this support the roles of PKG and STAT3 in promoting 
receptor-mediated apoptosis, but it also provides some insight in terms of their correlation, and the sequence of their signaling within this subcellular mechanism.

The role of STAT3 in tumor cell formation has been well established both within the literature and this dissertation. This has been shown to be due to constitutive activation of STAT3 in certain cancer cell lines [172-174]. The MDAMB-468 cell line is among those documented to exhibit constitutive STAT3 activity [88, 200]; however, consistent with our findings, some studies have shown that STAT3 is not constitutively active in MDA-MB-468 cells [175-177]. The discrepancy among these results remains inexplicit. In regard to our research, we employed low-passage MDA-MB-468 cells, which were stringently restricted from long-term propagation. In addition, we thoroughly optimized and executed proper conditions for serum starvation for each of the cell lines of use. Although these practices are quite simple by nature, they are pivotal in the proper maintenance of a tissue culture cell line in order to avoid cellular transformation. Each of these components may be a plausible explanation for the contradictory reports of STAT3 constitutive activity in MDA-MB-468 cells.

Our findings identify a minor mediator (PKG) and a more prominent mediator (STAT3) of EGF-induced cell death and apoptosis. In addition to expanding the knowledge to the mechanisms of EGFR-mediated apoptosis, this research suggests that the addition of PKG and or STAT3 agonists might increase the efficacy of current cancer therapeutics that target EGFRoverexpressed cancers. 


\section{Strengths and Weaknesses}

\section{Strengths}

There are several strengths of the research described in this dissertation. The first being the sensitivity and specificity of western blotting. As low as $20 \mathrm{ng}$ of protein can be resolved on an SDS PAGE and still detected upon immunoblot analyses [201]. Additionally, the antibody-antigen interaction provides a very specific mode of protein identification, which when properly optimized, provides results with very minimal cross-reactivity upon assessing proteins of similar sizes [202].

The unambiguous readout of studies that assess subcellular signaling mechanisms is another advantage of this project. Thorough identification of proteins and their roles in signaling cascades does not elicit much doubt or possibility of multiple interpretations. It is possible that a particular protein may be employed in multiple, non-correlated signaling cascades; however, through the use of pharmacological inhibitors and or RNAi, it is feasible to distinguish whether or not that particular protein is a critical mediator in a pathway of interest. Within this project specifically, this was advantageous in regard to our experimental hypotheses. Had our initial hypothesis (in our assessments of both PKG and STAT3) proven to be incorrect, our hypotheses were excellently designed in such a manner that the alternative outcome would have still provided novel contributions to the discipline of receptor biology. 


\section{Weaknesses}

The use of a tissue culture model system does have some limitations. It is useful in terms of conducting preliminary work; however, this model does not take into account the complexity of an entire living organism. Although our findings that PKG and STAT3 attenuate human breast cancer cell growth, they both may possibly exhibit unintended, deleterious affects in other tissue. A major progression within this study and project would be to assess our findings in a more molecularly complex organism.

Another weakness of this work lies in the lack of variation among the assays employed, more specifically in terms our analyses of apoptosis. The use of more diverse and quantitative assays to assess apoptosis would have definitely strengthened our data and overall conclusions. We did attempt to employ more quantitative apoptotic assays, including: Annexin $\mathrm{V}(\mathrm{BD}$ Pharmingen, Franklin Lakes, NJ), which asseses for Phosphatidylserine translocation; ApoStrand ELISA (Enzo, Farmingdal, NY), which assess single strand DNA in apoptotic cells; and a Caspase- 3/7 Assay kit (Anaspec, Fremont, CA), which assesses the kinetics of Caspase-3 and Caspase-7 activity. Upon employing all of these assays, we observed no significant induction of apoptosis in our EGF treated MDA-MB-468 cells, coincident with a substantially high induction of apoptosis in our serum free, viable cells. This may be attributed to employing a sample size below the limit of detection or the need for further assay optimization. Reports have shown that in cell lines with high EGFR and Erb-B2 
expression, EGFR-mediated apoptosis induced marginal Caspase-3 activation [132]. Our Caspase-3 cleavage data are consistent with this report, which suggests that Caspase-3 may not be critical mediator in EGF-induced apoptosis. Therefore, there may be other modes of cell death employed to achieve an EGFR-mediated apoptotic fate. These modes and the respective assays to assess them are components that will need to be considered in order to further progress this project.

Although the defect in EGFR trafficking provides an excellent model to study receptor signaling from the endosomes, this does however present some limitations. In MDA-MB-468 cells, the activated EGFR accumulates on the limiting membrane of the early endosome, and can be retained there for up to 24 hours [45]. This increases the duration of receptor activity while also providing a relatively large window for receptor-mediated apoptosis to occur. Due to this, it was challenging to determine the most optimal time points to assess EGFRmediated apoptosis and the effectors that were implicated with it.

\section{E. Future Directions}

This work has elucidated some of the signaling mechanisms that are implicated in EGF-induced apoptosis. However, this has inevitably raised more questions, requiring additional assessments to progress this project and to further expand upon the molecular mechanisms of receptor-mediated apoptosis. The first approach in progressing this project entails assessing PKG and STAT3 
activity relative to one another in MDA-MB-468 cells. Data from chapter IV suggest that EGFR-independent STAT3 activity elicits downstream activation of PKG prior to the ultimate induction of apoptosis. It would be interesting to confirm if STAT3 is in fact upstream and necessary for PKG activation to occur. Doing so would require PKG inhibition, and subsequent stimulation of STAT3 activity (with OSM), prior to ultimately assessing VASP phosphorylation. Following this, it would be interesting to assess PKG and STAT3 dual-knock down, and the ultimate outcome of this on EGFR-mediated apoptosis in MDA-MB-568 cells. Observing an even greater attenuation of apoptosis in cells with impaired PKG and STAT3 activity would further confirm their roles in receptor-mediated apoptosis, and would also define the correlation between PKG-induced and STAT3- induced cell death signaling pathways.

The next approach involves assessing the defect in EGFR trafficking observed in the MDA-MB-468 cells. It is our belief that the slowed kinetics of receptor degradation within this cell line is the more critical underlying culprit behind EGFR-mediated apoptosis. The EGFR has been shown to accumulate on the limiting membrane of the early endosome in these cells [45]. In addition to increasing the duration of total receptor activity, this defect also initiates the induction of apoptosis at the early endosome. This is suspected to be due to the saturation of the endocytic pathway, which subsequently induces cell stress. Phosphatase and tensin homolog deleted on chromosome 10 (PTEN) is a phosphatase that belongs to the subclass of dual-specificity enzymes. It is capable of dephosphorylating serine, threonine or tyrosine residues on protein 
targets [203]. In addition, PTEN has been shown to be necessary to promote EGFR trafficking from early to late endosomes [204], and has been shown to be void in MDA-MB-468 cells [205]. Expression of PTEN into MDA-MB-468 cells resulted in ligand-induced degradation of EGFR [204]. Additionally, genetic deletion of STAT3 and PTEN has been shown to trigger tumor progression in a mouse model for prostate cancer [180], suggesting a co-dependency among these proteins in terms of their role in cancer progression. If we were to transfect PTEN into MDA-MB-468 cells, while simultaneously knocking down STAT3 (and PKG), it would be interesting if we could enhance the kinetics of EGFR trafficking and simultaneously reduce the rate of receptor-mediated apoptosis. This would not provide a major contribution in terms of the cancer biology aspect of this project, but it would however further reveal additional components that contribute to the underlying mechanisms of EGF-induced apoptosis. 


\section{REFERENCES}

1. Savage, C.R., Jr. and S. Cohen, Epidermal growth factor and a new derivative. Rapid isolation procedures and biological and chemical characterization. J Biol Chem, 1972. 247(23): p. 7609-11.

2. Carpenter, G., L. King, Jr., and S. Cohen, Epidermal growth factor stimulates phosphorylation in membrane preparations in vitro. Nature, 1978. 276(5686): p. 409-10.

3. Cohen, S., R.A. Fava, and S.T. Sawyer, Purification and characterization of epidermal growth factor receptor/protein kinase from normal mouse liver. Proc Natl Acad Sci U S A, 1982. 79(20): p. 6237-41.

4. Lemmon, M.A. and J. Schlessinger, Cell signaling by receptor tyrosine kinases. Cell, 2010. 141(7): p. 1117-34.

5. Lax, I., et al., Localization of a major receptor-binding domain for epidermal growth factor by affinity labeling. Mol Cell Biol, 1988. 8(4): p. 1831-4.

6. $\quad$ Ferguson, K.M., et al., EGF activates its receptor by removing interactions that autoinhibit ectodomain dimerization. Mol Cell, 2003. 11(2): p. 507-17.

7. Ward, C.W., et al., The three dimensional structure of the type I insulin-like growth factor receptor. Mol Pathol, 2001. 54(3): p. 125-32.

8. Yarden, Y. and M.X. Sliwkowski, Untangling the ErbB signalling network. Nat Rev Mol Cell Biol, 2001. 2(2): p. 127-37.

9. Aaronson, S.A., Growth factors and cancer. Science, 1991. 254(5035): p. 114653.

10. Arteaga, C.L., The epidermal growth factor receptor: from mutant oncogene in nonhuman cancers to therapeutic target in human neoplasia. J Clin Oncol, 2001. 19 (18 Suppl): p. 32S-40S.

11. Rowinsky, E.K., The erbB family: targets for therapeutic development against cancer and therapeutic strategies using monoclonal antibodies and tyrosine kinase inhibitors. Annu Rev Med, 2004. 55: p. 433-57.

12. Real, F.X., et al., Expression of epidermal growth factor receptor in human cultured cells and tissues: relationship to cell lineage and stage of differentiation. Cancer Res, 1986. 46(9): p. 4726-31.

13. Reis, R.M., et al., Genetic profile of gliosarcomas. Am J Pathol, 2000. 156(2): p. 425-32.

14. Gan, H.K., A.N. Cvrljevic, and T.G. Johns, The epidermal growth factor receptor variant III (EGFRvIII): where wild things are altered. FEBS J, 2013. 280(21): $\mathrm{p}$. 5350-70.

15. Libermann, T.A., et al., Amplification, enhanced expression and possible rearrangement of EGF receptor gene in primary human brain tumours of glial origin. Nature, 1985. 313(5998): p. 144-7. 
16. Wang, F., et al., Phosphorylated EGFR expression may predict outcome of EGFRTKIs therapy for the advanced NSCLC patients with wild-type EGFR. J Exp Clin Cancer Res, 2012. 31: p. 65.

17. Sordella, R., et al., Gefitinib-sensitizing EGFR mutations in lung cancer activate anti-apoptotic pathways. Science, 2004. 305(5687): p. 1163-7.

18. Luetteke, N.C., et al., Targeted inactivation of the EGF and amphiregulin genes reveals distinct roles for EGF receptor ligands in mouse mammary gland development. Development, 1999. 126(12): p. 2739-50.

19. Roth, T.F. and K.R. Porter, Yolk Protein Uptake in the Oocyte of the Mosquito Aedes Aegypti. L. J Cell Biol, 1964. 20: p. 313-32.

20. Heuser, J.E. and T.S. Reese, Evidence for recycling of synaptic vesicle membrane during transmitter release at the frog neuromuscular junction. J Cell Biol, 1973. 57(2): p. 315-44.

21. Pearse, B.M., Coated vesicles from pig brain: purification and biochemical characterization. J Mol Biol, 1975. 97(1): p. 93-8.

22. Sigismund, S., et al., Clathrin-independent endocytosis of ubiquitinated cargos. Proc Natl Acad Sci U S A, 2005. 102(8): p. 2760-5.

23. Lund, K.A., et al., Quantitative analysis of the endocytic system involved in hormone-induced receptor internalization. J Biol Chem, 1990. 265(26): p. 15713-23.

24. Sigismund, S., et al., Threshold-controlled ubiquitination of the EGFR directs receptor fate. EMBO J, 2013. 32(15): p. 2140-57.

25. Presley, J.F., et al., Bafilomycin A1 treatment retards transferrin receptor recycling more than bulk membrane recycling. J Biol Chem, 1997. 272(21): p. 13929-36.

26. Perret, E., et al., Evolving endosomes: how many varieties and why? Curr Opin Cell Biol, 2005. 17(4): p. 423-34.

27. Ang, A.L., et al., Recycling endosomes can serve as intermediates during transport from the Golgi to the plasma membrane of MDCK cells. J Cell Biol, 2004. 167(3): p. 531-43.

28. Murray, R.Z., et al., A role for the phagosome in cytokine secretion. Science, 2005. 310(5753): p. 1492-5.

29. Sigismund, S., et al., Clathrin-mediated internalization is essential for sustained EGFR signaling but dispensable for degradation. Dev Cell, 2008. 15(2): p. 20919.

30. Ceresa, B.P., Spatial regulation of epidermal growth factor receptor signaling by endocytosis. Int J Mol Sci, 2012. 14(1): p. 72-87.

31. $\mathrm{Xu}, \mathrm{Y} . \mathrm{H} .$, et al., Characterization of epidermal growth factor receptor gene expression in malignant and normal human cell lines. Proc Natl Acad Sci U S A, 1984. 81(23): p. 7308-12.

32. Harris, R.C., E. Chung, and R.J. Coffey, EGF receptor ligands. Exp Cell Res, 2003. 284(1): p. 2-13.

33. Roepstorff, K., et al., Differential effects of EGFR ligands on endocytic sorting of the receptor. Traffic, 2009.10(8): p. 1115-27. 
34. Qu, J., et al., Distribution and epidermal growth factor receptor expression of primordial follicles in human ovarian tissue before and after cryopreservation. Hum Reprod, 2000. 15(2): p. 302-10.

35. Taylor, J.M., S. Cohen, and W.M. Mitchell, Epidermal growth factor: high and low molecular weight forms. Proc Natl Acad Sci U S A, 1970. 67(1): p. 164-71.

36. Thoresen, G.H., et al., Response to transforming growth factor alpha (TGFalpha) and epidermal growth factor (EGF) in hepatocytes: lower EGF receptor affinity of TGFalpha is associated with more sustained activation of p42/p44 mitogen-activated protein kinase and greater efficacy in stimulation of DNA synthesis. J Cell Physiol, 1998. 175(1): p. 10-8.

37. Luetteke, N.C., et al., Characterization of high molecular weight transforming grow th factor alpha produced by rat hepatocellular carcinoma cells. Biochemistry, 1988. 27(17): p. 6487-94.

38. Dunbar, A.J. and C. Goddard, Structure-function and biological role of betacellulin. Int J Biochem Cell Biol, 2000. 32(8): p. 805-15.

39. Watanabe, T., et al., Recombinant human betacellulin. Molecular structure, biological activities, and receptor interaction. J Biol Chem, 1994. 269(13): p. 9966-73.

40. Ebner, R. and R. Derynck, Epidermal growth factor and transforming growth factor-alpha: differential intracellular routing and processing of ligandreceptor complexes. Cell Regul, 1991. 2(8): p. 599-612.

41. Cailleau, R., M. Olive, and Q.V. Cruciger, Long-term human breast carcinoma cell lines of metastatic origin: preliminary characterization. In Vitro, 1978. 14(11): p. 911-5.

42. Filmus, J., et al., MDA-468, a human breast cancer cell line with a high number of epidermal growth factor (EGF) receptors, has an amplified EGF receptor gene and is growth inhibited by EGF. Biochem Biophys Res Commun, 1985. 128(2): p. 898-905.

43. Armstrong, D.K., et al., Epidermal growth factor-mediated apoptosis of MDAMB-468 human breast cancer cells. Cancer Res, 1994. 54(20): p. 5280-3.

44. Hyatt, D.C. and B.P. Ceresa, Cellular localization of the activated EGFR determines its effect on cell growth in MDA-MB-468 cells. Exp Cell Res, 2008. 314(18): p. 3415-25.

45. Rush, J.S., et al., Endosomal accumulation of the activated epidermal growth factor receptor (EGFR) induces apoptosis. J Biol Chem, 2012. 287(1): p. 71222.

46. Fung, C., et al., EGFR tyrosine kinase inhibition induces autophagy in cancer cells. Cancer Biol Ther, 2012. 13(14): p. 1417-24.

47. Brabyn, C.J. and L.P. Kleine, EGF causes hyperproliferation and apoptosis in T51B cells: involvement of high and low affinity EGFR binding sites. Cell Signal, 1995. 7(2): p. 139-50.

48. Chin, Y.E., et al., Activation of the STAT signaling pathway can cause expression of caspase 1 and apoptosis. Mol Cell Biol, 1997. 17(9): p. 5328-37.

49. Jacobson, M.D., M. Weil, and M.C. Raff, Programmed cell death in animal development. Cell, 1997. 88(3): p. 347-54. 
50. Elmore, S., Apoptosis: a review of programmed cell death. Toxicol Pathol, 2007. 35(4): p. 495-516.

51. Hacker, G., The morphology of apoptosis. Cell Tissue Res, 2000. 301(1): p. 517.

52. Kerr, J.F., A.H. Wyllie, and A.R. Currie, Apoptosis: a basic biological phenomenon with wide-ranging implications in tissue kinetics. Br J Cancer, 1972. 26(4): p. 239-57.

53. Crescitelli, R., et al., Distinct RNA profiles in subpopulations of extracellular vesicles: apoptotic bodies, microvesicles and exosomes. J Extracell Vesicles, 2013. 2.

54. Turk, B. and V. Turk, Lysosomes as "suicide bags" in cell death: myth or reality? J Biol Chem, 2009. 284(33): p. 21783-7.

55. Fulda, S. and K.M. Debatin, Apoptosis signaling in tumor therapy. Ann N Y Acad Sci, 2004. 1028: p. 150-6.

56. Hanahan, D. and R.A. Weinberg, The hallmarks of cancer. Cell, 2000. 100(1): p. 57-70.

57. Kabore, A.F., J.B. Johnston, and S.B. Gibson, Changes in the apoptotic and survival signaling in cancer cells and their potential therapeutic implications. Curr Cancer Drug Targets, 2004. 4(2): p. 147-63.

58. Ikehara, N., et al., BRAF mutation associated with dysregulation of apoptosis in human colorectal neoplasms. Int J Cancer, 2005. 115(6): p. 943-50.

59. Reed, J.C., Apoptosis-targeted therapies for cancer. Cancer Cell, 2003. 3(1): p. 17-22.

60. DiBona, D.R. and W.J. Powell, Jr., Quantitative correlation between cell swelling and necrosis in myocardial ischemia in dogs. Circ Res, 1980. 47(5): p. 653-65.

61. Levin, S., et al., The nomenclature of cell death: recommendations of an ad hoc Committee of the Society of Toxicologic Pathologists. Toxicol Pathol, 1999. 27(4): p. 484-90.

62. Zeiss, C.J., The apoptosis-necrosis continuum: insights from genetically altered mice. Vet Pathol, 2003. 40(5): p. 481-95.

63. Hengartner, M.O., The biochemistry of apoptosis. Nature, 2000. 407(6805): p. 770-6.

64. Logue, S.E. and S.J. Martin, Caspase activation cascades in apoptosis. Biochem Soc Trans, 2008. 36(Pt 1): p. 1-9.

65. Slee, E.A., C. Adrain, and S.J. Martin, Executioner caspase-3, -6, and -7 perform distinct, non-redundant roles during the demolition phase of apoptosis. J Biol Chem, 2001. 276(10): p. 7320-6.

66. Cohen, G.M., Caspases: the executioners of apoptosis. Biochem J, 1997. 326 ( Pt 1): p. 1-16.

67. Grutter, M.G., Caspases: key players in programmed cell death. Curr Opin Struct Biol, 2000. 10(6): p. 649-55.

68. Malireddi, R.K., et al., Cutting edge: proteolytic inactivation of poly(ADPribose) polymerase 1 by the Nlrp3 and Nlrc4 inflammasomes. J Immunol, 2010. 185(6): p. 3127-30.

69. Locksley, R.M., N. Killeen, and M.J. Lenardo, The TNF and TNF receptor superfamilies: integrating mammalian biology. Cell, 2001. 104(4): p. 487-501. 
70. Ashkenazi, A. and V.M. Dixit, Death receptors: signaling and modulation. Science, 1998. 281(5381): p. 1305-8.

71. Waring, P. and A. Mullbacher, Cell death induced by the Fas/Fas ligand pathway and its role in pathology. Immunol Cell Biol, 1999. 77(4): p. 312-7.

72. Wajant, H., The Fas signaling pathway: more than a paradigm. Science, 2002. 296(5573): p. 1635-6.

73. Kischkel, F.C., et al., Cytotoxicity-dependent APO-1 (Fas/CD95)-associated proteins form a death-inducing signaling complex (DISC) with the receptor. EMBO J, 1995. 14(22): p. 5579-88.

74. Adachi, M., et al., Targeted mutation in the Fas gene causes hyperplasia in peripheral lymphoid organs and liver. Nat Genet, 1995. 11(3): p. 294-300.

75. Wu, J., et al., Correction of accelerated autoimmune disease by early replacement of the mutated lpr gene with the normal Fas apoptosis gene in the T cells of transgenic MRL-lpr/lpr mice. Proc Natl Acad Sci U S A, 1994. 91(6): p. 2344-8.

76. Lawen, A., Apoptosis-an introduction. Bioessays, 2003. 25(9): p. 888-96.

77. Corbin, J.D. and S.H. Francis, Cyclic GMP phosphodiesterase-5: target of sildenafil. J Biol Chem, 1999. 274(20): p. 13729-32.

78. Lohmann, S.M., et al., Distinct and specific functions of cGMP-dependent protein kinases. Trends Biochem Sci, 1997. 22(8): p. 307-12.

79. Sausbier, M., et al., Mechanisms of NO/cGMP-dependent vasorelaxation. Circ Res, 2000. 87(9): p. 825-30.

80. Kuo, J.F. and P. Greengard, Cyclic nucleotide-dependent protein kinases. VII. Comparison of various histones as substrates for adenosine 3',5'monophosphate-dependent and guanosine 3',5'-monophosphate-dependent protein kinases. Biochim Biophys Acta, 1970. 212(3): p. 434-40.

81. Wall, M.E., et al., Mechanisms associated with cGMP binding and activation of cGMP-dependent protein kinase. Proc Natl Acad Sci U S A, 2003. 100(5): p. 2380-5.

82. Brown, N.R., et al., The structural basis for specificity of substrate and recruitment peptides for cyclin-dependent kinases. Nat Cell Biol, 1999. 1(7): p. 438-43.

83. Fraser, M., et al., Regulation of p53 and suppression of apoptosis by the soluble guanylyl cyclase/cGMP pathway in human ovarian cancer cells. Oncogene, 2006. 25(15): p. 2203-12.

84. Leung, E.L., et al., Protein kinase G type Ialpha activity in human ovarian cancer cells significantly contributes to enhanced Src activation and DNA synthesis/cell proliferation. Mol Cancer Res, 2010. 8(4): p. 578-91.

85. Wong, J.C. and R.R. Fiscus, Protein kinase G activity prevents pathological-level nitric oxide-induced apoptosis and promotes DNA synthesis/cell proliferation in vascular smooth muscle cells. Cardiovasc Pathol, 2010. 19(6): p. e221-31.

86. Fallahian, F., F. Karami-Tehrani, and S. Salami, Induction of apoptosis by type Ibeta protein kinase $G$ in the human breast cancer cell lines MCF-7 and MDAMB-468. Cell Biochem Funct, 2012. 30(3): p. 183-90.

87. Darnell, J.E., Jr., STATs and gene regulation. Science, 1997. 277(5332): p. 1630-5. 
88. Turkson, J., STAT proteins as novel targets for cancer drug discovery. Expert Opin Ther Targets, 2004. 8(5): p. 409-22.

89. Yue, P. and J. Turkson, Targeting STAT3 in cancer: how successful are we? Expert Opin Investig Drugs, 2009. 18(1): p. 45-56.

90. Ruff-Jamison, S., K. Chen, and S. Cohen, Induction by EGF and interferongamma of tyrosine phosphorylated DNA binding proteins in mouse liver nuclei. Science, 1993. 261(5129): p. 1733-6.

91. Darnell, J.E., Jr., I.M. Kerr, and G.R. Stark, Jak-STAT pathways and transcriptional activation in response to IFNs and other extracellular signaling proteins. Science, 1994. 264(5164): p. 1415-21.

92. Yu, H. and R. Jove, The STATs of cancer--new molecular targets come of age. Nat Rev Cancer, 2004. 4(2): p. 97-105.

93. Garcia, R., et al., Constitutive activation of Stat3 by the Src and JAK tyrosine kinases participates in growth regulation of human breast carcinoma cells. Oncogene, 2001. 20(20): p. 2499-513.

94. Uehara, Y., et al., Novel high-throughput screening system for identifying STAT3-SH2 antagonists. Biochem Biophys Res Commun, 2009. 380(3): p. 627-31.

95. Minami, M., et al., STAT3 activation is a critical step in gp130-mediated terminal differentiation and growth arrest of a myeloid cell line. Proc Natl Acad Sci U S A, 1996. 93(9): p. 3963-6.

96. Watson, C.J. and W.T. Khaled, Mammary development in the embryo and adult: a journey of morphogenesis and commitment. Development, 2008. 135(6): p. 995-1003.

97. Watson, C.J. and K. Neoh, The Stat family of transcription factors have diverse roles in mammary gland development. Semin Cell Dev Biol, 2008. 19(4): p. 401-6.

98. Resemann, H.K., C.J. Watson, and B. Lloyd-Lewis, The Stat3 paradox: a killer and an oncogene. Mol Cell Endocrinol, 2014. 382(1): p. 603-11.

99. Fallahian, F., et al., Cyclic GMP induced apoptosis via protein kinase $G$ in oestrogen receptor-positive and -negative breast cancer cell lines. FEBS J, 2011. 278(18): p. 3360-9.

100. Wheeler, D.L., E.F. Dunn, and P.M. Harari, Understanding resistance to EGFR inhibitors-impact on future treatment strategies. Nat Rev Clin Oncol, 2010. 7(9): p. 493-507.

101. Jackman, D., et al., Clinical definition of acquired resistance to epidermal growth factor receptor tyrosine kinase inhibitors in non-small-cell lung cancer. J Clin Oncol, 2010. 28(2): p. 357-60.

102. Colzani, M., et al., Metabolic labeling and protein linearization technology allow the study of proteins secreted by cultured cells in serum-containing media. J Proteome Res, 2009. 8(10): p. 4779-88.

103. Mbeunkui, F., O. Fodstad, and L.K. Pannell, Secretory protein enrichment and analysis: an optimized approach applied on cancer cell lines using $2 \mathrm{D}$ LCMS/MS. J Proteome Res, 2006. 5(4): p. 899-906. 
104. Reynolds, A.R., et al., EGFR activation coupled to inhibition of tyrosine phosphatases causes lateral signal propagation. Nat Cell Biol, 2003. 5(5): p. 447-53.

105. Schneider, M.R., et al., Beyond wavy hairs: the epidermal growth factor receptor and its ligands in skin biology and pathology. Am J Pathol, 2008. 173(1): p. 14-24.

106. Paez, J.G., et al., EGFR mutations in lung cancer: correlation with clinical response to gefitinib therapy. Science, 2004. 304(5676): p. 1497-500.

107. Zhang, X., et al., Mutations of epidermal growth factor receptor in colon cancer indicate susceptibility or resistance to gefitinib. Oncol Rep, 2008. 19(6): $\mathrm{p}$. 1541-4.

108. Lou, Y.F., et al., Combination of gefitinib and DNA methylation inhibitor decitabine exerts synergistic anti-cancer activity in colon cancer cells. PLoS One, 2014. 9(5): p. e97719.

109. Wong, S.F., Cetuximab: an epidermal growth factor receptor monoclonal antibody for the treatment of colorectal cancer. Clin Ther, 2005. 27(6): p. 68494.

110. Janjigian, Y.Y., et al., Dual inhibition of EGFR with afatinib and cetuximab in kinase inhibitor-resistant EGFR-mutant lung cancer with and without T790M mutations. Cancer Discov, 2014. 4(9): p. 1036-45.

111. Maemondo, M., et al., Gefitinib or chemotherapy for non-small-cell lung cancer with mutated EGFR. N Engl J Med, 2010. 362(25): p. 2380-8.

112. Oxnard, G.R., et al., New strategies in overcoming acquired resistance to epidermal growth factor receptor tyrosine kinase inhibitors in lung cancer. Clin Cancer Res, 2011. 17(17): p. 5530-7.

113. Stanton, P., et al., Epidermal growth factor receptor expression by human squamous cell carcinomas of the head and neck, cell lines and xenografts. Br J Cancer, 1994. 70(3): p. 427-33.

114. Davidson, N.E., et al., Epidermal growth factor receptor gene expression in estrogen receptor-positive and negative human breast cancer cell lines. Mol Endocrinol, 1987. 1(3): p. 216-23.

115. Hognason, T., et al., Epidermal growth factor receptor induced apoptosis: potentiation by inhibition of Ras signaling. FEBS Lett, 2001. 491(1-2): p. 9-15.

116. Francis, S.H., et al., cGMP-dependent protein kinases and cGMP phosphodiesterases in nitric oxide and cGMP action. Pharmacol Rev, 2010. 62(3): p. 525-63.

117. Walter, U. and S. Gambaryan, $c G M P$ and cGMP-dependent protein kinase in platelets and blood cells. Handb Exp Pharmacol, 2009(191): p. 533-48.

118. Wyatt, T.A., et al., ANF elicits phosphorylation of the cGMP phosphodiesterase in vascular smooth muscle cells. Am J Physiol, 1998. 274(2 Pt 2): p. H448-55.

119. Kottke, T.J., et al., Comparison of paclitaxel-, 5-fluoro-2'-deoxyuridine-, and epidermal growth factor (EGF)-induced apoptosis. Evidence for EGF-induced anoikis. J Biol Chem, 1999. 274(22): p. 15927-36.

120. Gill, G.N. and C.S. Lazar, Increased phosphotyrosine content and inhibition of proliferation in EGF-treated A431 cells. Nature, 1981. 293(5830): p. 305-7. 
121. Smolenski, A., et al., Analysis and regulation of vasodilator-stimulated phosphoprotein serine 239 phosphorylation in vitro and in intact cells using a phosphospecific monoclonal antibody. J Biol Chem, 1998. 273(32): p. 2002935.

122. Dhayade, S., et al., Sildenafil Potentiates a cGMP-Dependent Pathway to Promote Melanoma Growth. Cell Rep, 2016. 14(11): p. 2599-610.

123. Doppler, H.R., et al., Protein kinase D1-mediated phosphorylations regulate vasodilator-stimulated phosphoprotein (VASP) localization and cell migration. J Biol Chem, 2013. 288(34): p. 24382-93.

124. Knauer, O., et al., Differential phosphoproteome profiling reveals a functional role for VASP in Helicobacter pylori-induced cytoskeleton turnover in gastric epithelial cells. Cell Microbiol, 2008. 10(11): p. 2285-96.

125. Krupp, M.N., D.T. Connolly, and M.D. Lane, Synthesis, turnover, and downregulation of epidermal growth factor receptors in human A431 epidermoid carcinoma cells and skin fibroblasts. J Biol Chem, 1982. 257(19): p. 11489-96.

126. Berkers, J.A., P.M. van Bergen en Henegouwen, and J. Boonstra, Three classes of epidermal growth factor receptors on HeLa cells. J Biol Chem, 1991. 266(2): p. 922-7.

127. Zhuo, M., et al., Role of guanylyl cyclase and cGMP-dependent protein kinase in long-term potentiation. Nature, 1994. 368(6472): p. 635-9.

128. Schwede, F., et al., Cyclic nucleotide analogs as biochemical tools and prospective drugs. Pharmacol Ther, 2000. 87(2-3): p. 199-226.

129. Fernandes-Alnemri, T., G. Litwack, and E.S. Alnemri, CPP32, a novel human apoptotic protein with homology to Caenorhabditis elegans cell death protein Ced-3 and mammalian interleukin-1 beta-converting enzyme. J Biol Chem, 1994. 269(49): p. 30761-4.

130. Yang, J., et al., Sildenafil potentiates bone morphogenetic protein signaling in pulmonary arterial smooth muscle cells and in experimental pulmonary hypertension. Arterioscler Thromb Vasc Biol, 2013. 33(1): p. 34-42.

131. Kawamoto, T., et al., Relation of epidermal growth factor receptor concentration to growth of human epidermoid carcinoma A431 cells. J Biol Chem, 1984. 259(12): p. 7761-6.

132. Tikhomirov, 0 . and G. Carpenter, Ligand-induced, p38-dependent apoptosis in cells expressing high levels of epidermal growth factor receptor and ErbB-2. J Biol Chem, 2004. 279(13): p. 12988-96.

133. Oldenburg, O., et al., Bradykinin induces mitochondrial ROS generation via NO, cGMP, PKG, and mitoKATP channel opening and leads to cardioprotection. Am J Physiol Heart Circ Physiol, 2004. 286(1): p. H468-76.

134. Nakamizo, T., et al., Phosphodiesterase inhibitors are neuroprotective to cultured spinal motor neurons. J Neurosci Res, 2003. 71(4): p. 485-95.

135. Thippeswamy, T., et al., Glial-mediated neuroprotection: evidence for the protective role of the NO-cGMP pathway via neuron-glial communication in the peripheral nervous system. Glia, 2005. 49(2): p. 197-210.

136. Soh, J.W., et al., Cyclic GMP mediates apoptosis induced by sulindac derivatives via activation of c-Jun NH2-terminal kinase 1. Clin Cancer Res, 2000. 6(10): p. 4136-41. 
137. Quesnelle, K.M., A.L. Boehm, and J.R. Grandis, STAT-mediated EGFR signaling in cancer. J Cell Biochem, 2007. 102(2): p. 311-9.

138. Chin, Y.E., et al., Cell growth arrest and induction of cyclin-dependent kinase inhibitor p21 WAF1/CIP1 mediated by STAT1. Science, 1996. 272(5262): $\mathrm{p}$. 719-22.

139. Bhatia, K., et al., A mutant 221 cyclin-dependent kinase inhibitor isolated from a Burkitt's lymphoma. Cancer Res, 1995. 55(7): p. 1431-5.

140. Sheikh, M.S., H. Rochefort, and M. Garcia, Overexpression of p21WAF1/CIP1 induces growth arrest, giant cell formation and apoptosis in human breast carcinoma cell lines. Oncogene, 1995. 11(9): p. 1899-905.

141. Kim, K., H.G. Wu, and S.R. Jeon, Epidermal growth factor-induced cell death and radiosensitization in epidermal growth factor receptor-overexpressing cancer cell lines. Anticancer Res, 2015. 35(1): p. 245-53.

142. Akira, S., et al., Molecular cloning of APRF, a novel IFN-stimulated gene factor 3 p91-related transcription factor involved in the gp130-mediated signaling pathway. Cell, 1994. 77(1): p. 63-71.

143. Wegenka, U.M., et al., Acute-phase response factor, a nuclear factor binding to acute-phase response elements, is rapidly activated by interleukin- 6 at the posttranslational level. Mol Cell Biol, 1993. 13(1): p. 276-88.

144. Park, O.K., T.S. Schaefer, and D. Nathans, In vitro activation of Stat 3 by epidermal growth factor receptor kinase. Proc Natl Acad Sci U S A, 1996. 93(24): p. 13704-8.

145. Gamero, A.M., et al., Activation of Tyk2 and Stat3 is required for the apoptotic actions of interferon-beta in primary pro-B cells. J Biol Chem, 2006. 281(24): p. 16238-44.

146. Spiotto, M.T. and T.D. Chung, STAT3 mediates IL-6-induced growth inhibition in the human prostate cancer cell line LNCaP. Prostate, 2000. 42(2): p. 88-98.

147. Messersmith, W., et al., Assessment of Epidermal Growth Factor Receptor (EGFR) signaling in paired colorectal cancer and normal colon tissue samples using computer-aided immunohistochemical analysis. Cancer Biol Ther, 2005. 4(12): p. 1381-6.

148. Kozyulina, P.Y., et al., $p 38$ MAP kinase enhances EGF-induced apoptosis in A431 carcinoma cells by promoting tyrosine phosphorylation of STAT1. Biochem Biophys Res Commun, 2013. 430(1): p. 331-5.

149. Gingras, M.C., et al., Cytoplasmic death signal triggered by SRC-mediated phosphorylation of the adenovirus E4orf4 protein. Mol Cell Biol, 2002. 22(1): p. 41-56.

150. She, Q.B., et al., The BAD protein integrates survival signaling by EGFR/MAPK and PI3K/Akt kinase pathways in PTEN-deficient tumor cells. Cancer Cell, 2005. 8(4): p. 287-97.

151. Yang, E., et al., Bad, a heterodimeric partner for Bcl-XL and Bcl-2, displaces Bax and promotes cell death. Cell, 1995. 80(2): p. 285-91.

152. Wang, L., et al., IL-17 can promote tumor growth through an IL-6-Stat3 signaling pathway. J Exp Med, 2009. 206(7): p. 1457-64. 
153. Kumar, G., et al., Involvement of Janus kinases, $p 52 s h c, R a f-1$, and MEK-1 in the IL-6-induced mitogen-activated protein kinase cascade of a growth-responsive B cell line. J Immunol, 1994. 153(10): p. 4436-47.

154. Heinrich, P.C., et al., Principles of interleukin (IL)-6-type cytokine signalling and its regulation. Biochem J, 2003. 374(Pt 1): p. 1-20.

155. Hoffman, R.C., et al., Resonance assignments for Oncostatin M, a 24-kDa alphahelical protein. J Biomol NMR, 1996. 7(4): p. 273-82.

156. Kucia-Tran, J.A., et al., Overexpression of the oncostatin-M receptor in cervical squamous cell carcinoma is associated with epithelial-mesenchymal transition and poor overall survival. Br J Cancer, 2016. 115(2): p. 212-22.

157. Auernhammer, C.J., et al., The oncostatin M receptor/gp130 ligand murine oncostatin $M$ induces apoptosis in adrenocortical Y-1 tumor cells. J Endocrinol, 2004. 180(3): p. 479-86.

158. Chipoy, C., et al., Sensitization of osteosarcoma cells to apoptosis by oncostatin $M$ depends on STAT5 and p53. Oncogene, 2007. 26(46): p. 6653-64.

159. Negoro, S., et al., Glycoprotein 130 regulates cardiac myocyte survival in doxorubicin-induced apoptosis through phosphatidylinositol 3-kinase/Akt phosphorylation and Bcl-xL/caspase-3 interaction. Circulation, 2001. 103(4): p. 555-61.

160. Luttrell, D.K., et al., Involvement of pp60c-src with two major signaling pathways in human breast cancer. Proc Natl Acad Sci U S A, 1994. 91(1): p. 83-7.

161. Lutz, M.P., et al., Overexpression and activation of the tyrosine kinase Src in human pancreatic carcinoma. Biochem Biophys Res Commun, 1998. 243(2): p. 503-8.

162. Armstrong, D.K., et al., Epidermal growth factor-mediated apoptosis of MDAMB-468 human breast cancer cells. Cancer Res, 1994. 54(20): p. 5280-5283.

163. Chen, K.Y., et al., The role of tyrosine kinase Etk/Bmx in EGF-induced apoptosis of MDA-MB-468 breast cancer cells. Oncogene, 2004. 23(10): p. 1854-62.

164. Grudinkin, P.S., et al., EGF-induced apoptosis in A431 cells is dependent on STAT1, but not on STAT3. Eur J Cell Biol, 2007. 86(10): p. 591-603.

165. Jackson, N.M. and B.P. Ceresa, Protein Kinase G facilitates EGFR-mediated cell death in MDA-MB-468 cells. Exp Cell Res, 2016. 346(2): p. 224-32.

166. French, A.R., et al., Postendocytic Trafficking of Epidermal Growth FactorReceptor Complexes is Mediated through Saturable and Specific Endosomal Interactions. J Biol Chem, 1994. 269(22): p. 15749-15755.

167. Wiley, H.S., Anomalous Binding of Epidermal Growth Factor to A431 Cells Is Due to the Effect of High Receptor Densities and a Saturable Endocytic System. J Cell Biol, 1988. 1-7: p. 801-810.

168. Rush, J.S., et al., Endosomal accumulation of the activated epidermal growth factor receptor (EGFR) induces apoptosis. The Journal of biological chemistry, 2012. 287(1): p. 712-22.

169. Sherry, M.M., et al., STAT3 is required for proliferation and maintenance of multipotency in glioblastoma stem cells. Stem Cells, 2009. 27(10): p. 2383-92.

170. Alvarez, J.V., et al., Signal transducer and activator of transcription 3 is required for the oncogenic effects of non-small-cell lung cancer-associated 
mutations of the epidermal growth factor receptor. Cancer Res, 2006. 66(6): $\mathrm{p}$. 3162-8.

171. Berthenet, K., et al., HSP110 promotes colorectal cancer growth through STAT3 activation. Oncogene, 2016.

172. Azare, J., et al., Constitutively activated Stat3 induces tumorigenesis and enhances cell motility of prostate epithelial cells through integrin beta 6. Mol Cell Biol, 2007. 27(12): p. 4444-53.

173. Burke, W.M., et al., Inhibition of constitutively active Stat3 suppresses growth of human ovarian and breast cancer cells. Oncogene, 2001. 20(55): p. 792534.

174. Xie, T.X., et al., Stat3 activation regulates the expression of matrix metalloproteinase-2 and tumor invasion and metastasis. Oncogene, 2004. 23(20): p. 3550-60.

175. Li, L. and P.E. Shaw, Autocrine-mediated activation of STAT3 correlates with cell proliferation in breast carcinoma lines. J Biol Chem, 2002. 277(20): p. 17397-405.

176. Tan, Q., et al., Src/STAT3-dependent heme oxygenase-1 induction mediates chemoresistance of breast cancer cells to doxorubicin by promoting autophagy. Cancer Sci, 2015. 106(8): p. 1023-32.

177. West, N.R. and P.H. Watson, S100A7 (psoriasin) is induced by the proinflammatory cytokines oncostatin-M and interleukin- 6 in human breast cancer. Oncogene, 2010. 29(14): p. 2083-92.

178. Skov, S., et al., Activation of Stat-3 is involved in the induction of apoptosis after ligation of major histocompatibility complex class I molecules on human Jurkat T cells. Blood, 1998. 91(10): p. 3566-73.

179. Zhang, J., et al., STAT3 exerts two-way regulation in the biological effects of IL6 in M1 leukemia cells. Leuk Res, 2001. 25(6): p. 463-72.

180. Pencik, J., et al., STAT3 regulated ARF expression suppresses prostate cancer metastasis. Nat Commun, 2015. 6: p. 7736.

181. Sironi, J.J. and T. Ouchi, STAT1-induced apoptosis is mediated by caspases 2, 3, and 7. J Biol Chem, 2004. 279(6): p. 4066-74.

182. Stein, T., N. Salomonis, and B.A. Gusterson, Mammary gland involution as a multi-step process. J Mammary Gland Biol Neoplasia, 2007. 12(1): p. 25-35.

183. Abell, K., et al., Stat3-induced apoptosis requires a molecular switch in PI(3)K subunit composition. Nat Cell Biol, 2005. 7(4): p. 392-8.

184. Kritikou, E.A., et al., A dual, non-redundant, role for LIF as a regulator of development and STAT3-mediated cell death in mammary gland. Development, 2003. 130(15): p. 3459-68.

185. Rieanrakwong, D., et al., Prolactin Suppression of Gonadotropin-Releasing Hormone Initiation of Mammary Gland Involution in Female Rats. Endocrinology, 2016. 157(7): p. 2750-8.

186. Beardmore, J.M. and R.C. Richards, Concentrations of epidermal growth factor in mouse milk throughout lactation. J Endocrinol, 1983. 96(2): p. 287-92.

187. Kreuzaler, P.A., et al., Stat3 controls lysosomal-mediated cell death in vivo. Nat Cell Biol, 2011. 13(3): p. 303-9. 
188. Kanneganti, T.D., M. Lamkanfi, and G. Nunez, Intracellular NOD-like receptors in host defense and disease. Immunity, 2007. 27(4): p. 549-59.

189. Mariathasan, S., et al., Differential activation of the inflammasome by caspase-1 adaptors ASC and Ipaf. Nature, 2004. 430(6996): p. 213-8.

190. Alonzi, T., et al., Interleukin 6 is required for the development of collageninduced arthritis. J Exp Med, 1998. 187(4): p. 461-8.

191. Tsutsui, H., et al., Cytokine-induced inflammatory liver injuries. Curr Mol Med, 2003. 3(6): p. 545-59.

192. Yamamoto, M., et al., IL-6 is required for the development of Th1 cell-mediated murine colitis. J Immunol, 2000. 164(9): p. 4878-82.

193. Sorkin, A. and M. von Zastrow, Endocytosis and signalling: intertwining molecular networks. Nature reviews. Molecular cell biology, 2009. 10(9): p. 609-22.

194. Krall, J.A., E.M. Beyer, and G. MacBeath, High- and low-affinity epidermal growth factor receptor-ligand interactions activate distinct signaling pathways. PLoS One, 2011. 6(1): p. e15945.

195. Adachi, M., et al., Targeting STAT3 inhibits growth and enhances radiosensitivity in head and neck squamous cell carcinoma. Oral Oncol, 2012. 48(12): p. 1220-6.

196. Dave, B., et al., Selective small molecule Stat3 inhibitor reduces breast cancer tumor-initiating cells and improves recurrence free survival in a humanxenograft model. PLoS One, 2012. 7(8): p. e30207.

197. $\mathrm{Ni}, \mathrm{Z}$., et al., Inhibition of constitutively activated Stat3 signaling pathway suppresses growth of prostate cancer cells. Cancer Res, 2000. 60(5): p. 1225-8.

198. Price, F.D., et al., Inhibition of JAK-STAT signaling stimulates adult satellite cell function. Nat Med, 2014. 20(10): p. 1174-81.

199. Tierney, M.T., et al., STAT3 signaling controls satellite cell expansion and skeletal muscle repair. Nat Med, 2014. 20(10): p. 1182-6.

200. Berishaj, M., et al., Stat3 is tyrosine-phosphorylated through the interleukin6/glycoprotein 130/Janus kinase pathway in breast cancer. Breast Cancer Res, 2007. 9(3): p. R32.

201. Knecht, D.A. and R.L. Dimond, Visualization of antigenic proteins on Western blots. Anal Biochem, 1984. 136(1): p. 180-4.

202. Levey, A.I., et al., Monoclonal antibodies to choline acetyltransferase: production, specificity, and immunohistochemistry. J Neurosci, 1983. 3(1): p. $1-9$.

203. Myers, M.P., et al., P-TEN, the tumor suppressor from human chromosome 10q23, is a dual-specificity phosphatase. Proc Natl Acad Sci U S A, 1997. 94(17): p. 9052-7.

204. Shinde, S.R. and S. Maddika, PTEN modulates EGFR late endocytic trafficking and degradation by dephosphorylating Rab7. Nat Commun, 2016. 7: p. 10689.

205. Weigelt, B., P.H. Warne, and J. Downward, PIK3CA mutation, but not PTEN loss of function, determines the sensitivity of breast cancer cells to mTOR inhibitory drugs. Oncogene, 2011. 30(29): p. 3222-33. 


\section{CURRICULUM VITAE}

Nicole M. Jackson

University of Louisville

Department of Pharmacology and Toxicology

505 S. Hancock Street 352 F

Louisville, KY 40202

NMJack05@louisville.edu

(502) 852-2115

\section{EDUCATION}

2017

Ph.D. in Pharmacology and Toxicology University of Louisville, Louisville, KY

2015

M.S. in Pharmacology and Toxicology University of Louisville, Louisville, KY

2012

B.A. Summa Cum Laude in Chemistry Cheyney University of Pennsylvania, Cheyney, PA

\section{DISSERTATION}

University of Louisville, Louisville, KY

Department of Pharmacology and Toxicology

October 2012 - present

Mentor: Dr. Brian Ceresa

- Dissertation project entails identifying downstream effector proteins with implications in Epidermal Growth Factor Receptor (EGFR) mediated induction of apoptosis, as well as in EGFR-mediated cellular proliferation in metastatic cancer cell lines.

\section{RESEARCH EXPERIENCE}

University of Louisville, Louisville, KY

Department of Pharmacology and Toxicology

Undergraduate Intern, May 2012 - August 2012

Mentor: Dr. David Hein 
- Conducted research on N-Acetyltransferase I (NAT1), a phase II metabolizing enzyme with altered activity in cancer. Assessed several natural compounds in combination with a small molecule inhibitor of NAT1, in order to enhance the inhibitor's efficacy in metastatic breast cancer cell lines.

West Chester University, West Chester, PA

Equine Toxicology and Research Laboratory

Undergraduate Research Assistant, June 2011 - May 2012

Mentor: Dr. Cornelius Uboh

- Assisted in laboratory research involving toxicological analysis of anabolic steroids and performance enhancement supplements. Also assisted in blood plasma preparation, analysis and confirmation of anabolic steroids in horses that participated in competitive racing within the state of Pennsylvania.

Children's Hospital of Philadelphia, Philadelphia, PA Department of General Surgery

Undergraduate Intern, May 2010 - August 2010 Mentor: Dr. Timothy Brazelton

- Assisted on a drug discovery project entailing a hypertensive drug, Losartan, which was suspected of inducing myofiber regeneration in a mouse model for Duchenne Muscular Dystrophy. Also assisted the lab research team with in vivo GFP-labeled bone marrow injections into mice for sickle cell disease research.

\section{TEACHING EXPERIENCE}

Jefferson Community and Technical College, Louisville, KY

Adjunct Professor of Biology, May 2016 - July 2016

Courses Instructed:

- Introduction to Biology (BIO112)

Developed curriculum, lectured and independently taught basic concepts of biology to non-science majors. Course topics include the scientific method, subatomic molecules, biology of the cell, genetics, virology and biology in correlation with disease.

Composed and graded all exams. Determined and electronically posted final grades. Created and organized online student course evaluation at the end of the course.

- Introduction to Biology Laboratory (BIO113)

Lectured and independently taught basic laboratory concepts and methods utilized within biological studies. Laboratory lectures 
include the scientific method, the metric system, utilization of the microscope, biology of the cell, genetic drift and probability.

Assigned and graded all assessments. Determined and electronically posted final grades. Created and organized online student course evaluation at the end of the course.

\section{ACADEMIC AWARDS AND FELLOWSHIPS}

- Graduate Dean's Citation Award Recipient (April 2017)

- 2015 Minorities Association Committee (MAC) travel award recipient to the American Society for Cell Biology (ASCB) Meeting (December 2015)

- Third place award recipient in Louisville Chapter- Women in Science and Medicine category of Research!Louisville Symposium (October 2015)

- Third place award recipient in the graduate student category at the ASCB Membrane Trafficking Symposium (July 2015)

- Travel Award recipient to the $7^{\text {th }}$ International Conference on cGMP (June 2015)

- Southern Regional Education Board (SREB) Doctoral Scholar Fellowship recipient through the University of Louisville (August 2014 present)

- University of Louisville IPIBS Fellowship recipient (August 2012 - July 2014)

- Cheyney University Provost's Award for Leadership Award recipient (April 2012)

- Cheyney University Keystone Scholarship recipient (2010 - 2012)

- Cheyney University Academic Excellence (Fall 2008 - Spring 2012)

- Cheyney University NSF-BEAMS Scholarship recipient (2008 - 2010)

- Cheyney University Student of the Month (February 2009)

\section{ACTIVITIES}

- Member of the University of Louisville Graduate Student Council (GSC) Running Club (2016- present)

- Member and secretary of the Black Biomedical Graduate Student Organization (BBGSO) at the University of Louisville (2012 2016)

- Member of Beta Kappa Chi Scientific Honor Society (2011 2012)

- Member of the Keystone Honor Society (2010-2012) 
- Mathematics, Biology and Chemistry Tutor at the Cheyney University STEM laboratory (2008-2010)

\section{CONFERENCES}

American Society for Cell Biology (ASCB), San Diego, CA Poster Presenter, December 2015

- A scientific conference held for students, postdoctoral fellows, and faculty who study various signaling pathways and mechanisms implicated in normal and cancer cellular biology.

2015 ASCB Membrane Trafficking Symposium, Louisville, KY Poster Presenter, July 2015

- A scientific conference held for students, postdoctoral fellows, and faculty who study membrane trafficking events and cellular mechanisms involved in endocytosis.

$7^{\text {th }}$ International Conference on cGMP, Trier, Germany Poster Presenter, June 2015

- A scientific conference held for Faculty, Ph.D. students and postdoctoral fellows to present their research on cyclic-GMP protein interactions.

Research!Louisville, Louisville, KY

Graduate Student Poster Presenter, 2012, 2013, 2015, 2016

- An annual scientific conference held for students, postdoctoral fellows, and faculty who conduct scientific research at the University of Louisville, to congregate and present most recent research accomplishments.

Thurgood Marshall Leadership Conference, New York, NY Attendee, October 2011

- A selective conference held in order to aid students of color from participating Historically Black Colleges and Universities in their interpersonal development of leadership skills.

\section{Eastern Analytical Symposium and Exposition Conference,} Somerset, NJ

Attendee, November 2010

- A conference held for youth with exposure and interests in chemistry and chemical instrumentation.

Women of Color STEM Conference, Dallas, TX Attendee, October 2010

- A networking conference held for underrepresented minority women 
pursuing advanced careers in science, technology, engineering, and mathematics.

\section{ABSTRACTS}

1. Jackson, N.M. and Ceresa B.P. (2016) Identifying the Role of STAT3 in the EGFR-Mediated Induction of Apoptosis in Cancer. Abstract for poster presentation. Research!Louisville Symposium, Louisville, KY.

2. Jackson, N.M. and Ceresa B.P. (2015) Cyclic GMP Dependent Protein Kinase (PKG) as a mediator of EGFR-induced Apoptosis. Abstract for poster presentation. 2015 American Society for Cell Biology (ASCB) Meeting, San Diego, CA.

3. Jackson, N.M. and Ceresa B.P. (2015) Cyclic GMP Dependent Protein Kinase (PKG) as a mediator of EGFR-induced Apoptosis. Abstract for poster presentation Abstract for poster presentation, Research!Louisville, Symposium, Louisville, KY.

4. Jackson, N.M. and Ceresa B.P. (2015) Cyclic GMP Dependent Protein Kinase (PKG) as a mediator of EGFR-induced Apoptosis. Abstract for poster presentation, 2015 ASCB Membrane Trafficking Symposium, Louisville, KY.

5. Jackson, N.M. and Ceresa B.P. (2015) Cyclic GMP Dependent Protein Kinase (PKG) as a mediator of EGFR-induced Apoptosis. Abstract for poster presentation. $7^{\text {th }}$ International Conference on cGMP, Trier, Germany.

6. Jackson, N.M. and Ceresa, B.P. (2013) Endogenous EGFR Ligands as Mediators of Apoptosis in Metastatic Breast Cancer Cells. Abstract for poster presentation, Research! Louisville Symposium, Louisville, KY.

7. Jackson, N.M., Leggett, C., Doll. M., States. C., and Hein D. (2012) Inhibition of Human Arylamine N-Acetyltransferase I using Curcumin and Resveratrol Increases the Potency of Small Inhibitor Compound 10. Abstract for poster presentation, Research!Louisville Symposium, Louisville, KY. 


\section{PUBLICATIONS}

1. Jackson, N.M., and Ceresa, B.P. (2017) EGFR-Mediated Apoptosis via STAT3. Experimental Cell Research. Accepted, in press.

2. Jackson, N.M., Gosney, J.A., and Rush, J.S (2016) Epidermal Growth Factor Receptor (Review). Encyclopedia of Signaling Molecules. Accepted, in press.

3. Jackson, N.M. and Ceresa, B.P. (2016) Protein Kinase G Facilitates EGFR-Mediated Cell Death in MDA-MB-468 Cells. Experimental Cell Research, 362(2), p. 224-232. 